\title{
1 Recognition of Z-RNA by ADAR1 limits interferon responses
}

3 Qiannan Tang ${ }^{1}$, Rachel E. Rigby ${ }^{1, \dagger}$, George R. Young ${ }^{2, \dagger}$, Astrid Korning-Hvidt ${ }^{1}$,

4 Tiong Kit Tan ${ }^{1}$, Anne Bridgeman ${ }^{1}$, Alain R. Townsend ${ }^{1,3}$, George Kassiotis ${ }^{4,5}$ \&

5 Jan Rehwinkel ${ }^{1, *}$

6

$7 \quad{ }^{1}$ Medical Research Council Human Immunology Unit, Medical Research

8 Council Weatherall Institute of Molecular Medicine, Radcliffe Department of

9 Medicine, University of Oxford, Oxford, OX3 9DS, UK.

$10{ }^{2}$ Retrovirus-Host Interactions, The Francis Crick Institute, London, UK.

$11{ }^{3}$ Centre for Translational Immunology, Chinese Academy of Medical Sciences

12 Oxford Institute, University of Oxford, Oxford, UK.

$13{ }^{4}$ Retroviral Immunology, The Francis Crick Institute, London, UK.

14 5Department of Infectious Disease, Faculty of Medicine, Imperial College 15 London, London, UK.

16

*correspondence: jan.rehwinkel@imm.ox.ac.uk

†These authors contributed equally.

Keywords

ADAR1, Z $\alpha$ domain, Z-RNA, MDA5, MAVS, interferon, influenza A virus

Running Title 


\section{Abstract}

Nucleic acids are powerful triggers of innate immunity and can adopt the unusual Z-conformation. The p150 isoform of adenosine deaminase acting on RNA 1 (ADAR1) prevents aberrant interferon (IFN) induction and contains a Znucleic acid binding $(Z \alpha)$ domain. We report that knock-in mice bearing two

31 point mutations in the Z $\alpha$ domain of ADAR1, which abolish binding to Z-form nucleic acids, spontaneously induced type I IFNs and IFN-stimulated genes

33 (ISGs) in multiple organs. This included the lung where both stromal and

34 haematopoietic cells displayed ISG induction in Adar1mZ $1^{m Z \alpha}$ mice.

35 Concomitantly, Adar1 $1^{m Z \alpha / m Z \alpha}$ mice showed improved control of influenza A virus.

36 The spontaneous IFN response in $A d a r 1^{m Z \alpha / m Z \alpha}$ mice required MAVS,

37 implicating cytosolic RNA sensing. Finally, analysis of A-to-I changes revealed

38 a specific requirement of ADAR1's Z $\alpha$ domain in editing of a subset of RNAs.

39 In summary, our results reveal that endogenous RNAs in Z-conformation have

40 immunostimulatory potential that is curtailed by ADAR1. 
Introduction

The innate immune system monitors the intra- and extracellular environments for unusual nucleic acids (Bartok and Hartmann, 2020). This

44 process, known as 'nucleic acid sensing', detects pathogen invasion and disturbances to homeostasis. It involves a large number of germline encoded nucleic acid sensors. Upon engagement by immunostimulatory DNA or RNA, these sensors signal to initiate a large spectrum of responses, including transcription of the genes encoding type I interferons (IFNs). Type I IFNs secreted cytokines that act in paracrine and autocrine manner - induce expression of hundreds of IFN-stimulated genes (ISGs). The proteins encoded

51 by ISGs mediate a plethora of functions and include antiviral effectors 52 (Schoggins, 2019). Sustained type I IFN responses can have detrimental 53 effects and cause a range of diseases including the neuroinflammatory Aicardi54 Goutières Syndrome (AGS) (Uggenti et al., 2019). It is therefore important to understand the molecular mechanisms that prevent activation of nucleic acid sensors by 'normal' DNA and RNA present in healthy cells (Bartok and Hartmann, 2020).

We and others proposed that double-stranded (ds) nucleic acids adopting an unusual conformation known as Z-DNA/RNA activate innate immunity (Maelfait et al., 2017; Sridharan et al., 2017; Zhang et al., 2020b). Z-DNA was initially described by Alexander Rich (Wang et al., 1979). Unlike canonical B-

62 DNA, a right-handed double helix, Z-DNA is a left-handed double helix with a 63 zig-zag-shaped phosphodiester back bone (Wang et al., 1979). dsRNA can also 64 adopt the Z-conformation (Davis et al., 1986; Hall et al., 1984). Biological 65 functions of Z nucleic acids, in particular those of Z-RNA, are incompletely 66 understood (Herbert, 2019). A small number of proteins, all involved in innate 67 immunity, contain Z-DNA/RNA binding domains known as Z $\alpha$ domains 68 (Athanasiadis, 2012). These domains specifically bind to and stabilise Z- 
69 DNA/RNA, or induce the Z-conformation (Athanasiadis, 2012; Brown et al., 70 2000; Kim et al., 2018; Schwartz et al., 1999).

71 There are two mammalian proteins with Z $\alpha$ domains: Z-DNA binding protein 1 (ZBP1) and adenosine deaminase acting on RNA 1 (ADAR1, also known as DRADA1). ZBP1 contains two $Z \alpha$ domains that have been suggested to recognise viral and endogenous Z-RNAs (Devos et al., 2020; Jiao et al., 2020; Maelfait et al., 2017; Sridharan et al., 2017; Wang et al., 2020; Zhang et al., 2020b). Binding to Z-RNA activates ZBP1 and results in the induction of necroptosis, an inflammatory form of cell death (Maelfait et al., 2020).

ADAR1 has two splice isoforms: ADAR1-p110, which is constitutively expressed and localised in the cell nucleus, and ADAR1-p150 that is IFNinducible and present in the nucleus and cytosol. Both isoforms contain a Cterminal deaminase domain that converts adenosine to inosine in dsRNA, a process known as A-to-I RNA editing. Conversion of adenosine to inosine in protein-coding sequences can lead to incorporation of non-synonymous amino acids during translation due to base pairing of inosine with cytosine. However, the vast majority of A-to-I editing events occur in non-coding RNAs (Eisenberg and Levanon, 2018; Reich and Bass, 2019). This includes transcripts from repetitive elements (REs), particularly Alu elements and short interspersed nuclear elements (SINEs) in human and mouse, respectively. Both ADAR1 isoforms further contain three dsRNA binding domains (dsRBDs) and a socalled $Z \beta$ domain. $Z \beta$ adopts a fold similar to $Z \alpha$ domains but does not bind Z-

91 form nucleic acids due to substitutions of key amino acids (Athanasiadis et al., 2005; Kim et al., 2003). ADAR1-p150 has an extended N-terminus harbouring a Z $\alpha$ domain (Heraud-Farlow and Walkley, 2020).

ADAR1 deficiency results in profound inflammatory phenotypes. In human, germline ADAR1 mutations cause AGS (Rice et al., 2012). These mutations 
97 p.Pro193Ala is found in the Z $\alpha$ domain. Pro193 contributes to Z-form nucleic

98 acid binding (Schwartz et al., 1999) and changing it to Ala reduces RNA editing 99 in a reporter assay (Mannion et al., 2014). Adar1 ${ }^{-/}$mice, editing-deficient 100 Adar1E861A/E861A knock-in animals and Adar1 ${ }^{150-/ 150-}$ mice, which only lack 101 ADAR1-p150, all die in utero (Hartner et al., 2004; Liddicoat et al., 2015; Wang et al., 2004; Ward et al., 2011). Akin to spontaneous type I IFN induction in AGS patients with $A D A R 1$ mutation, Adar1\%- and Adar1 ${ }^{E 861 A / E 861 A}$ embryos display profound type I IFN responses prior to death (Hartner et al., 2009; Liddicoat et al., 2015). Multiple nucleic acid sensors mediate the anti-proliferative, cell death and type I IFN phenotypes observed in ADAR1-deficient settings: the 107 oligoadenylate synthetase (OAS)-RNase L system ( $\mathrm{Li}$ et al., 2017), protein 108 kinase $\mathrm{R}$ (PKR) (Chung et al., 2018; Li et al., 2010) and melanoma 109 differentiation-associated protein 5 (MDA5) (Liddicoat et al., 2015; Mannion et 110 al., 2014; Pestal et al., 2015). Upon activation by dsRNA, OAS proteins 111 synthesise 2'-5' oligoadenylate, a second messenger that in turn activates 112 RNase L, resulting in widespread RNA degradation. PKR also detects dsRNA 113 and represses protein translation. Both effects have been proposed to explain 114 lethality of ADAR1-deficient cells (Chung et al., 2018; Li et al., 2017). Induction 115 of type I IFNs in ADAR1-deficient mice and human cells is mediated by the RNA 116 sensor MDA5, that signals via its adaptor mitochondrial antiviral-signalling 117 protein (MAVS) (Bajad et al., 2020; Chung et al., 2018; Guallar et al., 2020; 118 Liddicoat et al., 2015; Mannion et al., 2014; Pestal et al., 2015).

119 These observations suggest a model in which endogenous dsRNAs are 120 stabilised in ADAR1-deficient cells due to the absence of RNA editing and are 121 then recognised by RNA sensors (Dias Junior et al., 2019; Eisenberg and 122 Levanon, 2018). Indeed, some ADAR1 substrates such as transcripts from Alu 123 elements base-pair to form duplex structures, which are predicted to be 124 destabilised by inosine : uracil mismatches introduced by RNA editing (Ahmad 
125 et al., 2018; Chung et al., 2018; Pfaller et al., 2018; Song et al., 2020). This

126 concept has been tested experimentally in an RNase protection assay:

127 transcripts spanning Alu elements in inverted orientation are protected by

128 recombinant MDA5 protein in RNA samples extracted from ADAR1-deficient

129 cells (Ahmad et al., 2018; Mehdipour et al., 2020).

130 How the different nucleic acid binding domains in ADAR1 select and recruit

131 RNA substrates for subsequent editing is unknown. In light of (i) emerging roles

132 of Z-form nucleic acids in innate immunity (Kesavardhana and Kanneganti,

133 2020), (ii) the MAVS-dependent phenotype of Adar1p150-/p150- mice (Pestal et al.,

134 2015), and (iii) natural occurrence of the p.Pro193Ala mutation in AGS patients

135 (Rice et al., 2012), we interrogated Z-form nucleic acid binding by the Z $\alpha$

136 domain in ADAR1-p150. Here, we report the generation of knock-in mice

137 bearing two missense mutations in the $Z \alpha$ domain, which prevent nucleic acid

138 binding. Although these Adar1 ${ }^{m Z \alpha / m Z \alpha}$ mice were developmentally normal and

139 fertile, they displayed spontaneous induction of type I IFNs and ISGs in multiple

140 organs and cell types. This phenotype was dependent on MAVS and conferred

141 partial protection against influenza A virus (IAV) infection. Analysis of

142 sequencing data revealed that $\sim 8 \%$ of RNA editing events in wild-type (WT)

143 cells required a functional ADAR1-p150 Z $\alpha$ domain. Taken together, our study

144 delineates the function of the Z $\alpha$ domain in ADAR1-p150 in vivo and suggests

145 that recognition of Z-form RNA by ADAR1 contributes to the suppression of IFN

146 responses. 


\section{Results}

Generation of $Z \alpha$ domain mutated mice

To study the role of Z-form nucleic acid binding to the Z $\alpha$ domain in ADAR1p150 in an in vivo setting, we generated knock-in mice bearing two missense mutations: p.Asn175Ala and p.Tyr179Ala. These residues are conserved and are homologous to Asn173 and Tyr177 in human ADAR1; they were chosen because of their essential role in Z-form nucleic acid binding (Feng et al., 2011; Li et al., 2009; Schade et al., 1999; Schwartz et al., 1999). Given the embryonic lethality of Adar1 ${ }^{150-/ p 150-}$ mice (Ward et al., 2011), we opted for a conditional knock-in strategy (Figure S1A). The Z $\alpha$ domain is encoded by exon 2 of the Adar1 gene. In brief, we introduced in inverted orientation into the intron between exons 2 and 3 a mutated copy of exon 2 (designated $2^{*}$ ) containing four nucleotide substitutions, changing both Asn175 and Tyr179 to Ala. We

161 flanked exons 2 and 2* with LoxP and Lox2272 sites such that Cre-mediated recombination removes exon 2 and flips exon $2^{*}$ into forward orientation (Figure $\mathrm{S} 1 \mathrm{~A})$. We designated the conditional allele ' $f(-m Z \alpha$ ' and the recombined allele expressing mutant Adar1 ' $m Z \alpha$ '. To determine the impact of the $Z \alpha$ domain mutations when present in all cells and tissues, we crossed Adar1 ${ }^{+f f-m Z \alpha}$ mice with a line expressing Cre recombinase under control of the ubiquitously active Pgk promoter. The resulting Adar1 ${ }^{+/ m Z \alpha}$ mice were intercrossed to generate

168 homozygous animals. We validated the presence of the mutations by 169 sequencing and found that $A d a r 1^{m Z \alpha / m Z \alpha}$ animals were born at expected 170 mendelian ratios (Figure S1B and S1C). Furthermore, they developed normally

171 and were fertile. The mutations introduced into the $Z \alpha$ domain did not alter the 172 expression of the two isoforms of ADAR1 in bone marrow-derived myeloid cells 173 (BMMCs) (Figure S1D). Taken together, Z-form nucleic acid binding by ADAR1$174 \mathrm{p} 150$ is not essential for survival at whole organism level. 
Mutation of the Z $\alpha$ domain in ADAR1-p150 triggers a multi-organ type I IFN

response

We tested whether Adar1 ${ }^{m Z \alpha / m Z \alpha}$ mice display spontaneous activation of type I IFNs as was reported in ADAR1-deficient settings. We collected lung, liver and spleen tissues and extracted RNA for RT-qPCR analysis. Transcript levels of Ifnb1 (encoding IFN $\beta$ ) were elevated in lung RNA samples from Adar1 ${ }^{m Z \alpha / m Z \alpha}$ mice (Figure 1A). Moreover, the ISG transcripts Ifit1 and Ifi44 were expressed at higher levels in all three organs from $\mathrm{Z} \alpha$ domain mutated animals

184 (Figure 1A). This gene expression signature was type I IFN-specific: tissues 185 from Adar1 ${ }^{m Z \alpha / m Z \alpha}$ mice contained comparable mRNA levels of Ifng, Thfa and 186 I/1b (encoding IFN $\gamma$, TNF $\alpha$ and pro-IL-1 $\beta$ ), with only a minor increase of Tnfa 187 mRNA in lung (Figure 1A). We validated the ISG signature at protein level by 188 analysing expression of interferon stimulated gene 15 (ISG15) in whole lung 189 lysates. ISG15 is a ubiquitin-like modifier that is induced by IFN and is 190 conjugated to target proteins in a process called ISGylation (Perng and 191 Lenschow, 2018). Western blot showed that lung lysates from Adar1mZa/mZ $\alpha$ 192 mice contained increased amounts of monomeric ISG15 as well as increased 193 levels of ISGylated proteins, visible as a high-molecular weight smear (Figure 194 1B).

We next analysed different types of cultured primary cells from WT and Adar1 ${ }^{m Z \alpha / m Z \alpha}$ mice. We observed heightened ISG expression in Z $\alpha$ domain 197 mutated lung fibroblasts (Figure 1C). In contrast, comparable levels of ISG 198 transcripts were found in WT and Adar1 ${ }^{m Z \alpha / m Z \alpha}$ BMMCs, as well as in mouse 199 embryonic fibroblasts (MEFs) (Figure 1D, E). This indicates that ISG induction 200 may be cell-type specific.

201 Among the organs we analysed, lung exhibited the most profound ISG 202 signature, and spontaneous ISG induction was also observed in cultured lung 
203 fibroblasts (Figure 1A, D). We therefore focused on the lung for the next set of

204 experiments. We used RNA extracted from lung for RNA sequencing to obtain 205 a global view of gene expression in Adar $1^{m Z \alpha / m Z \alpha}$ mice. We found that 99 protein 206 coding genes were differentially expressed by at least 2-fold in mutant lungs, 207 including 89 upregulated and 10 downregulated transcripts (Figure 2A). 40\% of 208 the induced mRNAs were encoded by ISGs; this included well-known factors 209 such as Irf7, Cxcl10, Zbp1 and Usp18 (Figure 2A). We used gene ontology (GO) 210 analysis of biological processes to further classify upregulated genes. GO 211 terms related to type I IFNs and anti-viral defence were enriched amongst 212 genes induced in Adar1 ${ }^{m Z \alpha / m Z \alpha}$ lungs (Figure 2B). The most highly enriched GO 213 category, regulation of ribonuclease activity, included many Oas transcripts, 214 which are known to be IFN-inducible (Schoggins, 2019).

215 We also analysed REs in our RNA sequencing data and found 540 induced 216 and 112 repressed REs (Figure 2C and Table S1). SINEs were 217 underrepresented amongst differentially expressed REs, whilst long terminal 218 repeat (LTR) elements were enriched (Figure 2C). Dysregulation of REs has 219 been reported in settings of inflammation and can be driven by IFNs (Chuong 220 et al., 2016). Taken together, these data show that the lungs of $Z \alpha$ domain 221 mutated animals displayed a type I IFN-driven gene signature.

Stromal and haematopoietic cells contribute to the ISG signature in the lungs

224 of $\operatorname{Adar}^{m Z \alpha / m Z \alpha}$ mice

225 To identify the type of cell(s) that display the ISG signature in the lungs of 226 Adar1 ${ }^{m Z \alpha / m Z \alpha}$ mice, we used magnetic-activated cell sorting (MACS) to isolate 227 haematopoietic cells, marked by CD45 expression, and stromal cells lacking 228 this marker. There was no difference in the proportions of haematopoietic and 229 stromal cells between WT and Adar1 ${ }^{m Z \alpha / m Z \alpha}$ lungs (Figure 3A). We confirmed 230 the purity of MACS-enriched haematopoietic and stromal cells to be $>97 \%$ 
231 (Figure S2). We then extracted RNA for RT-qPCR analysis of ISGs and found 232 that both lung haematopoietic and stromal cells displayed ISG induction (Figure 233 3B). For the three ISGs tested, fold inductions in Adar1 ${ }^{m Z \alpha / m Z \alpha}$ samples were 234 similar in CD45+ and CD45- cells (Figure 3B). However, it is noteworthy that 235 baseline ISG levels appeared to be lower in haematopoietic cells compared to stromal cells (Figure 3B).

Next, we analysed ISG expression in different types of lung haematopoietic and stromal cells. Using two staining panels and fluorescence-activated cell sorting (FACS), we obtained eight different populations of CD45+ cells, including B cells, T cells, dendritic cells (DCs), monocytes, macrophages, NK 241 cells, neutrophils and eosinophils (Figure S3). There were no differences 242 between WT and Adar1 ${ }^{m Z \alpha / m Z \alpha}$ mice in the proportions of these cell populations, 243 with the exception of DCs, which were less abundant in the mutant lungs 244 (Figure S3A). Ifit1, Ifit2 and Isg15 were significantly induced in neutrophils from 245 the lungs of $A d a r 1^{m Z \alpha / m Z \alpha}$ mice (Figure 4A, B). However, these ISGs showed 246 no, or limited and statistically insignificant, upregulation in other types of CD45+ 247 cells (Figure 4A, B). In contrast, the ISGs Ifi44 and Oas1a were upregulated in 248 multiple haematopoietic cell types (Figure 4A, B). Transcripts encoding type I 249 IFNs were undetectable by RT-qPCR in all samples analysed (data not shown). 250 Several ISGs, including Ifit1, Ifit2 and Isg15, are not only induced by IFNAR 251 signalling but can also be upregulated by IRF3/7, independent of type I IFN252 initiated JAK-STAT activation (Ashley et al., 2019; DeFilippis et al., 2006; 253 Goubau et al., 2009; Grandvaux et al., 2002; Lazear et al., 2013). Induction of 254 this ISG-subset can therefore occur in a cell-autonomous manner, for example 255 when aberrant nucleic acids are sensed by pattern recognition receptors (PRRs) 256 that signal via IRF3/7. Other ISGs, including Ifi44 and Oas1a, are only induced 257 via IFNAR signalling (Lazear et al., 2013). Therefore, our observation that Ifit1, 258 Ifit2 and Isg15 were primarily induced in neutrophils, while Ifi44 and Oas1a were 
upregulated more broadly (Figure 4A, B), suggests that Adar1 ${ }^{m Z \alpha / m Z \alpha}$ neutrophils may autonomously activate IRF3. We further speculate that the ISG signature in other haematopoietic cells such as B cells may be due to paracrine type I IFN signalling via IFNAR.

We also analysed the lung stromal compartment and isolated by FACS endothelial and epithelial cells using CD31 and CD326 as markers, respectively (Figure S4). We further isolated CD45- cells lacking these markers; this mixed population likely included fibroblasts and other cell types. We observed induction of Ifit1, Isg15 and Ifi44 in Adar1 $1^{m Z \alpha / m Z \alpha}$ cells of all three populations analysed (Figure 4C). It is therefore likely that, in addition to neutrophils, multiple non-haematopoietic cells initiate type I IFN production in the lungs of Adar1 ${ }^{m Z \alpha / m Z \alpha}$ mice.

$\underline{\text { Haematopoietic cells are sufficient to induce ISGs in Adar1 }{ }^{m Z \alpha / m Z \alpha} \text { mice }}$

To further dissect the cellular requirements for ISG induction in Adar1mZ ${ }^{m / m Z \alpha}$

274 mice, we generated bone marrow (BM) chimeric animals. Lethally irradiated Cd45.1 WT recipients were reconstituted with Cd45.2 BM from WT or Adar1 ${ }^{m Z \alpha / m Z \alpha}$ animals (Figure S5A). We found reconstitution levels of the

277 haematopoietic compartment to be about $90 \%$ by analysing cell surface levels 278 of CD45.1 and CD45.2 on white blood cells from recipient mice (Figure S5B). 279 Similar levels of reconstitution were observed in the lung (Figure S5C). We first 280 obtained RNA from whole lung tissue for RT-qPCR analysis. The ISGs Ifit1, 281 Oas1a and $Z b p 1$ were upregulated in Adar1 ${ }^{m Z \alpha / m Z} \alpha \rightarrow$ WT chimeras compared to 282 WT $\rightarrow$ WT chimeras (Figure 4D, "Total"). This indicates that Adar1 ${ }^{m Z \alpha / m Z \alpha}$ BM283 derived cells triggered an IFN response in WT animals. We also isolated 284 different cell populations from the lungs of chimeric animals by FACS (see 285 Figure S3 for gating), extracted RNA and performed RT-qPCR. Ifit1 and Ifit2 mRNA levels were significantly induced in neutrophils from Adar1 ${ }^{m Z \alpha / m Z \alpha} \rightarrow$ WT 
287 chimeras, but not in B cells and CD45- cells (Figure 4D). In contrast, Oas1a

288 and/or Zbp1 were upregulated in multiple cell populations including CD45- cells, 289 neutrophils and B cells (Figure 4D). These observations are consistent with the 290 results shown in Figure $4 \mathrm{~A}$ and $4 \mathrm{~B}$ and indicate that neutrophils may initiate 291 type I IFN production that then results in ISGs induction in other cell types. 292 Taken together, Adar1 ${ }^{m Z \alpha / m Z \alpha}$ haematopoietic cells were sufficient to induce 293 ISGs in the lungs of WT mice.

$\underline{\mathrm{IAV} \text { replication is inhibited in Adar1 }{ }^{m Z \alpha / m Z \alpha} \text { mice }}$

In light of the spontaneous type I IFN response in Adar1 ${ }^{m Z \alpha / m Z \alpha}$ mice, we next asked whether these $Z \alpha$ domain mutant mice were protected against viral infection. ISGs upregulated in the lungs of $A d a r 1^{m Z \alpha / m Z \alpha}$ mice included factors such as Ifit1 and Zbp1 that are known to control IAV (Pichlmair et al., 2011; Zhang et al., 2020b) (Figure 2A). We intranasally infected WT and Adar1 ${ }^{m Z \alpha / m Z \alpha}$ mice with the H3N2 strain of recombinant IAV (A-X31; A/HongKong/1/1968) using a dose that caused moderate weight loss. WT animals lost about $10 \%$ body weight from day 3 until day 7 after infection, and subsequently recovered their weight (Figure 5A). In contrast, $A d a r 1^{m Z \alpha / m Z \alpha}$ mice gained weight until day 4 after infection (Figure 5A). This was followed by weight loss on days 5-7, which slightly exceeded weight loss in WT mice, and recovery from day 8 onwards. These observations suggest that $A d a r 1^{m Z \alpha / m Z \alpha}$ mice were protected against IAV at an early stage of the infection.

We further characterised early IAV infection in $A d a r 1^{m Z \alpha / m Z \alpha}$ mice at day 3

310 after inoculation. We calculated a 'lung index' (lung weight/body weight $\times 100$;

311 Luo et al., 2012) and found this marker of pathology and inflammation to be 312 significantly higher in infected WT mice compared to Adar1 ${ }^{m Z \alpha / m Z \alpha}$ animals 313 (Figure 5B). Next, we analysed viral loads by determining the levels of the viral $314 N P$ and $M$ transcripts by RT-qPCR. Compared to infected WT lungs, levels of 
315 these viral RNAs were reduced in infected Adar1 ${ }^{m Z \alpha / m Z \alpha}$ lungs (Figure 5C).

316 Concomitantly, mRNA levels of Ifnb1, Ifng, I/1b, Tnfa and II6, as well as IL6

317 protein, were strongly induced in infected WT lungs, and these effects were 318 curtailed in Adar1 ${ }^{m Z \alpha / m Z \alpha}$ lungs (Figure 5D, E). In sum, IAV replication and virus-

319 induced inflammation were reduced in $A d a r 1^{m Z \alpha / m Z \alpha}$ animals.

$\underline{\text { ISG induction in Adar1 }{ }^{m Z \alpha / m Z \alpha} \text { mice is MAVS-dependent }}$

We next investigated which nucleic acid sensing pathway triggered spontaneous ISG expression in Adar1 ${ }^{m Z \alpha / m Z \alpha}$ mice. Since ADAR1-deficiency results in activation of the MDA5-MAVS pathway (Liddicoat et al., 2015; 325 Mannion et al., 2014; Pestal et al., 2015), we hypothesised that the ISG 326 signature in Adar1 ${ }^{m Z \alpha / m Z \alpha}$ mice was driven by MAVS. To test this, we crossed 327 Adar1 mutant mice with MAVS knock-out animals to generate Adar1 ${ }^{m Z \alpha / m Z \alpha}$; 328 Mavs $^{-/}$mice. Loss of MAVS prevented the ISG induction observed in 329 Adar1 ${ }^{m Z \alpha} / m Z \alpha$ lungs, livers and spleens (Figure 6A). Because of the 330 neuropathology observed in patients with AGS, we also analysed brain tissue. 331 Adar1 ${ }^{m Z \alpha / m Z \alpha}$ mice showed elevated Ifnb1 expression and a pronounced ISG signature in the brain (Figure 6B). Akin to the situation in other tissues, these

333 effects were fully MAVS-dependent (Figure 6B). Taken together, the Z $\alpha$ domain 334 of ADAR1-p150 was involved in preventing MAVS-mediated IFN induction, implicating a role in limiting activation of MDA5 or RIG-I.

\section{The Z $\alpha$ domain of ADAR1-p150 is required for editing of a subset of RNAs}

Human ADAR1-p150 bearing the p.Pro193Ala mutation shows reduced 339 editing activity in a reporter assay (Mannion et al., 2014). To identify natural

340 RNA substrates edited by ADAR1-p150 in a Z $\alpha$ domain-dependent manner, we 341 analysed our RNA sequencing data from WT and $A d a r 1^{m Z \alpha / m Z \alpha}$ lungs for $A \rightarrow G$ transitions. These are indicative of A-to-I RNA editing as inosine pairs with 
343 cytosine during reverse transcription. The most sensitive and specific method

344 for annotating this mutational profile compares the fit of Dirichlet models of 345 observed base frequencies between test and control samples (Piechotta et al., 346 2017). We extended this methodology to allow comparisons of biological 347 replicates, to incorporate the orientation of the originating RNA (revealed by our 348 stranded RNAseq protocol), to include fine-grained filtering of potential editing 349 sites, and to add a 'detection' step, whereby observed base frequencies at 350 potential editing sites are additionally compared to a model of the per-base error 351 rate obtained de novo from the dataset.

352 Considered individually, for each of the three WT and three Adar1 ${ }^{m Z \alpha / m Z \alpha}$ 353 lung samples analysed, we detected $\sim 35,000-40,000$ editing sites (Figure 7A).

354 Considered as biological replicates, increasing statistical robustness, 40,342 and 46,164 sites were identified that were shared amongst all three WT or Adar1 ${ }^{m Z \alpha / m Z \alpha}$ lung samples, respectively. These 'detected' sites had a median 357 editing level of $\sim 10 \%$ in both WT and Adar1 ${ }^{m Z \alpha / m Z \alpha}$ samples (Figure 7B). This 358 shows that there was no global defect in RNA editing in Adar1 ${ }^{m Z \alpha / m Z \alpha}$ mice.

We further defined 'differential' sites as those that were 'detected' in the WT samples and showed higher (>2-fold) levels of editing than in Adar1 ${ }^{\mathrm{mZ} \alpha / \mathrm{mZ} \alpha}$ mice. 3613,249 sites ( $8 \%$ of sites 'detected' in WT) were 'differential' and displayed $\sim 9 \%$ 362 median editing in WT lungs, which was strongly reduced for the majority of sites 363 in Adar1 ${ }^{m Z \alpha / m Z \alpha}$ mice (Figure 7B). Read depth was equivalent between 364 'detected' and 'differential' sites (data not shown), excluding the possibility that 365 lack of editing in $A d a r 1^{m Z \alpha / m Z \alpha}$ samples was simply due to reduced sequence 366 coverage. We then attempted to understand whether these Z $\alpha$ domain367 dependent sites were characterised by unique properties. First, we annotated 368 editing sites to 5' untranslated regions (UTRs), coding sequences (CDSs), 369 3'UTRs, intronic and intergenic regions (Figure 7C). The majority of editing sites 370 'detected' in WT samples were found in intronic regions ( 83\%). 3'UTRs 
371 accounted for $\sim 11 \%$ of edits and intergenic regions contained $\sim 5 \%$ of sites.

372 Less than $1 \%$ of sites mapped to 5 'UTRs and CDSs. The annotation of

373 'differential' sites was similar with a small increase in intronic sites ( $86 \%)$, while

$3748 \%$ of 'differential' edits were found in 3'UTRs.

375 Given that many A-to-I RNA editing events are known to occur in repetitive 376 elements (REs) (Eisenberg and Levanon, 2018), we analysed the enrichment 377 of editing events in WT samples, by computing observed versus expected 378 numbers, for each RE class (Figure 7D). This analysis showed that editing 379 events were greatly enriched within SINEs (Figure 7D) and further showed that, 380 with the exception of the B4 family, all SINE sub-families exhibited enrichment, 381 albeit to varying degrees (Figure S6A). Furthermore, there were no large-scale 382 differences between the SINEs represented when comparing 'detected' and 383 'differential' sites (Figure S6B), suggesting that all SINEs had equal potential to 384 contribute sites that were differentially edited between WT and Adar1 ${ }^{m Z \alpha / m Z \alpha}$ 385 mice.

386 We next analysed the genomic distance of edited SINEs to another SINE 387 in inverted orientation. In human, transcripts spanning inverted repeat $A / u$ 388 elements have been suggested to form duplex RNA structures recognised by 389 ADAR1 and MDA5 (Ahmad et al., 2018; Mehdipour et al., 2020). Compared to 390 all SINEs, we found that edited SINEs were closer to another SINE in inverted 391 orientation (Figure 7E), although there was no difference between SINEs 392 containing 'detected' (in WT samples) and 'differential' sites. Taken together, 393 these data demonstrate that a subset consisting of about $8 \%$ of editing sites 394 required a functional ADAR1-p150 Z $\alpha$ domain for efficient A-to-I conversion. 


\section{Discussion}

Although Z-nucleic acids were discovered $\sim 40$ years ago, little is known to

397 this date about their biological activities. This is in part due to their thermodynamic properties: the B- and A-conformations of dsDNA and dsRNA, respectively, are energetically favoured compared to the Z-conformation, making Z-DNA and Z-RNA difficult to study (Herbert, 2019). The formation of Z-

401 DNA has been proposed to release torsional strain induced by the movement 402 of polymerases (Wittig et al., 1992; Wolfl et al., 1995). Physiological functions 403 of Z-RNA have remained enigmatic until recently. We and others proposed that 404 Z-RNA is recognised by ZBP1 in settings of viral infection and autoinflammation, 405 resulting in the induction of programmed cell death (Devos et al., 2020; Jiao et 406 al., 2020; Maelfait et al., 2017; Sridharan et al., 2017; Wang et al., 2020; Zhang 407 et al., 2020b).

408 Here, we studied ADAR1-p150 that like ZBP1 contains a Z $\alpha$ domain 409 specialised in binding to $Z$ nucleic acids. We report spontaneous induction of 410 type I IFNs in vivo upon introduction of mutations into the ADAR1-p150 Z $\alpha$ 411 domain that prevent binding to Z-DNA/RNA. This effect was observed in 412 multiple organs and cell types from $A d a r 1^{m Z \alpha / m Z \alpha}$ mice and required MAVS.

413 These data show that RIG-I-like receptors were activated by endogenously 414 generated Z-RNAs, and that editing of these Z-RNAs by ADAR1-p150 limited 415 the response. We therefore reveal type I IFN induction as a new biological 416 function of Z-RNA.

417 Our computational analysis mapped $\sim 40,000$ editing sites in lung RNA 418 samples from WT mice. These sites were enriched in SINEs but not in other 419 classes of REs. Furthermore, we found that edited SINEs were more likely to 420 be in proximity to another SINE in inverted orientation. These results agree with 421 previous findings demonstrating that editing sites are enriched in non-coding 422 sequences containing self-complementary regions predicted to form duplex 
423 RNA structures (Eisenberg and Levanon, 2018; Porath et al., 2017; Solomon

424 et al., 2017; Tan et al., 2017).

425 Importantly, we revealed that $\sim 8 \%$ of editing sites detected in WT samples

426 required a functional ADAR1-p150 Z $\alpha$ domain. This subset of Z $\alpha$-dependent

427 sites mapped to genomic features and REs similarly to all detected sites. To 428 characterise whether the sequences surrounding Z $\alpha$-dependent editing sites 429 have a propensity to form Z-RNA, we analysed sequences $500 \mathrm{nt}$ up- and 430 down-stream of editing sites. We tested GC content, given that GC-repeats 431 have a higher tendency to adopt the Z-conformation (Davis et al., 1986). There 432 was no enrichment of GC dinucleotides, or other motifs, around differentially 433 edited sites compared to all detected sites (data not shown). We also used the 434 Z-hunt algorithm (Champ et al., 2004; Ho et al., 1986) to predict the likelihood 435 of sequences around editing sites to form the Z-conformation. In parallel, we 436 calculated the distance of editing sites to genomic regions predicted by SIBZ to 437 form the Z-conformation (Zhabinskaya and Benham, 2011). Neither 438 computational approach revealed differences between 'detected' and 439 'differential' sites. It is noteworthy that both algorithms were developed for 440 dsDNA and may be unsuitable for predicting the Z-conformation in RNA. Future 441 studies will be required to dissect the properties the Z $\alpha$-dependent RNA editing 442 sites.

443 We also found diminished editing in WT samples at $\sim 14 \%$ of the sites 444 detected as edited in $A d a r 1^{m Z \alpha / m Z \alpha}$ mice (data not shown). ADAR1-p150 is 445 encoded by an ISG and Adar1 transcript levels increased by 1.6-fold in 446 Adar1 ${ }^{m Z \alpha / m Z \alpha}$ lungs (data not shown). Thus, it is likely that type I IFN-induced 447 expression of ADAR1-p150 in mutant mice and recruitment of A-form dsRNAs 448 via the dsRBDs explains editing at these sites.

449 ADAR1 mutations in human cause AGS and include the missense 450 p.Pro193Ala mutation in the $\mathrm{Z} \alpha$ domain. Interestingly, this $A D A R 1$ allele is 
common with frequencies of up to 1/160 (www.ensembl.org) (Mannion et al., 2014). In AGS patients, homozygous p.Pro193Ala mutation has not been observed; instead, this mutation occurs together with other ADAR1 mutations

454 (Rice et al., 2012). It is therefore likely that ADAR1 p.Pro193Ala is hypomorphic and does not cause disease when present homozygously. Consistent with this notion, we found that $A d a r 1^{m Z \alpha / m Z \alpha}$ mice did not have any gross abnormalities and were fertile. These mice nonetheless displayed type I IFN and ISG induction in multiple organs. This included the lung and bestowed protection against IAV infection at early stages. It is therefore conceivable that the ADAR1 p.Pro193Ala variant has been maintained in humans by providing a selective advantage during viral infections due to elevated expression of antiviral factors at baseline.

It is noteworthy in this context that anti- and pro-viral functions of ADAR1 464 have been reported. ADAR1 limits or controls replication of several viruses, 465 including measles virus, members of Paramyxoviridae family, IAV, HIV-1, 466 vesicular stomatitis virus and Hepatitis delta virus (Casey, 2012; Li et al., 2010; 467 Vogel et al., 2020; Ward et al., 2011; Weiden et al., 2014). However, for other 468 viruses such as Zika and KSHV, ADAR1 has been shown to facilitate replication 469 (Zhang et al., 2020a; Zhou et al., 2019). It will be interesting for future studies 470 to determine the role of the $A D A R 1$ variants unable to bind $\mathrm{Z}$ nucleic acids in 471 these viral infections.

472 ADAR1 has recently emerged as a promising target for cancer treatment.

473 If expressed by transformed cells in vitro or by tumours in vivo, ADAR1 protects 474 against both cell death and anti-cancer immune responses (Gannon et al., 2018; 475 Ishizuka et al., 2019; Liu et al., 2019). Loss of ADAR1 in cancer cells results in 476 death or reduced growth and sensitises to immunotherapy. Interestingly, the 477 protective effects appear to depend on ADAR1-p150 (Gannon et al., 2018; 478 Ishizuka et al., 2019). It is therefore possible that endogenous Z-RNAs induce 
479 anti-cancer effects upon ADAR1 loss. Future studies should test this, for 480 example by reconstitution of ADAR1-p150 mutants unable to bind Z-RNA. 481 Furthermore, development of inhibitors that target the Z $\alpha$ domain of ADAR1, 482 the Z $\alpha$ - Z-RNA interaction or Z-RNA formation should be considered. 483 Compared to deaminase inhibitors, such 'Z-inhibitors' would have the 484 advantage of specifically targeting the p150 isoform, avoiding possible 485 detrimental consequences of targeting ADAR1-p110 (Pestal et al., 2015). In addition to the activation of MDA5, loss of ADAR1 also results in 487 activation of the OAS-RNaseL system and PKR. The latter may be particularly 488 important in cancer settings (Gannon et al., 2018; Ishizuka et al., 2019; Liu et 489 al., 2019). Although PKR activation results in a global shutdown of translation, 490 some proteins are selectively made and mediate the integrated stress response 491 (Pakos-Zebrucka et al., 2016). These include the transcription factor ATF4 that 492 induces stress-response genes. We observed moderate induction of some 493 ATF4-dependent genes (Harding et al., 2003) including Asns (1.3-fold), Slc7a5 494 (1.3-fold), Slc7a11 (1.9-fold) and Mthfd2 (1.7-fold) (data not shown). It is 495 therefore possible that editing of Z-RNA by ADAR1-p150 limits not only type I 496 IFN induction but also PKR-dependent stress responses.

497 In conclusion, we discovered MAVS-dependent type I IFN induction as a 498 biological function of Z-RNA that is curtailed by ADAR1-p150. These insights 499 are not only of fundamental value but also have important implications for 500 understanding and modulating detrimental and beneficial type I IFN responses 501 in autoinflammation and cancer. 


\section{Materials and Methods}

Mice

Adar1 $1^{+f f-m Z \alpha}$ mice were generated by Cyagen. In brief, genomic fragments

507 containing homology arms were amplified from a BAC and were sequentially 508 assembled into a targeting vector together with recombination sites and 509 selection markers as shown in Figure S1A. Successful assembly of the

510 targeting vector was verified by restriction digest and sequencing. The

511 linearised vector was subsequently delivered to ES cells (C57BL/6) via 512 electroporation, followed by drug selection, PCR screening and sequencing. 513 After confirming correctly targeted ES clones via Southern blotting, we selected

514 clones for blastocyst microinjection, followed by chimera production. Founders 515 were confirmed as germline-transmitted via crossbreeding with WT animals. 516 The Neo cassette was flanked by Rox sites and contained a Dre recombinase

517 controlled by a promoter active in the germline, resulting in deletion of the Neo 518 cassette in $\mathrm{F} 1$ animals (Figure S1A). These $A d a r 1^{+/ f l-m Z \alpha}$ mice were further 519 crossed with Pgk-Cre mice provided by Samira Lakhal-Littleton to produce 520 Adar1 $^{+/ m Z \alpha}$ animals (Figure S1A). The following PCR primers were used for 521 genotyping:

F, 5'-TGACGAGAGACTTGTTTTCCTAGCATG-3',

$$
\text { R1, 5'-TGCCTCAATGAGACCTCCAACTTAACTC-3', }
$$

$$
\text { R2 }{ }^{\text {WT }} \text {, 5'-CAGGGAGTACAAAATACGATT-3', and }
$$

PCR with primers F and R1 yielded a product of $357 \mathrm{bp}$ for the WT Adar1 allele and a 421 bp product for both ' $f$ l- $m Z \alpha$ ' and ' $m Z \alpha$ ' alleles. PCR with primers F 528 and R2 ${ }^{\mathrm{WT}}$ resulted in 1095 and 1158 bp products for the WT and 'fl- $m Z \alpha$ ' alleles, 529 respectively, and no product for the ' $m Z \alpha$ ' allele. Finally, PCR with primers F and $\mathrm{R} 2^{\mathrm{MUT}}$ resulted in a 1158 bp product for the ' $m Z \alpha$ ' allele only. 
Mavs $^{-/}$mice were a gift from C. Reis e Sousa and were originally from J.

532 Tschopp (Michallet et al., 2008). All mice were on the C57BL/6 background.

533 This work was performed in accordance with the UK Animal (Scientific

534 Procedures) Act 1986 and institutional guidelines for animal care. This work

535 was approved by project licenses granted by the UK Home Office (PPL 536 numbers PC041D0AB, PBA43A2E4 and P79A4C5BA) and was also approved 537 by the Institutional Animal Ethics Committee Review Board at the University of 538 Oxford.

$\underline{\text { Cell culture }}$

541 Lung fibroblasts and MEFs were grown in DMEM and BMMCs in RPMI, as 542 described previously ( $\mathrm{Li}$ et al., 2013; Maelfait et al., 2017). Media were 543 supplemented with $10 \%$ heat-inactivated FCS and $2 \mathrm{mM} \mathrm{L-glutamine;} \mathrm{for}$ 544 BMMCs, $200 \mathrm{U} / \mathrm{ml}$ recombinant mouse GM-CSF (Peprotech) was added. MEFs 545 were cultured at $3 \%$ oxygen.

$\underline{\text { RNA extraction and RT-qPCR }}$

548 Organs collected from freshly killed mice (8-10 weeks of age) were snap

549 frozen in liquid nitrogen immediately after dissection and stored at $-80^{\circ} \mathrm{C}$ until 550 further processing. Organs were homogenised with glass beads (425-600 $\mu \mathrm{m}$, 551 Sigma-Aldrich) in TRIzol (Thermo Fisher Scientific) using a FastPrep F120 552 instrument (Thermo Savant). RNA was extracted following the manufacturer's 553 instructions and further purified using RNeasy Plus columns (Qiagen) including 554 a gDNA eliminator column step. cDNA synthesis was performed with 555 SuperScript II reverse transcriptase (Thermo Fisher Scientific) with random

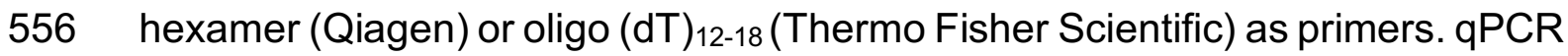
557 was done using Taqman Universal PCR Mix (Thermo Fisher Scientific) and 558 Taqman probes (Applied Biosystems). Alternatively, qPCR was performed 
using EXPRSS SYBR GreenER qPCR Supermix (Thermo Fisher Scientific)

560 and DNA oligonucleotides (Sigma Aldrich). qPCR was performed on a

561 QuantStudio 7 Flex real-time PCR system (Applied Biosystem). The qPCR

562 probes and primers used in this study are listed in Table S2.

$\underline{\text { In vivo infection }}$

WT and Adar1 ${ }^{m Z \alpha / m Z \alpha}$ mice were used at 8-10 weeks of age. Mice were

566 intranasally inoculated with $50 \mu \mathrm{l}$ X31 (0.04 haemagglutination units (HAU))

567 diluted in viral growth medium (VGM; DMEM with 1\% bovine serum albumin 568 (Sigma-Aldrich A0336), $10 \mathrm{mM}$ HEPES buffer, penicillin (100 U/ml) and 569 streptomycin $(100 \mu \mathrm{g} / \mathrm{ml}))$ or mock infected with $50 \mu \mathrm{l}$ VGM under light 570 isoflurane anaesthesia. Animals were assessed daily for weight loss and signs 571 of disease. Mice reaching $20 \%$ weight loss were euthanised.

\section{$573 \quad$ Western Blot}

574 Cells were lysed in RIPA buffer (50 mM Tris. $\mathrm{HCl}, \mathrm{pH} 7.4 ; 150 \mathrm{mM} \mathrm{NaCl} ; 1 \%$ 575 NP-40 (Sigma-Aldrich), 0.5\% Deoxycholate, 0.1\% SDS and Complete protease 576 inhibitor (Roche)) at $4^{\circ} \mathrm{C}$ for 10 minutes. Protein lysates were then cleared by 577 centrifugation at 13000 rpm for 10 minutes. Samples were mixed with NuPAGE 578 SDS-PAGE sample loading buffer (ThermoFisher) containing 10\% 2579 mercaptoethanol. A primary antibody against ADAR1 was purchased from 580 Santa Cruz (sc-73408). The antibody recognising ISG15 was a gift from Klaus581 Peter Knobeloch. HRP-coupled secondary antibodies were from GE 582 Healthcare.

584 Flow cytometry

585 Lungs from 8-10 week old mice were dissected and mechanically disrupted using scissors before incubation in RPMI containing $1 \mu \mathrm{g} / \mathrm{ml}$ type II collagenase 
587 (Worthington Biochemical Corporation) and $40 \mathrm{U} / \mathrm{ml}$ DNase I (Sigma Aldrich) at

$58837^{\circ} \mathrm{C}$ for 60 minutes, with resuspension after 30 minutes to facilitate tissue 589 dissociation. Cells were filtered through a $70 \mu \mathrm{m}$ cell strainer (BD Falcon), 590 rinsed with RPMI and pelleted at $400 \times \mathrm{g}$ for 5 minutes. The cell pellet was 591 resuspended in $5 \mathrm{ml} \mathrm{RBC}$ lysis buffer (Qiagen), incubated at room temperature 592 for 5 minutes and then washed twice with $45 \mathrm{ml}$ RPMI. Cells were resuspended 593 in $500 \mu \mathrm{l}$ FACS buffer (PBS containing 10\% (v/v) FCS and 2 mM EDTA) and 594 passed through a $70 \mu \mathrm{m}$ cell strainer. Viable cells were counted using a 595 haemocytometer. Cells were washed with PBS before incubation with 596 LIVE/DEAD Fixable Aqua Dead Cell Stain (Invitrogen) diluted 1:200 in PBS for 59730 minutes at room temperature. Cells were washed once with FACS buffer 598 and then stained with surface antibodies diluted 1:200 in Brilliant buffer (BD 599 Biosciences) for 30 minutes. Cells were sorted directly into TRIzol-LS Reagent 600 (Thermo Fisher Scientific) on BD FACSAria II and III machines (BD 601 Biosciences). Alternatively, $1.5 \times 10^{6}$ cells were stained and analysed using an 602 Attune NxT Flow Cytometer (Thermo Fisher Scientific). Data were analysed 603 using FlowJo (v10.6.2).

604

605

Magnetic cell fraction

606 Cells from lungs were prepared as described above. $10^{7}$ cells were 607 resuspended in $90 \mu \mathrm{l}$ of MACS buffer (PBS containing 0.5\% BSA and $2 \mathrm{mM}$ 608 EDTA) and then incubated with $10 \mu$ of CD45 microbeads (Miltenyi) for 15 609 minutes. The mixture was then washed with MACS buffer and resuspend in $610500 \mu \mathrm{l}$ MACS buffer for magnetic separation on MACS LS columns (Miltenyi) 611 according to the manufacturer's instructions. Cells were recovered from the 612 flow-through (CD45-) and column (CD45+). 10\% of cells were stained and 613 analysed by FACS to confirm purity. The remaining cells were pelleted, 614 resuspend in TRIzol (ThermoFisher) and processed for RT-qPCR. 
Bone marrow chimera

B6.SJL-CD45.1 mice were used as bone marrow recipients and were

618 lethally irradiated twice (4.5 Gy for 300 seconds, separated by a $\sim 3$ hour rest).

619 Mice were then injected intravenously with bone marrow from either WT

620 (CD45.2) or Adar1 ${ }^{m Z \alpha / m Z \alpha}$ mice. Recipient mice received antibiotics $(0.16$ $621 \mathrm{mg} / \mathrm{mL}$, Enrofloxacin (Baytril), Bayer Corporation) in drinking water for four 622 weeks following irradiation and were rested for $>8$ weeks before tissue 623 collection.

$\underline{\text { RNA-seq and data processing }}$

Stranded Illumina sequencing libraries were prepared with the RNA-Seq

627 Ribozero kit from isolated RNAs and submitted for PE150 sequencing using an 628 Illumina NovaSeq6000 machine, yielding $\sim 100 \mathrm{M}$ reads per sample.

629 Sequencing data was processed using a Nextflow v20.07 (Di Tommaso et al., 630 2017) pipeline automating quality control using FastQC v0.11.8 631 (bioinformatics.babraham.ac.uk/projects/fastqc/), quality and adapter trimming 632 using cutadapt v1.18 (Martin, 2011), contaminant detection using screen.sh 633 (within BBMap v36.20, sourceforge.net/projects/bbmap/), strand-aware 634 alignment using HISAT2 v2.1.0 (Kim et al., 2019) and STAR v2.7.1a (Dobin 635 et al., 2013), post-alignment quality-assurance using 'gene body coverage', 636 'transcript integrity', and 'inner distance' metrics from RSeQC v2.6.4 (Wang et 637 al., 2012), and strand-specific counting of uniquely-mapping reads using 638 featureCounts (within Subread v1.6.4, (Liao et al., 2014)) against Ensembl 639 GRCm38.100 annotations. Additional, unstranded counts were obtained with 640 featureCounts against a database of repetitive elements previously prepared 641 for GRCm38 (Attig et al., 2017) using reads unassigned to features during the previous step. 
Differential expression analysis

Downstream differential expression analysis was conducted using counts

646 obtained for STAR read mappings using DESeq2 (Love et al., 2014) (v1.22.1)

647 within R (v4.0.2). Gene ontology analysis was performed using goseq (Young 648 et al., 2010) (1.34.1). Heatmaps were generated using the pheatmap package $649 \quad(\mathrm{v} 1.0 .12)$

Detection of A-to-I editing

A Python 3.8 program, edlted (github.com/A-N-Other/pedestal), was produced to identify editing sites. edlted performs stranded assessments of

654 RNA editing from samtools mpileup ( $\mathrm{Li}, 2011)$ data, building on the Dirichletbased models implemented in ACCUSA2 and JACUSA (Piechotta and 656 Dieterich, 2013; Piechotta et al., 2017). When run with test data alone, edlted 657 runs in 'detect' mode, finding base modifications by comparing the goodness of 658 fit of Dirchlet models of the base error (derived from the Phred quality data in 659 the mpileup input) and the background sequencing error to the base 660 frequencies recorded at a specific position. With an additional control dataset, 661 edlted runs in 'differential' mode, performing the above analysis to determine 662 significantly edited sites before additionally testing for differential editing by 663 comparing the goodness of fit of Dirichlet models of the base error from the test 664 and control datasets to their own and each other's base frequencies. When 665 biological replicates are provided, edlted adjusts the reported Z scores to reflect 666 the proportion of test dataset samples displaying editing. edlted was run in both 667 modes with samtools mpileup files (supplemented with TS tag metadata) 668 separately for HISAT2 and STAR alignments of the data with the flags '-669 min_depth 5 --min_alt_depth 2 --min_edited 0.01 --max_edited 0.9 --z_score 670 2.58'. For differential analyses the '--min_fold 2' flag was used and, where 
671 considering biological replicates the '--reps 3' flag, such that editing is required

672 in all three samples. All analyses were conducted supplying BED files of

673 ENCODE blacklisted regions (Amemiya et al., 2019) and known splice sites

674 (regions set to splice site +/- 2 nts) to the '--blacklist' flag. Sites that were found

675 in common between the HISAT2- and STAR-mapped data were retained for

676 further analysis.

677

$678 \quad$ Analysis of A-to-I editing sites

679 Sites obtained from edlted were assigned to genomic features using 680 annotatr v1.16 within R (Cavalcante and Sartor, 2017). Assessments of editing 681 enrichment within repetitive elements were conducted using regioneR v1.22 682 within R (Gel et al., 2016) using randomization-based permutation tests with 683100 bootstraps. Assessment of distance to neighbouring inverted SINE super684 family (B1, B2, B3, B4) members was conducted with bedtools v2.29.2 closest 685 (Quinlan and Hall, 2010) using the '-io -S' flags. Outputs and the detailed 686 statistics were produced with GraphPad Prism v8.

687

688 ELISA

689 Mouse IL-6 was quantified by uncoated ELISA Kit (ThermoFisher) 690 according to manufacturer's instruction. 
Author contributions (using the CRediT taxonomy)

692 Conceptualisation: Q.T. and J.R.; Methodology: Q.T., R.E.R. and G.Y.; Software:

693 R.E.R. and G.Y.; Validation: Q.T. and J.R.; Formal analysis: Q.T., R.E.R., G.Y. 694 and J.R.; Investigation: Q.T., R.E.R., G.Y., A.K.H., T.K.T. and A.B.; Resources:

695 A.T. and G.K.; Data curation: Q.T., R.E.R. and G.Y.; Writing - Original Draft:

696 Q.T., G.Y. and J.R.; Writing - Review \& Editing: all authors; Visualisation: Q.T., 697 R.E.R., G.Y. and J.R.; Supervision: J.R., A.T., and G.K.; Project administration: 698 Q.T.; Funding acquisition: J.R.

\section{Acknowledgments}

701 The authors thank P. Shing Ho and Craig Benham for providing access to the 702 Z-hunt and SIBZ codes, respectively. We further thank Daniel Stetson, Andrew 703 Oberst, Jonathan Maelfait, Caetano Reis e Sousa, David Ron, Annemarthe van 704 Der Veen and members of the Rehwinkel lab for discussion. The authors thank 705 Ziqi Long and Oliver Bannard for their help with generating BM chimeras.

706 This work was funded by the UK Medical Research Council [MRC core funding 707 of the MRC Human Immunology Unit; J.R.], the Wellcome Trust [grant number 708 100954; J.R.], the Lister Institute [J.R.] and the Francis Crick Institute [G.K.], 709 which receives its core funding from Cancer Research UK, the UK Medical 710 Research Council, and the Wellcome Trust. T.K.T. was funded by the 711 Townsend-Jeantet Charitable Trust (charity number 1011770) and the EPA

712 Cephalosporin Early Career Researcher Fund. The funders had no role in study 713 design, data collection and analysis, decision to publish, or preparation of the 714 manuscript.

\section{Declaration of interests}

717 The authors have declared that no conflict of interest exits. 


\section{References}

719 Ahmad, S., Mu, X., Yang, F., Greenwald, E., Park, J.W., Jacob, E., Zhang, C.Z., 720 and Hur, S. (2018). Breaching Self-Tolerance to Alu Duplex RNA Underlies 721 MDA5-Mediated Inflammation. Cell 172, 797-810 e713.

722 Amemiya, H.M., Kundaje, A., and Boyle, A.P. (2019). The ENCODE Blacklist: 723 Identification of Problematic Regions of the Genome. Sci Rep 9, 9354.

724 Ashley, C.L., Abendroth, A., McSharry, B.P., and Slobedman, B. (2019). 725 Interferon-Independent Upregulation of Interferon-Stimulated Genes during 726 Human Cytomegalovirus Infection is Dependent on IRF3 Expression. Viruses 11.

Athanasiadis, A. (2012). Zalpha-domains: at the intersection between RNA editing and innate immunity. Seminars in cell \& developmental biology 23, $275-$ 280.

731 Athanasiadis, A., Placido, D., Maas, S., Brown, B.A., 2nd, Lowenhaupt, K., and 732 Rich, A. (2005). The crystal structure of the Zbeta domain of the RNA-editing 733 enzyme ADAR1 reveals distinct conserved surfaces among Z-domains. Journal 734 of molecular biology 351, 496-507.

735 Attig, J., Young, G.R., Stoye, J.P., and Kassiotis, G. (2017). Physiological and 736 Pathological Transcriptional Activation of Endogenous Retroelements 737 Assessed by RNA-Sequencing of B Lymphocytes. Frontiers in microbiology 8 , 7382489.

739 Bajad, P., Ebner, F., Amman, F., Szabo, B., Kapoor, U., Manjali, G., Hildebrandt, 740 A., Janisiw, M.P., and Jantsch, M.F. (2020). An internal deletion of ADAR 741 rescued by MAVS deficiency leads to a minute phenotype. Nucleic acids 742 research 48, 3286-3303.

743 Bartok, E., and Hartmann, G. (2020). Immune Sensing Mechanisms that 744 Discriminate Self from Altered Self and Foreign Nucleic Acids. Immunity 53, 5474577.

746 Brown, B.A., 2nd, Lowenhaupt, K., Wilbert, C.M., Hanlon, E.B., and Rich, A. 747 (2000). The zalpha domain of the editing enzyme dsRNA adenosine deaminase 748 binds left-handed Z-RNA as well as Z-DNA. Proceedings of the National 749 Academy of Sciences of the United States of America 97, 13532-13536.

750 Casey, J.L. (2012). Control of ADAR1 editing of hepatitis delta virus RNAs. Curr 751 Top Microbiol Immunol 353, 123-143.

752 Cavalcante, R.G., and Sartor, M.A. (2017). annotatr: genomic regions in context. 
Champ, P.C., Maurice, S., Vargason, J.M., Camp, T., and Ho, P.S. (2004). Distributions of Z-DNA and nuclear factor I in human chromosome 22: a model for coupled transcriptional regulation. Nucleic acids research 32, 6501-6510.

Chung, H., Calis, J.J.A., Wu, X., Sun, T., Yu, Y., Sarbanes, S.L., Dao Thi, V.L., Shilvock, A.R., Hoffmann, H.H., Rosenberg, B.R., and Rice, C.M. (2018). Human ADAR1 Prevents Endogenous RNA from Triggering Translational Shutdown. Cell 172, 811-824 e814.

761 Chuong, E.B., Elde, N.C., and Feschotte, C. (2016). Regulatory evolution of 762 innate immunity through co-option of endogenous retroviruses. Science 351, 763 1083-1087.

764 Davis, P.W., Hall, K., Cruz, P., Tinoco, I., Jr., and Neilson, T. (1986). The 765 tetraribonucleotide $\mathrm{rCpGpCpG}$ forms a left-handed Z-RNA double-helix. Nucleic Acids Res 14, 1279-1291.

767 DeFilippis, V.R., Robinson, B., Keck, T.M., Hansen, S.G., Nelson, J.A., and 768 Fruh, K.J. (2006). Interferon regulatory factor 3 is necessary for induction of 769 antiviral genes during human cytomegalovirus infection. Journal of virology 80 , $770 \quad 1032-1037$.

771 Devos, M., Tanghe, G., Gilbert, B., Dierick, E., Verheirstraeten, M., Nemegeer, 772 J., de Reuver, R., Lefebvre, S., De Munck, J., Rehwinkel, J., et al. (2020). 773 Sensing of endogenous nucleic acids by ZBP1 induces keratinocyte 774 necroptosis and skin inflammation. The Journal of experimental medicine 217.

775 Di Tommaso, P., Chatzou, M., Floden, E.W., Barja, P.P., Palumbo, E., and 776 Notredame, C. (2017). Nextflow enables reproducible computational workflows. $777 \quad$ Nat Biotechnol 35, 316-319.

778 Dias Junior, A.G., Sampaio, N.G., and Rehwinkel, J. (2019). A Balancing Act: 779 MDA5 in Antiviral Immunity and Autoinflammation. Trends in microbiology 27, $780 \quad 75-85$.

781 Dobin, A., Davis, C.A., Schlesinger, F., Drenkow, J., Zaleski, C., Jha, S., Batut, 782 P., Chaisson, M., and Gingeras, T.R. (2013). STAR: ultrafast universal RNA783 seq aligner. Bioinformatics 29, 15-21.

784 Eisenberg, E., and Levanon, E.Y. (2018). A-to-I RNA editing - immune protector 785 and transcriptome diversifier. Nature reviews. Genetics 19, 473-490.

786 Feng, S., Li, H., Zhao, J., Pervushin, K., Lowenhaupt, K., Schwartz, T.U., and 
Droge, P. (2011). Alternate rRNA secondary structures as regulators of translation. Nature structural \& molecular biology 18, 169-176.

789 Gannon, H.S., Zou, T., Kiessling, M.K., Gao, G.F., Cai, D., Choi, P.S., Ivan, A.P., 790 Buchumenski, I., Berger, A.C., Goldstein, J.T., et al. (2018). Identification of 791 ADAR1 adenosine deaminase dependency in a subset of cancer cells. Nature 792 communications 9,5450 .

793 Gel, B., Diez-Villanueva, A., Serra, E., Buschbeck, M., Peinado, M.A., and 794 Malinverni, R. (2016). regioneR: an R/Bioconductor package for the association analysis of genomic regions based on permutation tests. Bioinformatics 32 , 289-291.

797 Goubau, D., Romieu-Mourez, R., Solis, M., Hernandez, E., Mesplede, T., Lin, 798 R., Leaman, D., and Hiscott, J. (2009). Transcriptional re-programming of 799 primary macrophages reveals distinct apoptotic and anti-tumoral functions of 800 IRF-3 and IRF-7. Eur J Immunol 39, 527-540.

801 Grandvaux, N., Servant, M.J., tenOever, B., Sen, G.C., Balachandran, S., 802 Barber, G.N., Lin, R., and Hiscott, J. (2002). Transcriptional profiling of 803 interferon regulatory factor 3 target genes: direct involvement in the regulation 804 of interferon-stimulated genes. Journal of virology 76, 5532-5539.

805 Guallar, D., Fuentes-Iglesias, A., Souto, Y., Ameneiro, C., Freire-Agulleiro, O., 806 Pardavila, J.A., Escudero, A., Garcia-Outeiral, V., Moreira, T., Saenz, C., et al. 807 (2020). ADAR1-Dependent RNA Editing Promotes MET and iPSC 808 Reprogramming by Alleviating ER Stress. Cell stem cell 27, 300-314 e311.

809 Hall, K., Cruz, P., Tinoco, I., Jr., Jovin, T.M., and van de Sande, J.H. (1984). 'Z810 RNA'--a left-handed RNA double helix. Nature 311, 584-586.

811 Harding, H.P., Zhang, Y., Zeng, H., Novoa, I., Lu, P.D., Calfon, M., Sadri, N., 812 Yun, C., Popko, B., Paules, R., et al. (2003). An integrated stress response 813 regulates amino acid metabolism and resistance to oxidative stress. Molecular 814 cell 11, 619-633.

815 Hartner, J.C., Schmittwolf, C., Kispert, A., Muller, A.M., Higuchi, M., and 816 Seeburg, P.H. (2004). Liver disintegration in the mouse embryo caused by 817 deficiency in the RNA-editing enzyme ADAR1. J Biol Chem 279, 4894-4902.

818 Hartner, J.C., Walkley, C.R., Lu, J., and Orkin, S.H. (2009). ADAR1 is essential 819 for the maintenance of hematopoiesis and suppression of interferon signaling. 820 Nature immunology 10, 109-115.

821 Heraud-Farlow, J.E., and Walkley, C.R. (2020). What do editors do? 
Understanding the physiological functions of A-to-I RNA editing by adenosine deaminase acting on RNAs. Open Biol 10, 200085.

824 Herbert, A. (2019). Z-DNA and Z-RNA in human disease. Commun Biol 2, 7.

825

826

827

828

829

830

831

832

833

834

835

836

837

838

839

840

841

842

843

844

845

846

847

848

849

850

851

852

853

854

855

Ho, P.S., Ellison, M.J., Quigley, G.J., and Rich, A. (1986). A computer aided thermodynamic approach for predicting the formation of Z-DNA in naturally occurring sequences. The EMBO journal 5, 2737-2744.

Ishizuka, J.J., Manguso, R.T., Cheruiyot, C.K., Bi, K., Panda, A., Iracheta-Vellve, A., Miller, B.C., Du, P.P., Yates, K.B., Dubrot, J., et al. (2019). Loss of ADAR1 in tumours overcomes resistance to immune checkpoint blockade. Nature 565 , 43-48.

Jiao, H., Wachsmuth, L., Kumari, S., Schwarzer, R., Lin, J., Eren, R.O., Fisher, A., Lane, R., Young, G.R., Kassiotis, G., et al. (2020). Z-nucleic-acid sensing triggers ZBP1-dependent necroptosis and inflammation. Nature 580, 391-395.

Kesavardhana, S., and Kanneganti, T.D. (2020). ZBP1: A STARGTE to decode the biology of Z-nucleic acids in disease. The Journal of experimental medicine 217.

Kim, D., Paggi, J.M., Park, C., Bennett, C., and Salzberg, S.L. (2019). Graphbased genome alignment and genotyping with HISAT2 and HISAT-genotype. Nat Biotechnol 37, 907-915.

Kim, S.H., Lim, S.H., Lee, A.R., Kwon, D.H., Song, H.K., Lee, J.H., Cho, M., Johner, A., Lee, N.K., and Hong, S.C. (2018). Unveiling the pathway to Z-DNA in the protein-induced B-Z transition. Nucleic acids research 46, 4129-4137.

Kim, Y.G., Muralinath, M., Brandt, T., Pearcy, M., Hauns, K., Lowenhaupt, K., Jacobs, B.L., and Rich, A. (2003). A role for Z-DNA binding in vaccinia virus pathogenesis. Proceedings of the National Academy of Sciences of the United States of America 100, 6974-6979.

Lazear, H.M., Lancaster, A., Wilkins, C., Suthar, M.S., Huang, A., Vick, S.C., Clepper, L., Thackray, L., Brassil, M.M., Virgin, H.W., et al. (2013). IRF-3, IRF5 , and IRF-7 coordinately regulate the type I IFN response in myeloid dendritic cells downstream of MAVS signaling. PLoS Pathog 9, e1003118.

Li, H. (2011). A statistical framework for SNP calling, mutation discovery, association mapping and population genetical parameter estimation from sequencing data. Bioinformatics 27, 2987-2993.

Li, H., Xiao, J., Li, J., Lu, L., Feng, S., and Droge, P. (2009). Human genomic 
Z-DNA segments probed by the $Z$ alpha domain of ADAR1. Nucleic acids research 37, 2737-2746.

858 Li, X.D., Wu, J., Gao, D., Wang, H., Sun, L., and Chen, Z.J. (2013). Pivotal roles 859 of cGAS-cGAMP signaling in antiviral defense and immune adjuvant effects. 860 Science $341,1390-1394$.

861 Li, Y., Banerjee, S., Goldstein, S.A., Dong, B., Gaughan, C., Rath, S., Donovan, 862 J., Korennykh, A., Silverman, R.H., and Weiss, S.R. (2017). Ribonuclease L 863 mediates the cell-lethal phenotype of double-stranded RNA editing enzyme 864 ADAR1 deficiency in a human cell line. Elife 6.

865 Li, Z., Wolff, K.C., and Samuel, C.E. (2010). RNA adenosine deaminase 866 ADAR1 deficiency leads to increased activation of protein kinase PKR and 867 reduced vesicular stomatitis virus growth following interferon treatment. 868 Virology 396, 316-322.

869 Liao, Y., Smyth, G.K., and Shi, W. (2014). featureCounts: an efficient general 870 purpose program for assigning sequence reads to genomic features. 871 Bioinformatics 30, 923-930.

872 Liddicoat, B.J., Piskol, R., Chalk, A.M., Ramaswami, G., Higuchi, M., Hartner, 873 J.C., Li, J.B., Seeburg, P.H., and Walkley, C.R. (2015). RNA editing by ADAR1 874 prevents MDA5 sensing of endogenous dsRNA as nonself. Science 349, 11158751120.

876 Liu, H., Golji, J., Brodeur, L.K., Chung, F.S., Chen, J.T., deBeaumont, R.S., 877 Bullock, C.P., Jones, M.D., Kerr, G., Li, L., et al. (2019). Tumor-derived IFN 878 triggers chronic pathway agonism and sensitivity to ADAR loss. Nature 879 medicine $25,95-102$.

880 Love, M.I., Huber, W., and Anders, S. (2014). Moderated estimation of fold 881 change and dispersion for RNA-seq data with DESeq2. Genome Biol 15, 550.

882 Luo, H., Wang, D., Che, H.L., Zhao, Y., and Jin, H. (2012). Pathological 883 observations of lung inflammation after administration of IP-10 in influenza 884 virus- and respiratory syncytial virus-infected mice. Exp Ther Med 3, 76-79.

885 Maelfait, J., Liverpool, L., Bridgeman, A., Ragan, K.B., Upton, J.W., and 886 Rehwinkel, J. (2017). Sensing of viral and endogenous RNA by ZBP1/DAI 887 induces necroptosis. The EMBO journal 36, 2529-2543.

888 Maelfait, J., Liverpool, L., and Rehwinkel, J. (2020). Nucleic Acid Sensors and 889 Programmed Cell Death. Journal of molecular biology 432, 552-568. 
Mannion, N.M., Greenwood, S.M., Young, R., Cox, S., Brindle, J., Read, D., Nellaker, C., Vesely, C., Ponting, C.P., McLaughlin, P.J., et al. (2014). The RNAediting enzyme ADAR1 controls innate immune responses to RNA. Cell reports 9, $1482-1494$.

894 Martin, M. (2011). Cutadapt removes adapter sequences from high-throughput sequencing reads. 2011 17, 3.

Mehdipour, P., Marhon, S.A., Ettayebi, I., Chakravarthy, A., Hosseini, A., Wang, Y., de Castro, F.A., Loo Yau, H., Ishak, C., Abelson, S., et al. (2020). Epigenetic therapy induces transcription of inverted SINEs and ADAR1 dependency. Nature 588, 169-173.

Michallet, M.C., Meylan, E., Ermolaeva, M.A., Vazquez, J., Rebsamen, M., Curran, J., Poeck, H., Bscheider, M., Hartmann, G., Konig, M., et al. (2008). TRADD protein is an essential component of the RIG-like helicase antiviral pathway. Immunity 28, 651-661.

Pakos-Zebrucka, K., Koryga, I., Mnich, K., Ljujic, M., Samali, A., and Gorman, A.M. (2016). The integrated stress response. EMBO reports 17, 1374-1395.

906 Perng, Y.C., and Lenschow, D.J. (2018). ISG15 in antiviral immunity and beyond. Nature reviews. Microbiology 16, 423-439.

908 Pestal, K., Funk, C.C., Snyder, J.M., Price, N.D., Treuting, P.M., and Stetson, 909 D.B. (2015). Isoforms of RNA-Editing Enzyme ADAR1 Independently Control 910 Nucleic Acid Sensor MDA5-Driven Autoimmunity and Multi-organ Development. 911 Immunity 43, 933-944.

912 Pfaller, C.K., Donohue, R.C., Nersisyan, S., Brodsky, L., and Cattaneo, R. 913 (2018). Extensive editing of cellular and viral double-stranded RNA structures 914 accounts for innate immunity suppression and the proviral activity of 915 ADAR1p150. PLoS Biol 16, e2006577.

916 Pichlmair, A., Lassnig, C., Eberle, C.A., Gorna, M.W., Baumann, C.L., Burkard, 917 T.R., Burckstummer, T., Stefanovic, A., Krieger, S., Bennett, K.L., et al. (2011). 918 IFIT1 is an antiviral protein that recognizes 5 '-triphosphate RNA. Nature 919 immunology $12,624-630$.

920 Piechotta, M., and Dieterich, C. (2013). ACCUSA2: multi-purpose SNV calling 921 enhanced by probabilistic integration of quality scores. Bioinformatics $29,1809-$ 9221810.

923 Piechotta, M., Wyler, E., Ohler, U., Landthaler, M., and Dieterich, C. (2017). 924 JACUSA: site-specific identification of RNA editing events from replicate 
sequencing data. BMC Bioinformatics 18, 7.

926 Porath, H.T., Knisbacher, B.A., Eisenberg, E., and Levanon, E.Y. (2017).

927 Massive A-to-I RNA editing is common across the Metazoa and correlates with 928 dsRNA abundance. Genome Biol 18, 185.

929 Quinlan, A.R., and Hall, I.M. (2010). BEDTools: a flexible suite of utilities for 930 comparing genomic features. Bioinformatics 26, 841-842.

931 Reich, D.P., and Bass, B.L. (2019). Mapping the dsRNA World. Cold Spring 932 Harb Perspect Biol 11.

933 Rice, G.I., Kasher, P.R., Forte, G.M., Mannion, N.M., Greenwood, S.M., 934 Szynkiewicz, M., Dickerson, J.E., Bhaskar, S.S., Zampini, M., Briggs, T.A., et 935 al. (2012). Mutations in ADAR1 cause Aicardi-Goutieres syndrome associated 936 with a type I interferon signature. Nature genetics 44, 1243-1248.

937 Schade, M., Turner, C.J., Lowenhaupt, K., Rich, A., and Herbert, A. (1999). 938 Structure-function analysis of the Z-DNA-binding domain Zalpha of dsRNA 939 adenosine deaminase type I reveals similarity to the (alpha + beta) family of 940 helix-turn-helix proteins. The EMBO journal 18, 470-479.

941 Schoggins, J.W. (2019). Interferon-Stimulated Genes: What Do They All Do? 942 Annu Rev Virol 6, 567-584.

943 Schwartz, T., Rould, M.A., Lowenhaupt, K., Herbert, A., and Rich, A. (1999). 944 Crystal structure of the Zalpha domain of the human editing enzyme ADAR1 945 bound to left-handed Z-DNA. Science 284, 1841-1845.

946 Solomon, O., Di Segni, A., Cesarkas, K., Porath, H.T., Marcu-Malina, V., Mizrahi, 947 O., Stern-Ginossar, N., Kol, N., Farage-Barhom, S., Glick-Saar, E., et al. (2017). 948 RNA editing by ADAR1 leads to context-dependent transcriptome-wide 949 changes in RNA secondary structure. Nature communications 8, 1440.

950 Song, Y., Yang, W., Fu, Q., Wu, L., Zhao, X., Zhang, Y., and Zhang, R. (2020). 951 irCLASH reveals RNA substrates recognized by human ADARs. Nature 952 structural \& molecular biology $27,351-362$.

953 Sridharan, H., Ragan, K.B., Guo, H., Gilley, R.P., Landsteiner, V.J., Kaiser, W.J., 954 and Upton, J.W. (2017). Murine cytomegalovirus IE3-dependent transcription 955 is required for DAI/ZBP1-mediated necroptosis. EMBO reports 18, 1429-1441.

956 Tan, M.H., Li, Q., Shanmugam, R., Piskol, R., Kohler, J., Young, A.N., Liu, K.I., 957 Zhang, R., Ramaswami, G., Ariyoshi, K., et al. (2017). Dynamic landscape and 958 regulation of RNA editing in mammals. Nature 550, 249-254. 
960 Driven Inflammation and the Type I Interferonopathies. Annual review of 961 immunology 37, 247-267.

962 Vogel, O.A., Han, J., Liang, C.Y., Manicassamy, S., Perez, J.T., and 963 Manicassamy, B. (2020). The p150 Isoform of ADAR1 Blocks Sustained RLR 964 signaling and Apoptosis during Influenza Virus Infection. PLoS Pathog 16, 965 e1008842.

966

967

968

969

970

971

972

973

974

975

976

977

978

979

980

981

982

983

984

985

986

987

988

989

990

991

992

993

Wang, A.H., Quigley, G.J., Kolpak, F.J., Crawford, J.L., van Boom, J.H., van der Marel, G., and Rich, A. (1979). Molecular structure of a left-handed double helical DNA fragment at atomic resolution. Nature 282, 680-686.

Wang, L., Wang, S., and Li, W. (2012). RSeQC: quality control of RNA-seq experiments. Bioinformatics 28, 2184-2185.

Wang, Q., Miyakoda, M., Yang, W., Khillan, J., Stachura, D.L., Weiss, M.J., and Nishikura, K. (2004). Stress-induced apoptosis associated with null mutation of ADAR1 RNA editing deaminase gene. J Biol Chem 279, 4952-4961.

Wang, R., Li, H., Wu, J., Cai, Z.Y., Li, B., Ni, H., Qiu, X., Chen, H., Liu, W., Yang, Z.H., et al. (2020). Gut stem cell necroptosis by genome instability triggers bowel inflammation. Nature 580, 386-390.

Ward, S.V., George, C.X., Welch, M.J., Liou, L.Y., Hahm, B., Lewicki, H., de la Torre, J.C., Samuel, C.E., and Oldstone, M.B. (2011). RNA editing enzyme adenosine deaminase is a restriction factor for controlling measles virus replication that also is required for embryogenesis. Proceedings of the National Academy of Sciences of the United States of America 108, 331-336.

Weiden, M.D., Hoshino, S., Levy, D.N., Li, Y., Kumar, R., Burke, S.A., Dawson, R., Hioe, C.E., Borkowsky, W., Rom, W.N., and Hoshino, Y. (2014). Adenosine deaminase acting on RNA-1 (ADAR1) inhibits HIV-1 replication in human alveolar macrophages. PloS one 9, e108476.

Wittig, B., Wolfl, S., Dorbic, T., Vahrson, W., and Rich, A. (1992). Transcription of human c-myc in permeabilized nuclei is associated with formation of Z-DNA in three discrete regions of the gene. The EMBO journal 11, 4653-4663.

Wolfl, S., Wittig, B., and Rich, A. (1995). Identification of transcriptionally induced Z-DNA segments in the human c-myc gene. Biochim Biophys Acta 1264, 294-302.

Young, M.D., Wakefield, M.J., Smyth, G.K., and Oshlack, A. (2010). Gene ontology analysis for RNA-seq: accounting for selection bias. Genome Biol 11, 
R14.

995 Zhabinskaya, D., and Benham, C.J. (2011). Theoretical analysis of the stress 996 induced B-Z transition in superhelical DNA. PLoS Comput Biol 7, e1001051.

997 Zhang, H., Ni, G., and Damania, B. (2020a). ADAR1 Facilitates KSHV Lytic 998 Reactivation by Modulating the RLR-Dependent Signaling Pathway. Cell 999 reports $31,107564$.

1000 Zhang, T., Yin, C., Boyd, D.F., Quarato, G., Ingram, J.P., Shubina, M., Ragan, 1001 K.B., Ishizuka, T., Crawford, J.C., Tummers, B., et al. (2020b). Influenza Virus 1002 Z-RNAs Induce ZBP1-Mediated Necroptosis. Cell 180, 1115-1129 e1113.

1003 Zhou, S., Yang, C., Zhao, F., Huang, Y., Lin, Y., Huang, C., Ma, X., Du, J., Wang, 1004 Y., Long, G., et al. (2019). Double-stranded RNA deaminase ADAR1 promotes 1005 the Zika virus replication by inhibiting the activation of protein kinase PKR. J 1006 Biol Chem 294, 18168-18180. 
Figure 1.

A
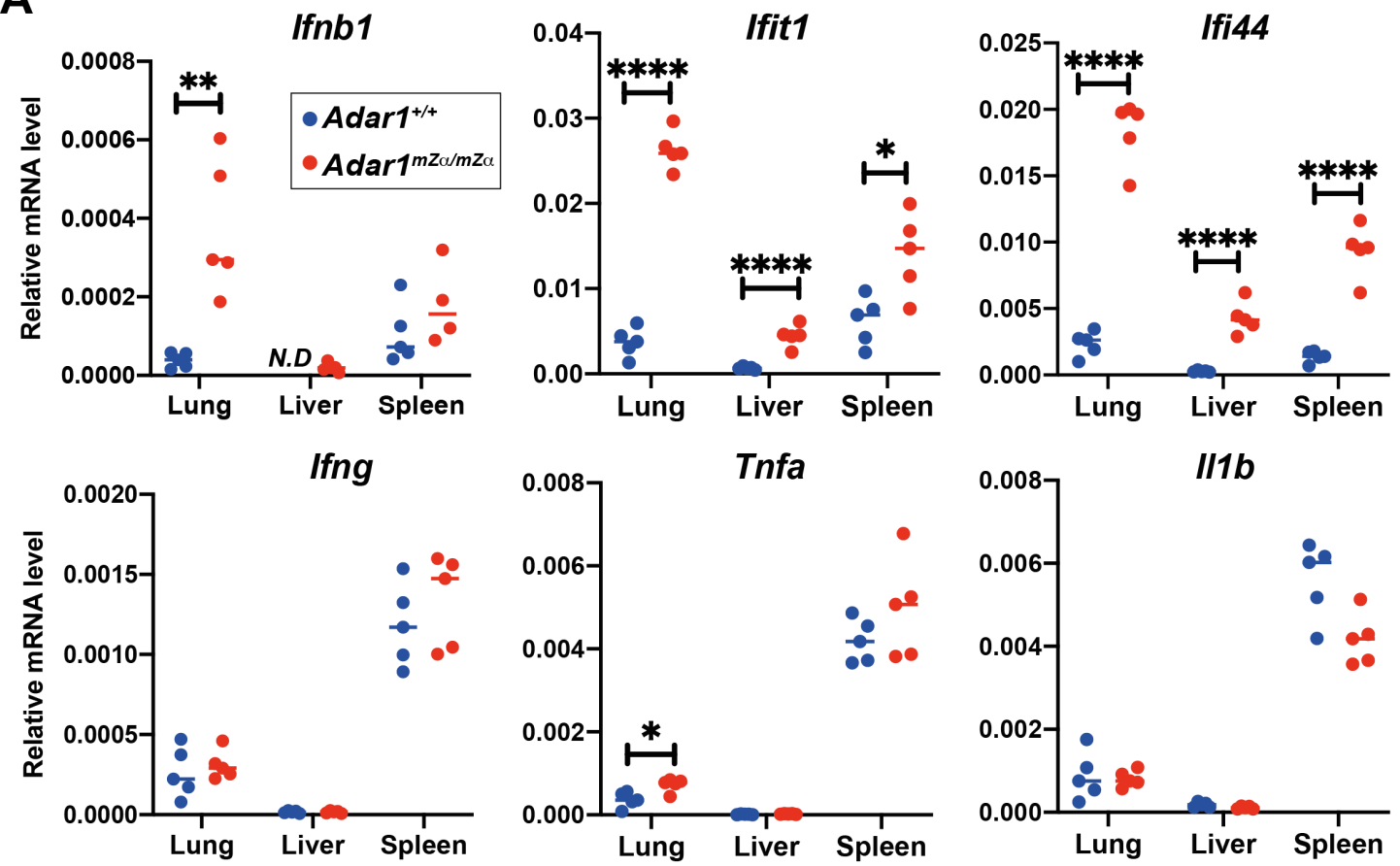

B
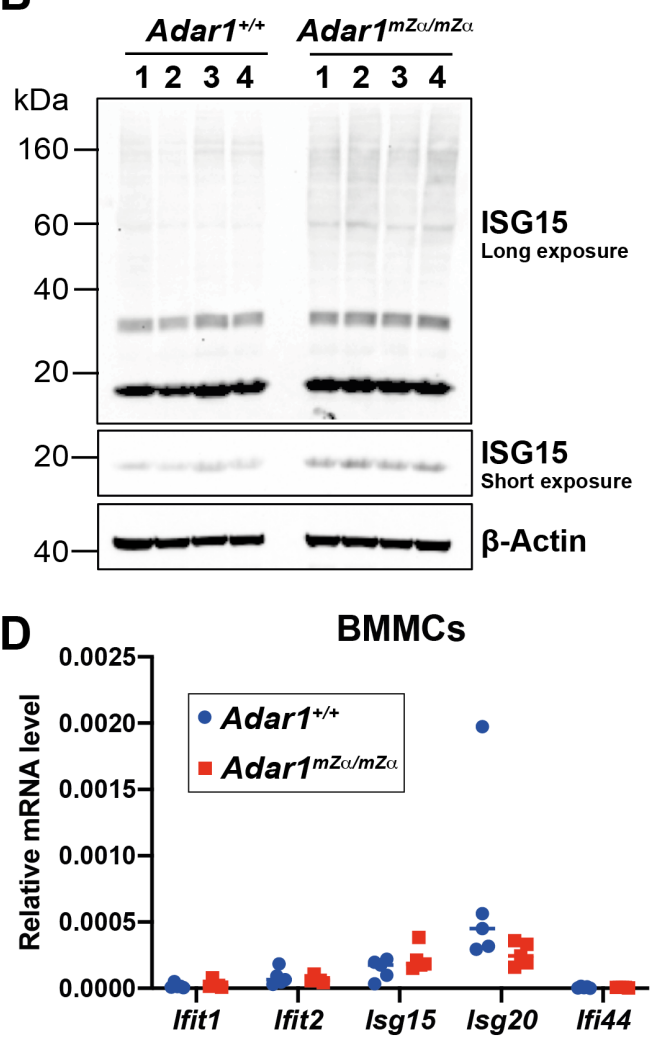

C

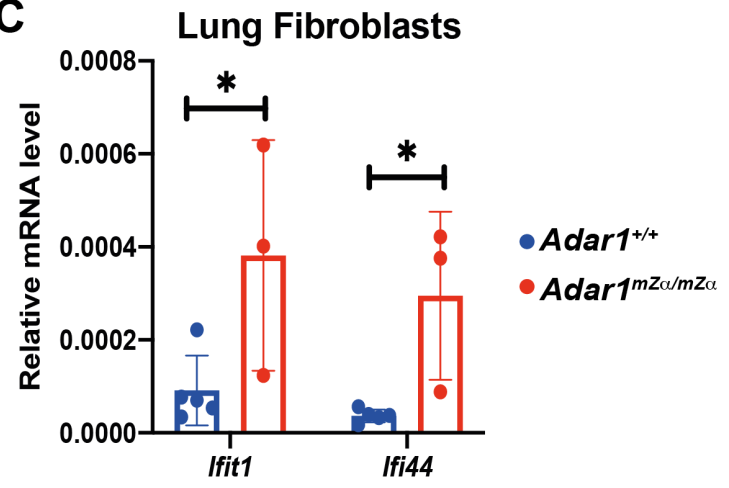

E

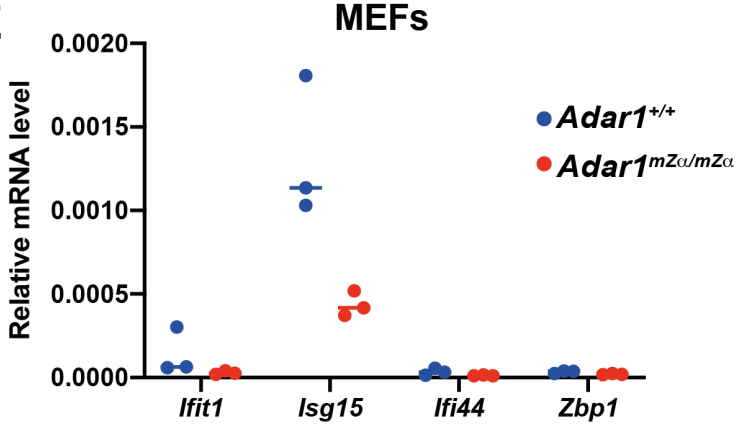


1013 Figure 1. Mutation of ADAR1-p150's Z $\alpha$ domain triggers spontaneous type I

1014 IFN responses in multiple organs.

1015 A. Levels of the indicated mRNAs were analysed by RT-qPCR in RNA samples 1016 extracted from tissues of WT and $A d a r 1^{m Z \alpha / m Z \alpha}$ animals and are shown relative 1017 to Gapdh. Each dot represents an individual mouse. N.D, not detectable.

1018 B. Protein extracts from whole lungs from animals of the indicated genotypes 1019 were used for western blot with an $\alpha$-ISG15 antibody. $\beta$-Actin served as a 1020 loading control. Each lane represents a sample from an individual mouse.

1021 C-E. mRNA levels of the indicated ISGs were analysed by RT-qPCR from 1022 cultured lung fibroblasts (C), BMMCs (D), and MEFs (E) of the indicated 1023 genotypes and are shown relative to Gapdh. Each dot represents cells derived 1024 from an individual mouse.

1025 Pooled data from biological replicates are shown with mean (A, D, E) or mean $1026 \pm$ SD (C) and were analysed by unpaired t test $\left({ }^{* * * *} p<0.0001,{ }^{* *} p<0.01\right.$, $\left.1027{ }^{*} p<0.05\right)$. See also Figure S1. 


\section{Figure S1.}

A

Wildtype allele

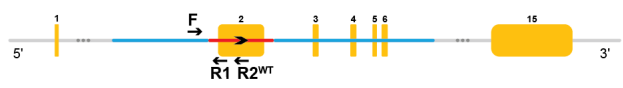

Targeting vector

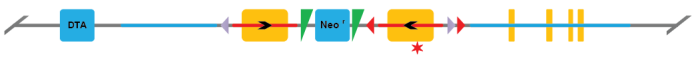

Targeted allele

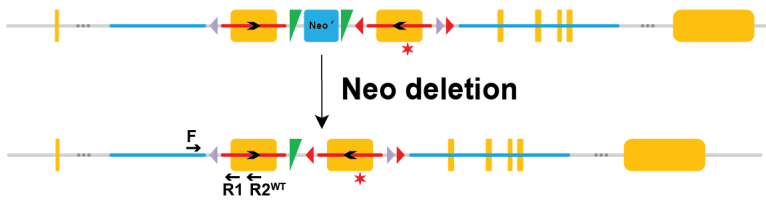

Adard $^{f-m z \alpha}$ allele

Inversion using LoxP

Inversion using Lox2272

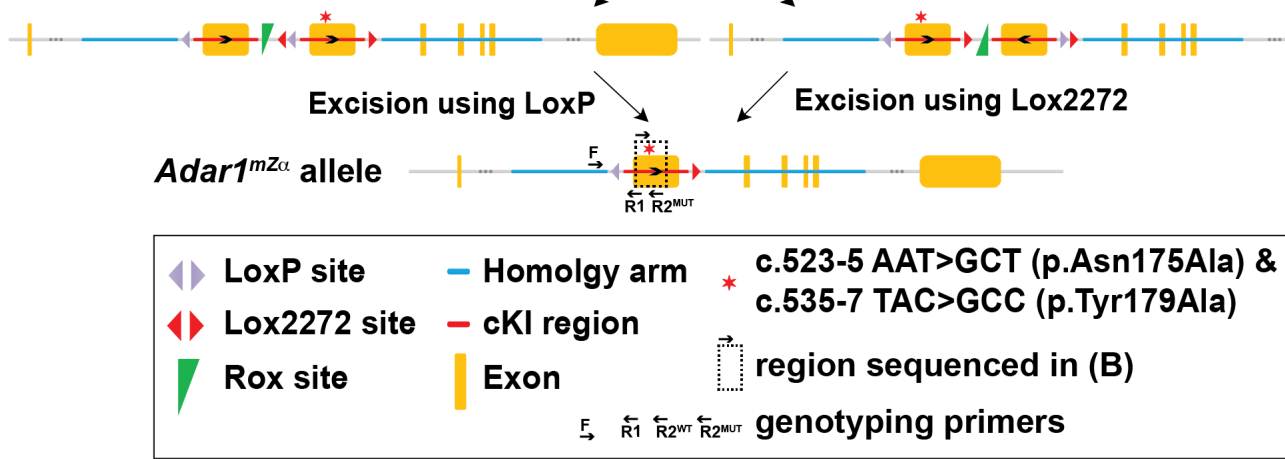

B

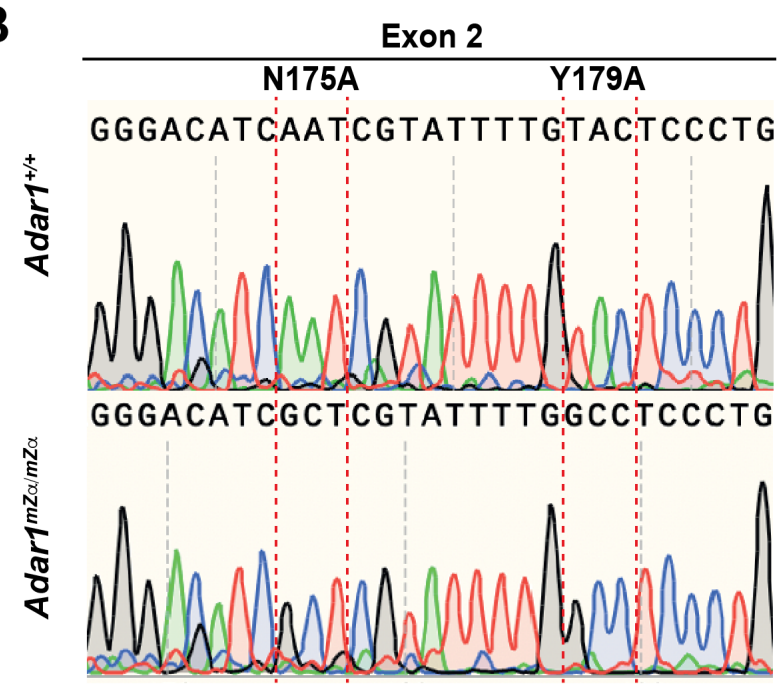

C

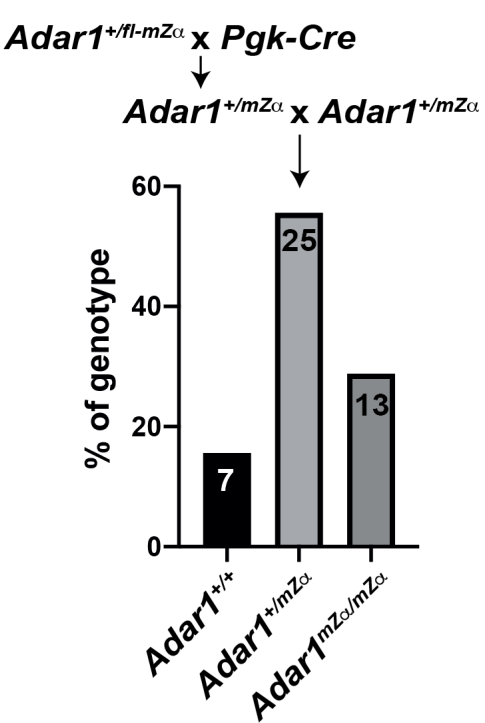

D

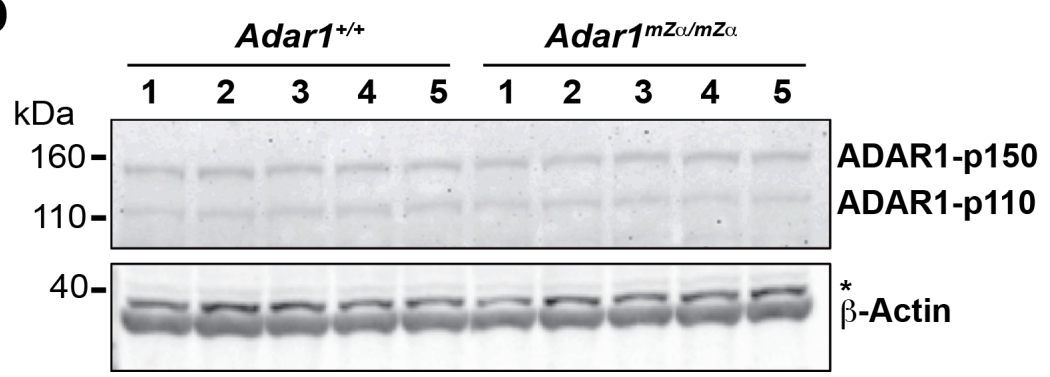


1031 Figure S1, related to Figure1. Generation of Adar1 ${ }^{m Z \alpha / m Z \alpha}$ animals.

1032 A. Schematic representation of the Adar1 WT allele, targeting vector, targeted 1033 allele, Adar1 ${ }^{f-m Z \alpha}$ allele and the two-step Cre-mediated recombination process 1034 that resulted in the $A d a r 1^{m Z \alpha}$ allele. Please see text for details. cKI, conditional 1035 knock-in.

1036 B. Genomic DNA was prepared from WT and Adar1 ${ }^{m Z \alpha / m Z \alpha}$ animals and the 1037 mutated region in exon 2 was sequenced.

1038 C. Adar1 $1^{+/ f-m Z \alpha}$ mice were bred with the Pgk-Cre line. Adar ${ }^{+/ m Z \alpha}$ offspring were 1039 then mated to generate $A d a r 1^{m Z \alpha / m Z \alpha}$ animals. The numbers and percentages 1040 of animals obtained with the indicated genotypes are shown.

1041 D. BMMCs were grown from bone marrow from five mice of the indicated 1042 genotypes. Protein extracts were used for western blot with $\alpha$-ADAR1 antibody. $1043 \beta$-Actin served as a loading control. * , non-specific band 


\section{Figure 2.}

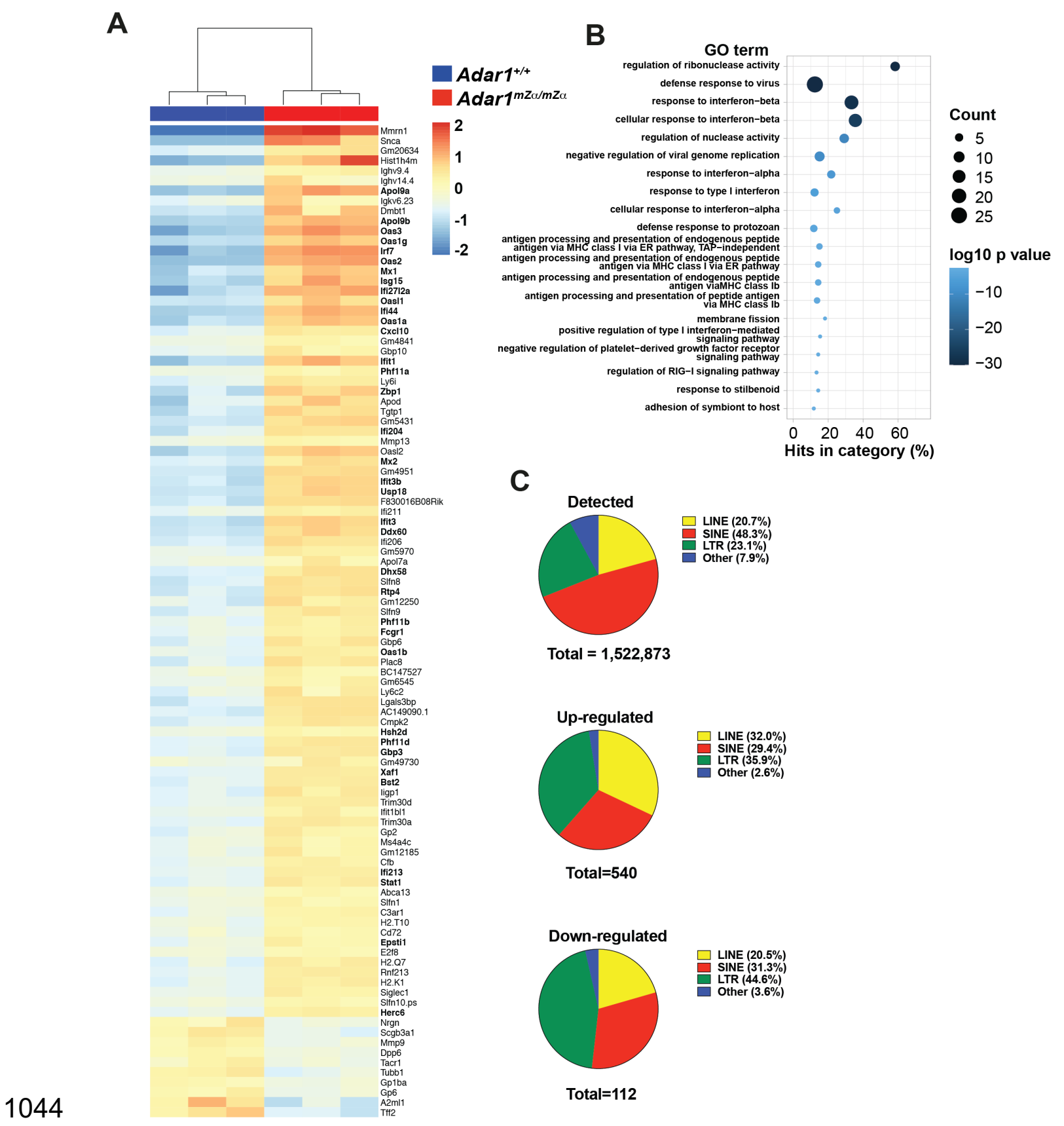

1046 Figure 2. Adar1 ${ }^{m Z \alpha / m Z \alpha}$ lungs display a type I IFN gene signature.

1047 Total RNA was extracted from lungs of three WT and three Adar1 ${ }^{m Z \alpha / m Z \alpha}$ mice.

1048 Ribosomal RNAs were depleted before random-primed library preparation and

1049 RNA sequencing. About 100 million reads were obtained per sample.

1050 A. Differentially expressed genes were defined as displaying a fold change of $1051 \geq 2$ with an adjusted $p$-value $<0.01$. The 89 upregulated and 10 downregulated 
1052 genes were ordered by decreasing fold change and the data were clustered by

1053 sample. ISGs are indicated in bold.

1054 B. GO analysis of up-regulated genes. The top $20 \mathrm{GO}$ terms (biological 1055 processes), ranked and ordered by p-value, are shown. Diameters indicate the 1056 number of induced genes assigned to the GO term and colours show the p1057 value.

1058 C. Detected and differentially expressed REs were assigned to the indicated 1059 classes and are shown as pie charts. Differentially expressed REs were 1060 identified as having a minimum fold change of 2 and an adjusted $p$ value of less 1061 than 0.01.

1062 See also Table S1. 


\section{Figure 3.}

A

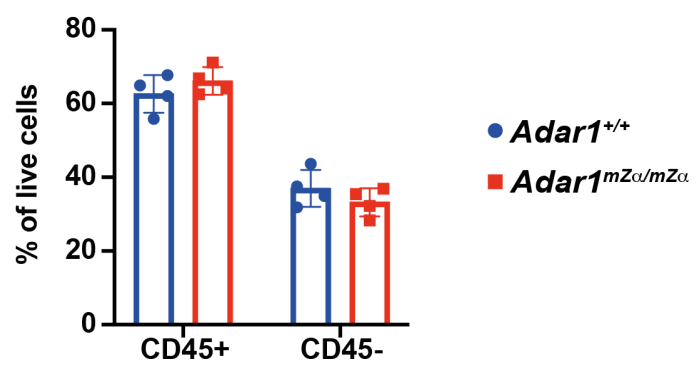

B
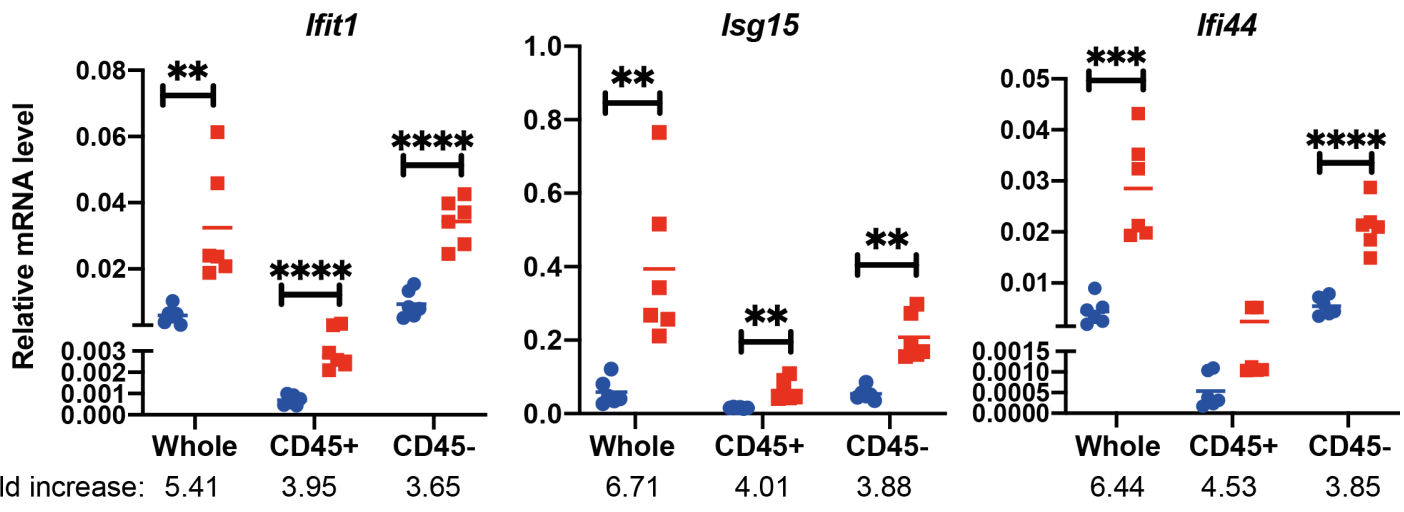

1065 Figure 3. Stromal and haematopoietic cells upregulate ISGs in Adar1 ${ }^{m Z \alpha / m Z \alpha}$ 1066 lungs.

1067 A. The proportion of haematopoietic (CD45+) and stromal (CD45-) cells in WT 1068 and $A d a r 1^{m Z \alpha / m Z \alpha}$ lungs is shown.

1069 B. mRNA levels of the indicated ISGs were analysed by RT-qPCR using RNA 1070 extracted from whole lung, or from CD45+ or CD45- cells, and are shown 1071 relative to Actb. Fold increases relative to WT samples were calculated.

1072 Data points represent individual animals. In (A), data from a representative 1073 experiment are shown with mean $\pm S D$. In (B), pooled data from two 1074 independent experiments including a total of six animals are shown with mean 1075 and were analysed by unpaired $t$ test $\left({ }^{* * *} p<0.0001,{ }^{* * *} p<0.001,{ }^{* *} p<0.01\right)$. 1076 See also Figure S2. 


\section{Figure S2.}

A
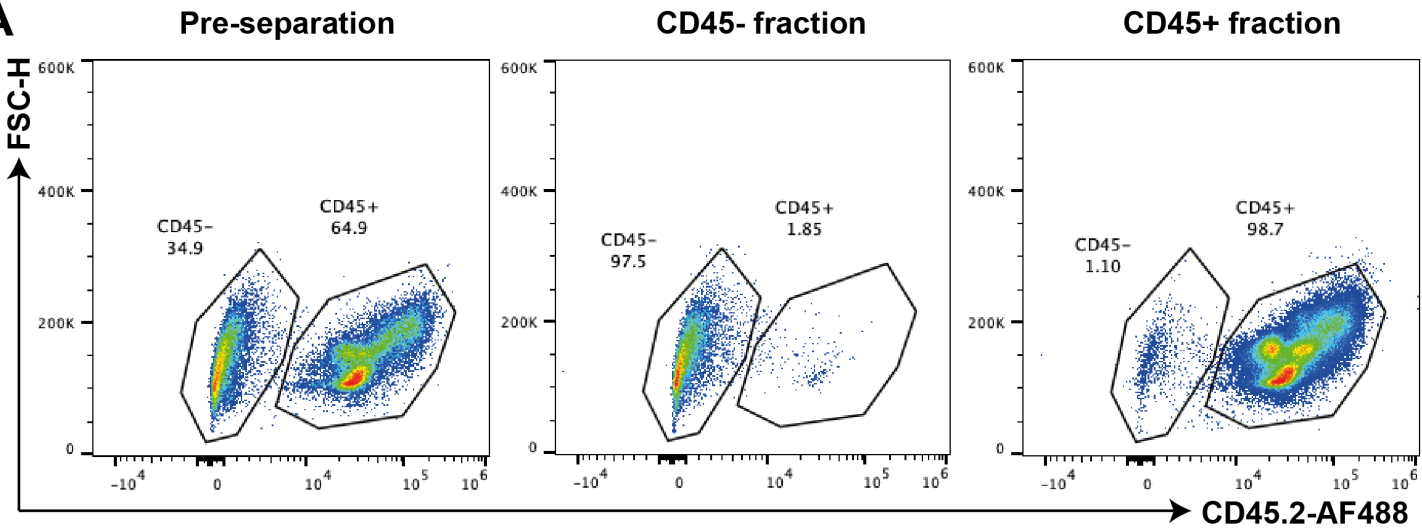

B
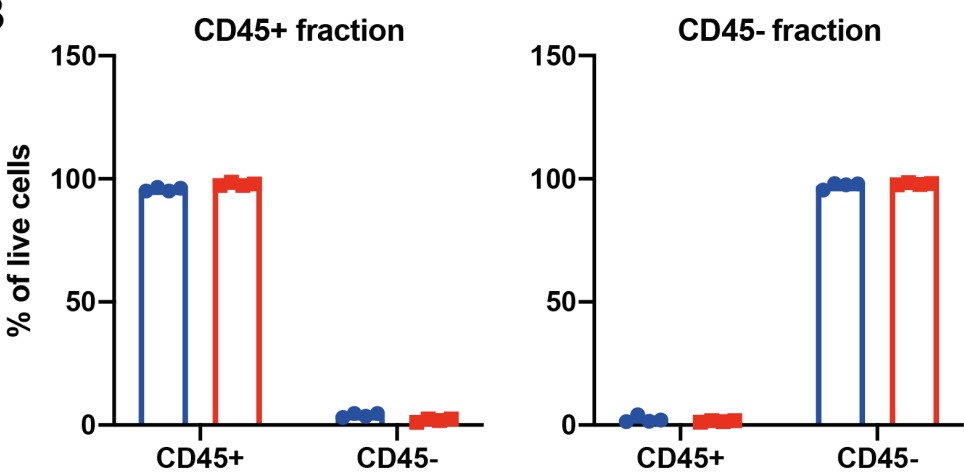

- $\operatorname{Adar1}^{+/+}$

- Adar1 ${ }^{m z / m z_{\alpha}}$

CD45-

1079 Figure S2, related to Figure 3. MACS separation of lung cells.

1080 A. Cell surface levels of CD45 were analysed by flow cytometry in single cell 1081 suspensions obtained from lung tissue before MACS (left) and in CD45- and 1082 CD45+ cell fractions obtained after MACS (middle and right). Data are from a 1083 representative WT animal.

1084 B. The percentage of CD45-expressing cells is shown for CD45+ and CD451085 MACS fractions. Data points represent individual animals $(n=4)$ from a representative experiment and bars indicate the mean. 
Figure 4.

A

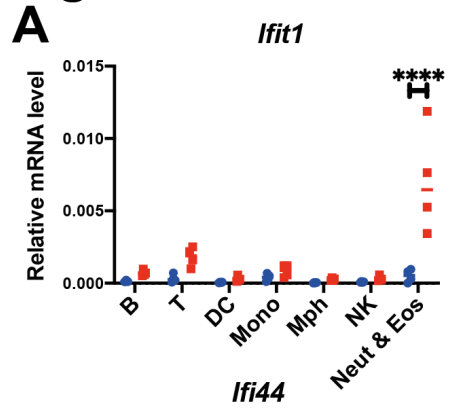

(1)

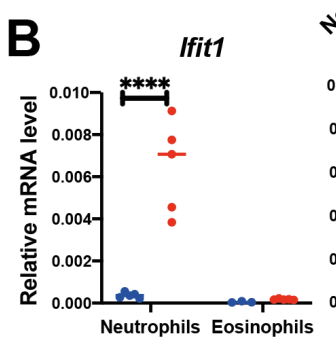

C
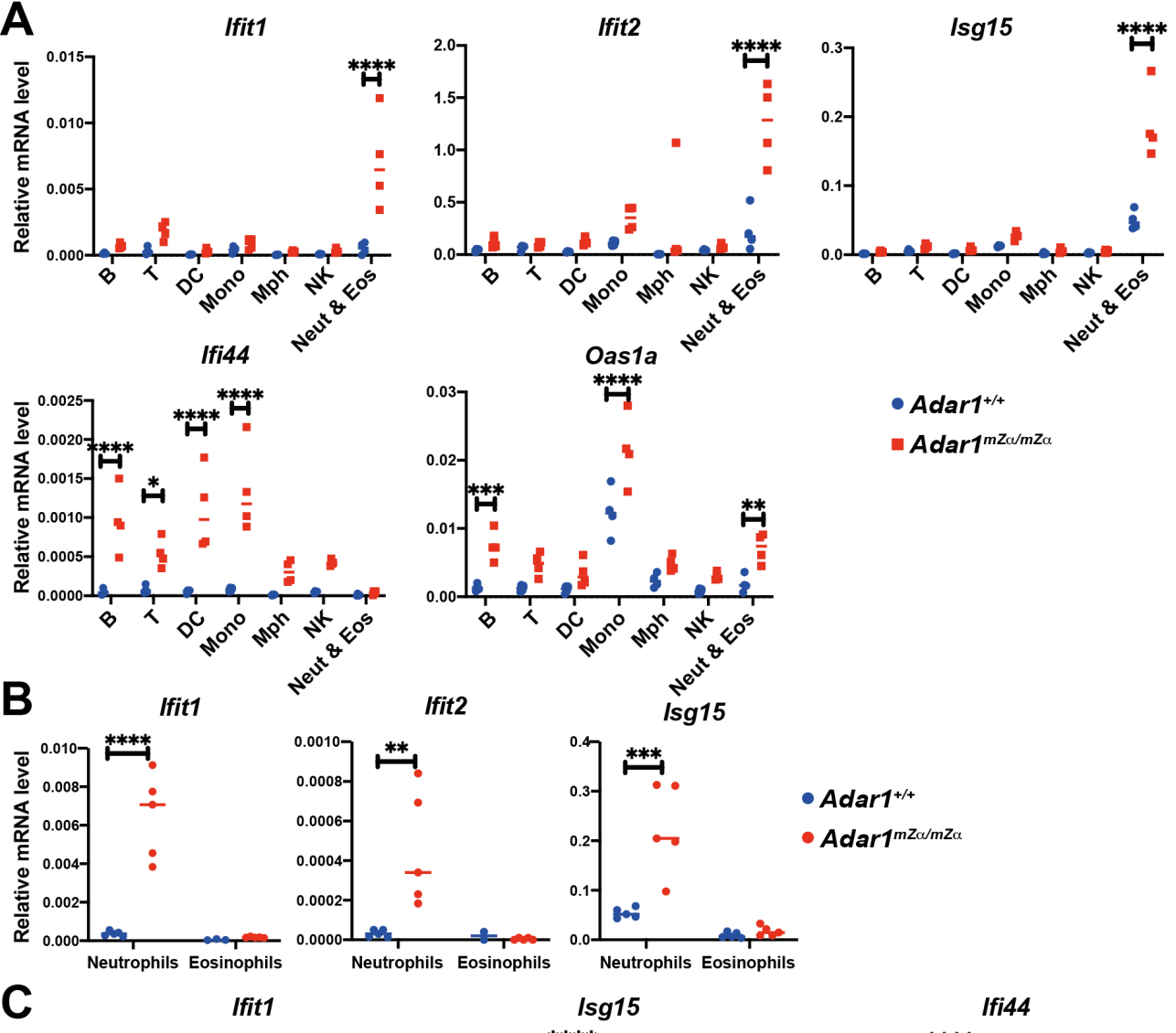

- Adar1 ${ }^{+/+}$

- Adar1 ${ }^{m Z_{\alpha} / m Z_{\alpha}}$

- $\operatorname{Adar1}^{+/+}$

- $\operatorname{Adar1}^{m \mathrm{z} / \mathrm{mz} \text {. }}$

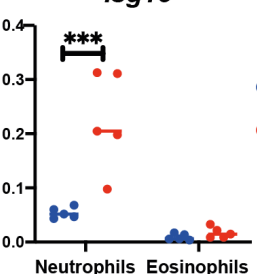

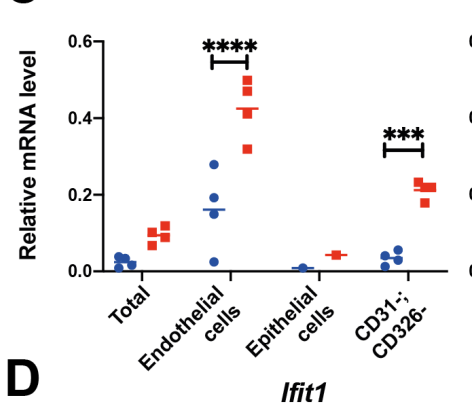
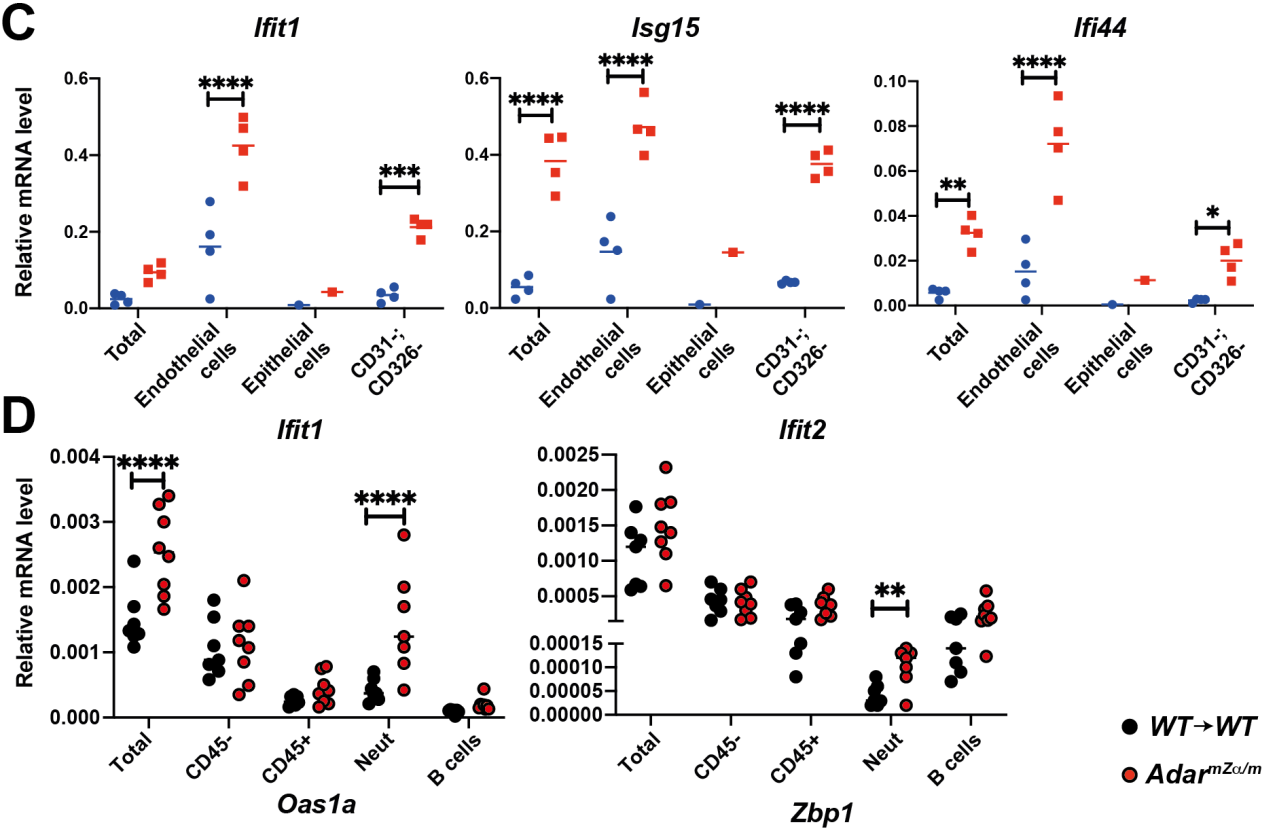

- $W T \rightarrow W T$

○ Adar ${ }^{m Z \alpha / m z_{\alpha}} \rightarrow W T$
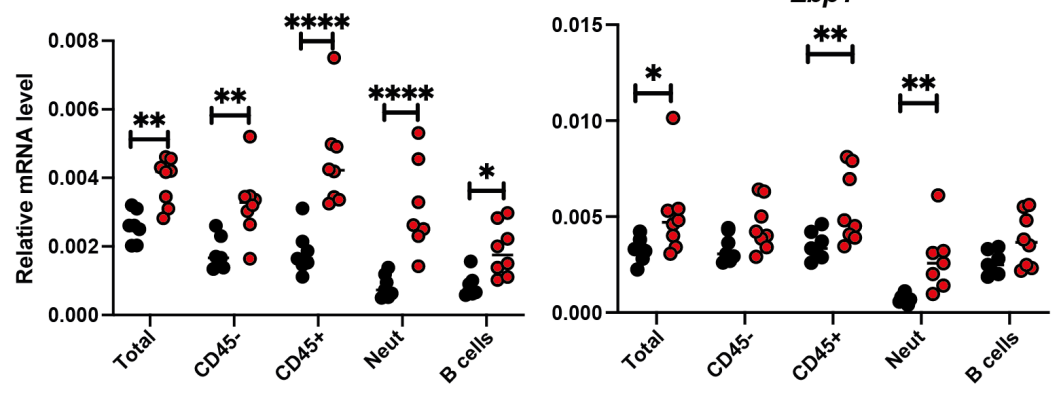
1088 Figure 4. Multiple haematopoietic and non-haematopoietic cell types display

1089 ISGs upregulation in Adar1 ${ }^{m Z \alpha / m Z \alpha}$ lungs.

1090 A-C. mRNA levels of the indicated ISGs were analysed by RT-qPCR using RNA 1091 extracted from cell populations sorted from lungs of WT and Adar1 ${ }^{m Z \alpha / m Z \alpha}$ mice 1092 and are shown relative to Actb. B, B cells; T, T cells; DC, dendritic cells; Mono, 1093 monocytes; Mph, macrophages; NK, natural killer cells; Neut, neutrophils; Eos, 1094 eosinophils; Total, whole lung.

1095 D. ISG mRNA levels were analysed as in (A-C) in cell populations sorted from 1096 lungs of BM chimeric mice and are shown relative to Gapdh.

1097 Each data point represents an individual mouse. Due to the small number of 1098 epithelial cells recovered, samples were pooled from multiple mice before RNA 1099 extraction (C). Pooled data from two (A,B) or three (D) independent 1100 experiments are shown with mean $\left({ }^{* * *} p<0.0001,{ }^{* * *} p<0.001,{ }^{* *} p<0.01\right.$, $1101{ }^{*} p<0.05$, unpaired $t$ test). See also Figures S3, S4 and S5. 


\section{Figure S3.}

\section{A}

CD45.2-AF488; CD11C-APC; CD11b-BV785 MHCII-AF700; CD24-BV605; CD64-PE
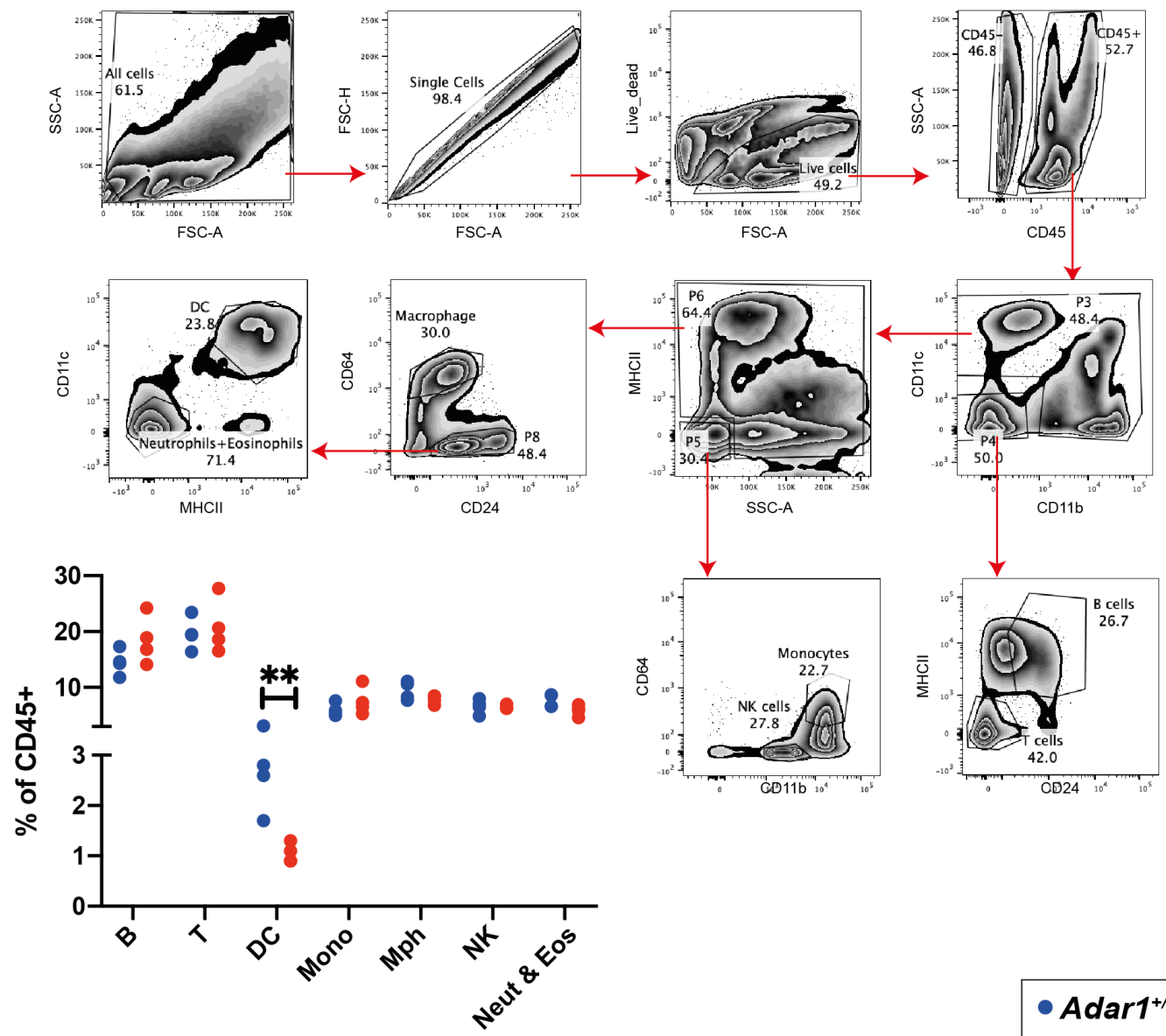

\section{B}

CD45.2-AF488; CD24-BV605; CD11C-APC MHCII-e780; Ly6G-AF700; SiglecF-BV421
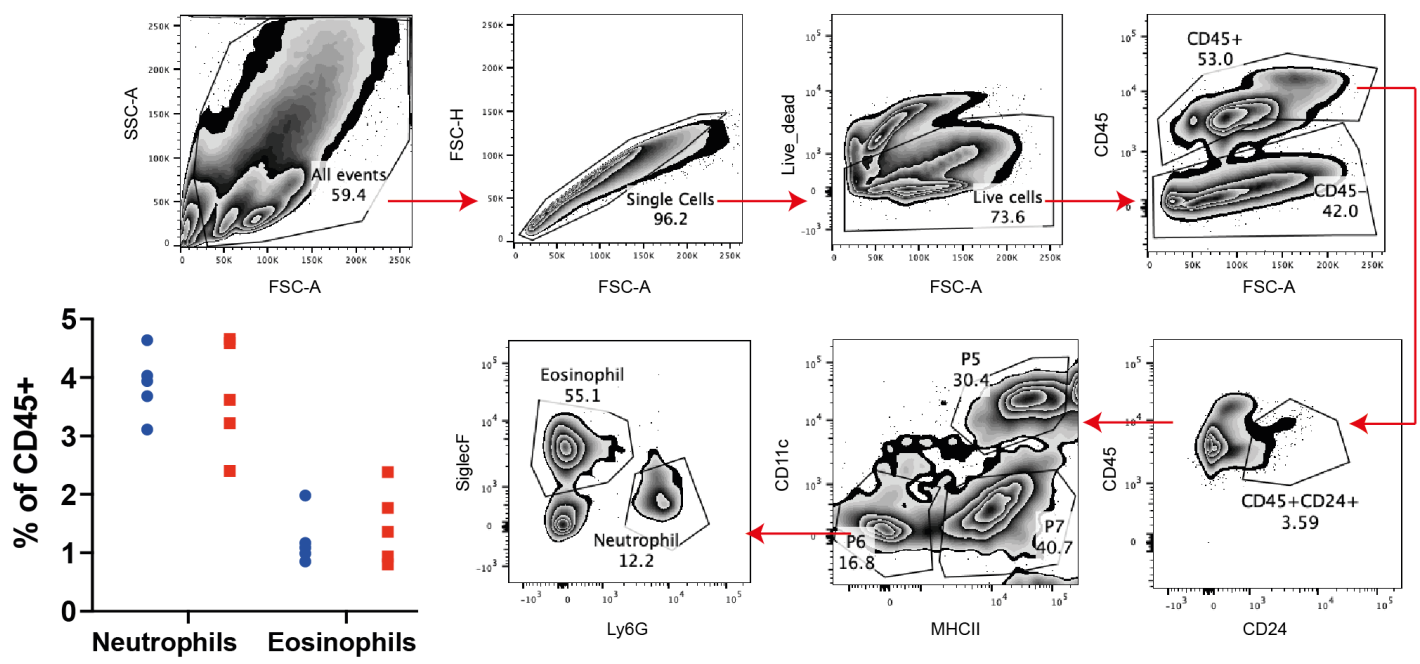
1103 Figure S3, related to Figure 4A and 4B. Gating strategy for sorting of

1104 haematopoietic lung cells.

1105 Two staining panels were used to identify and isolate haematopoietic cell

1106 populations by FACS. Panel (A) is related to Figure 4A and panel (B) to Figure

1107 4B. Antibodies and conjugated fluorophores are shown in boxes. Gating

1108 strategies are shown for a representative WT $(\mathrm{A})$ and $A d a r 1^{m Z \alpha / m Z \alpha}(\mathrm{B})$ animal.

1109 Bar graphs show the proportion of each cell population as a percentage of

1110 CD45+ cells. Each dot represents an individual mouse and data from two

1111 independent experiments were pooled $\left({ }^{* *} p<0.01\right.$, unpaired $t$ test $)$. 


\section{Figure S4.}

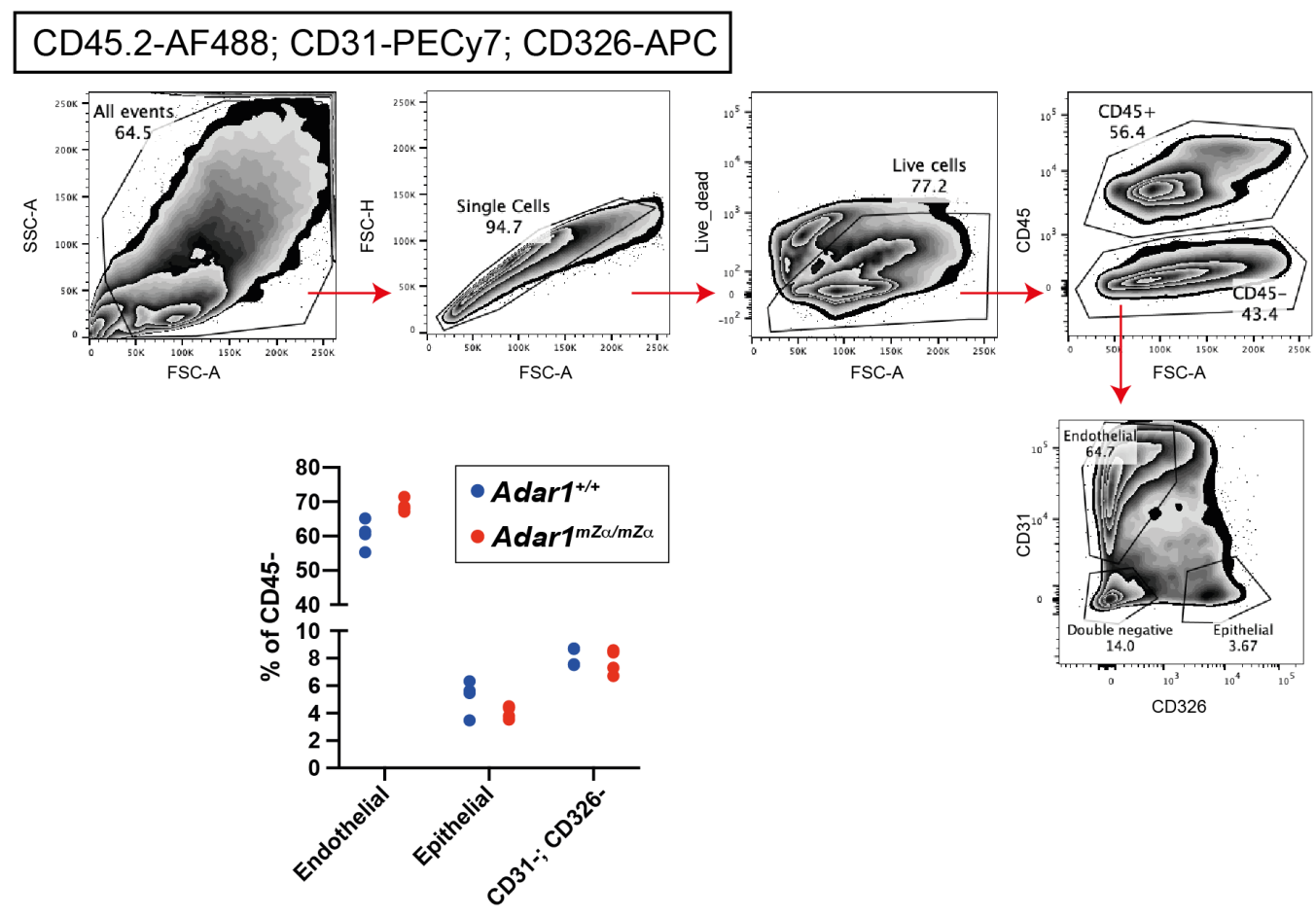

1114 Figure S4, related to Figure 4C. Gating strategy for sorting of stromal lung cells.

1115 The staining panel used to identify and isolate non-haematopoietic cell 1116 populations by FACS is shown. Antibodies and conjugated fluorophores are 1117 shown in the box. The gating strategy is shown for a representative WT animal.

1118 The bar graph shows the proportion of each cell population as a percentage of 1119 CD45- cells. Each dot represents an individual mouse. 


\section{Figure S5.}

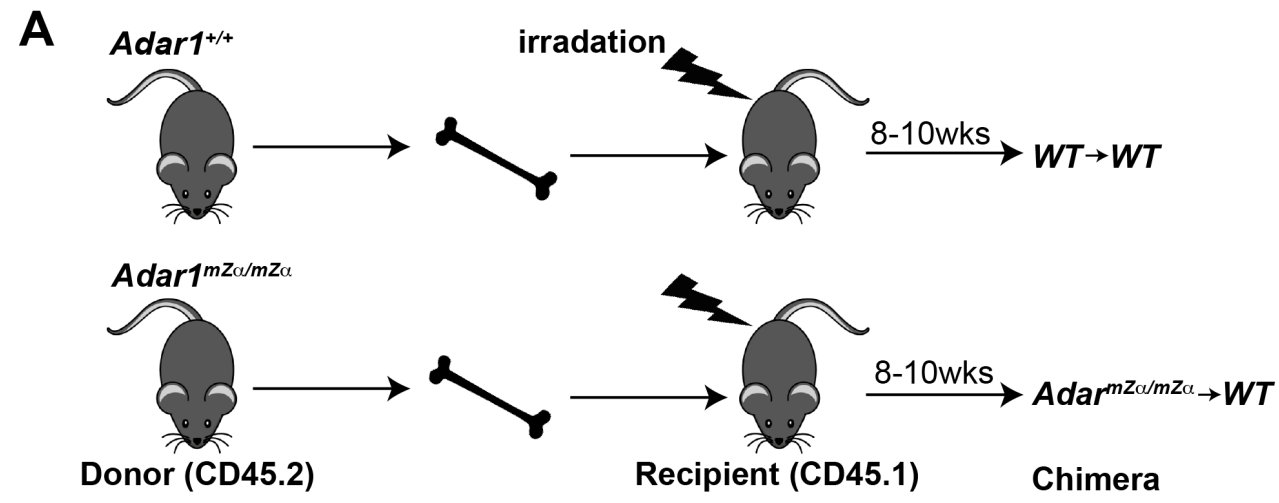

B blood
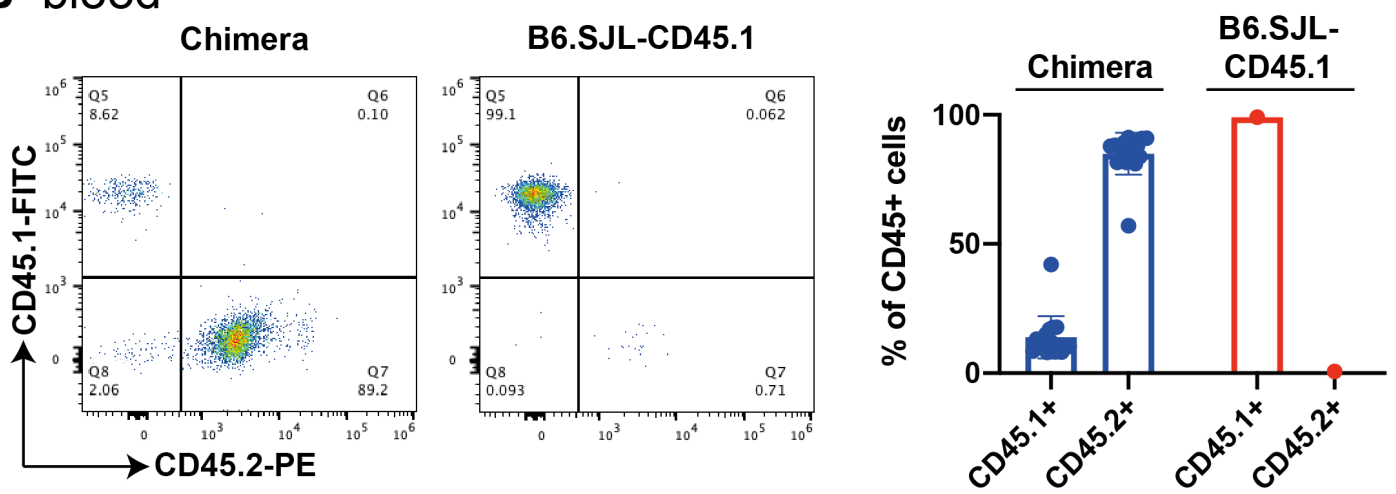

C lung
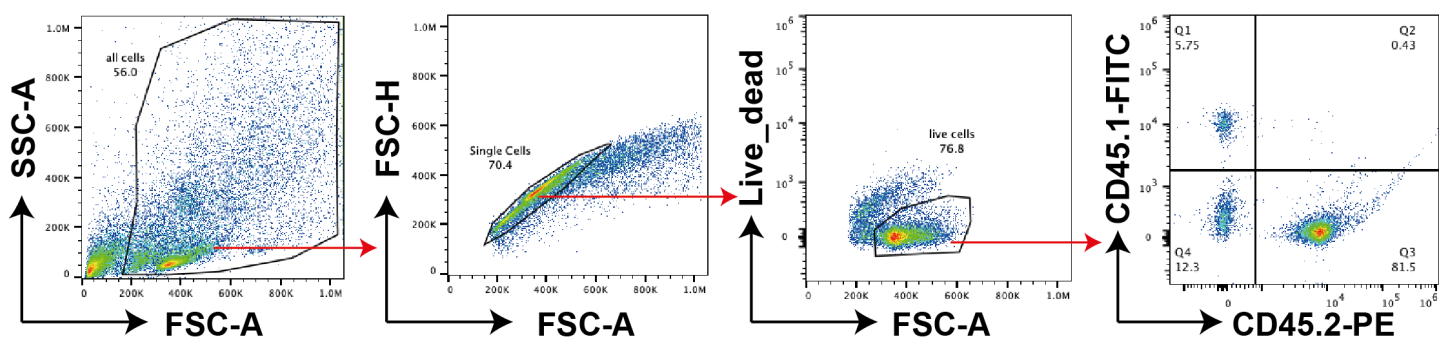

1122 Figure S5, related to Figure 4D. Analysis of BM chimeras.

A. Schematic representation of the generation of BM chimeric animals.

B. White blood cells from BM chimeric mice and, as control, from an untreated B6.SJL-CD45.1 animal, were analysed by FACS. Cells were gated on single, live cells. Representative FACS plots from a WT $\rightarrow$ WT animal (left) and pooled data from two independent experiments involving a total seven WT $\rightarrow$ WT and

1128 eight Adar1 ${ }^{m Z \alpha / m Z} \alpha \rightarrow$ WT BM chimeric animals (right) are shown. Bars show the 1129 mean and error bars represent SD. 
bioRxiv preprint doi: https://doi.org/10.1101/2020.12.04.411793; this version posted December 4,2020 . The copyright holder for this

preprint (which was not certified by peer review) is the author/funder, who has granted bioRxiv a license to display the preprint in perpetuity. It is made available under aCC-BY 4.0 International license.

C. Lung cells from BM chimeric mice were analysed by FACS. Data from a

1131 representative WT $\rightarrow$ WT animal are shown. 
Figure 5.

A

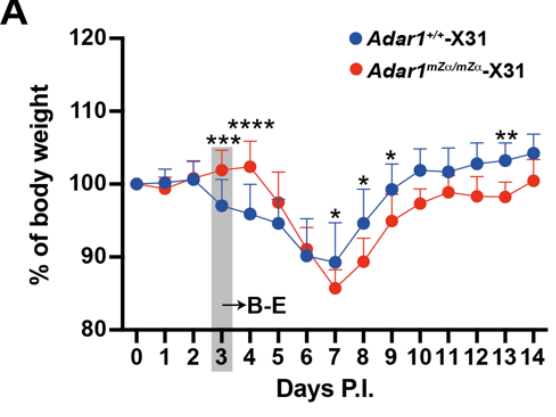

C

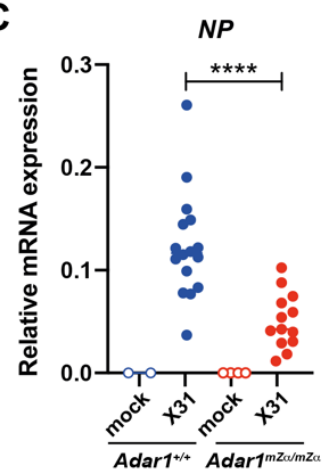

B

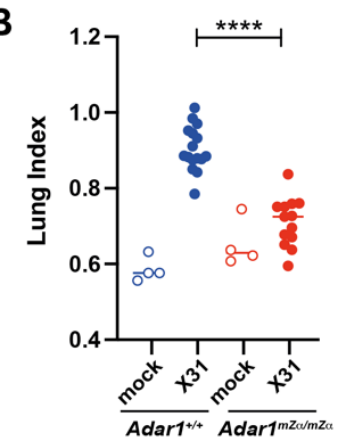

E

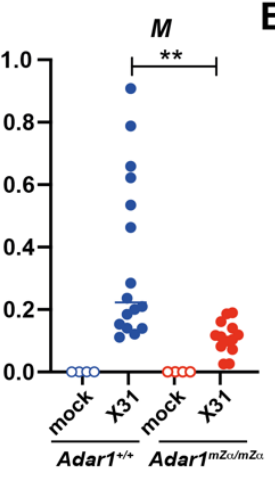

IL-6

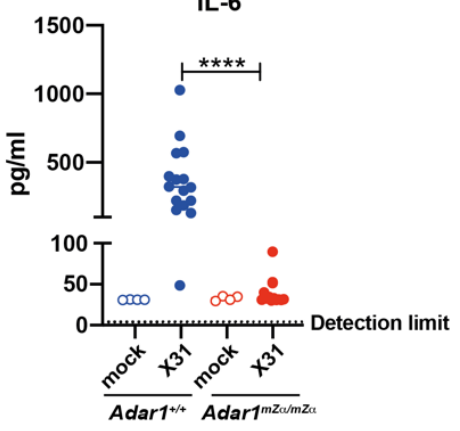

D
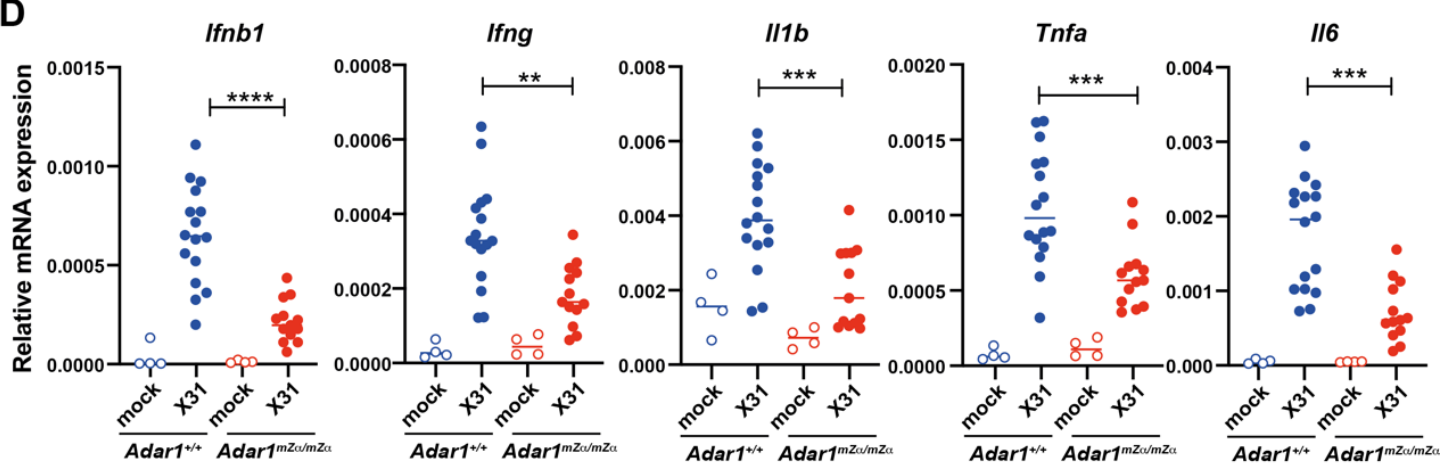

1134 Figure 5. Adar1 ${ }^{m Z \alpha / m Z \alpha}$ mice are protected from early IAV infection.

1135 A. WT or Adar1 $1^{m Z \alpha / m Z \alpha}$ mice were infected intranasally with 0.04 HAU of IAV

1136 strain $A / X 31$. Body weight was monitored daily and is shown as a percentage

1137 of starting body weight.

1138 B-E. WT or Adar1 $1^{m Z \alpha / m Z \alpha}$ mice were infected as in (A) or mock infected using

1139 viral growth medium. On day 3 post infection, lungs and sera were collected.

1140 B. A 'lung index' was calculated (lung weight/body weight x100).

1141 C. Levels of the viral NP and $M$ transcripts were analysed by RT-qPCR in RNA

1142 samples extracted from total lung. Data are shown relative to Actb (NP) or

1143 Gapdh $(M)$. 
1144 D. Levels of the indicated mRNAs were determined as in (C).

1145 E. Serum IL-6 concentrations were analysed by ELISA.

1146 In (A), data from three independent experiments including a total of 15 mice per

1147 genotype were pooled (mean $+\mathrm{SD} ;{ }^{* * *} \mathrm{p}<0.0001,{ }^{* * *} \mathrm{p}<0.001,{ }^{* *} \mathrm{p}<0.01$,

$1148{ }^{*} p<0.05$, mixed-effects analysis). In (B-E), pooled data from two independent

1149 experiments (mock infected: $n=4$ mice per genotype; X31-infected: $n=16$ WT

1150 and $\mathrm{n}=13 \operatorname{Adar}^{\mathrm{mZ} \alpha / m \mathrm{~m} \alpha}$ mice) are shown. Each dot represents an individual

1151 mouse and the mean is indicated $\left({ }^{* * *} p<0.0001,{ }^{* * *} p<0.001,{ }^{* *} p<0.01\right.$,

1152 unpaired t test). 
Figure 6.

A
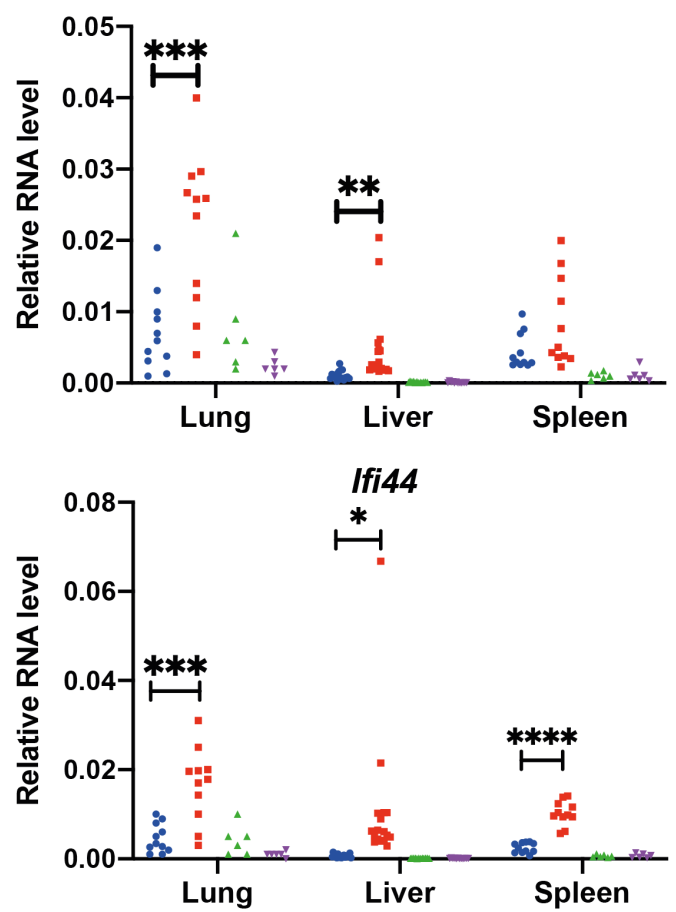

B

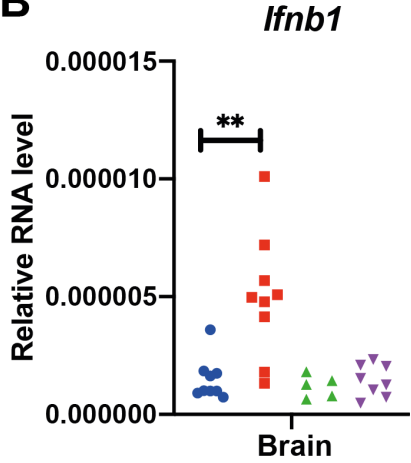

Ifit1

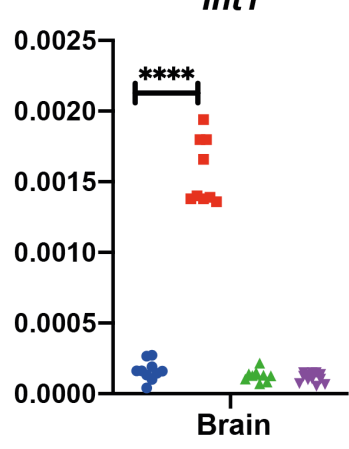

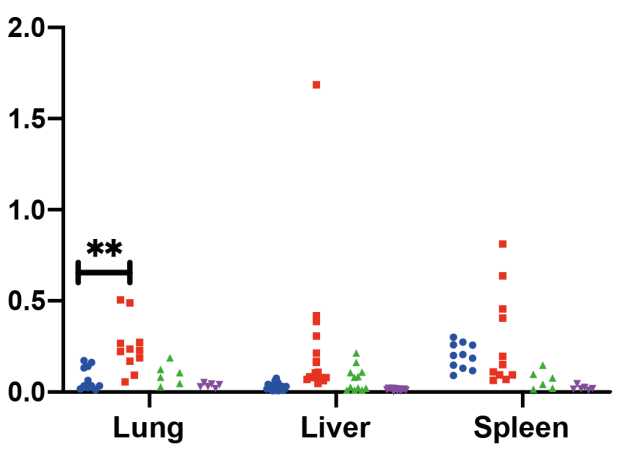

- Adar1 $^{+/+} ;$Mavs $^{+/+}$

- Adar1 ${ }^{m z \alpha / m z \alpha} ;$ Mavs $^{+/+}$

$\triangle$ Adar1 $^{+/+} ;$Mavs $^{/-}$

จ Adar1 ${ }^{m z \alpha / m z \alpha} ;$ Mavs $^{-/}$

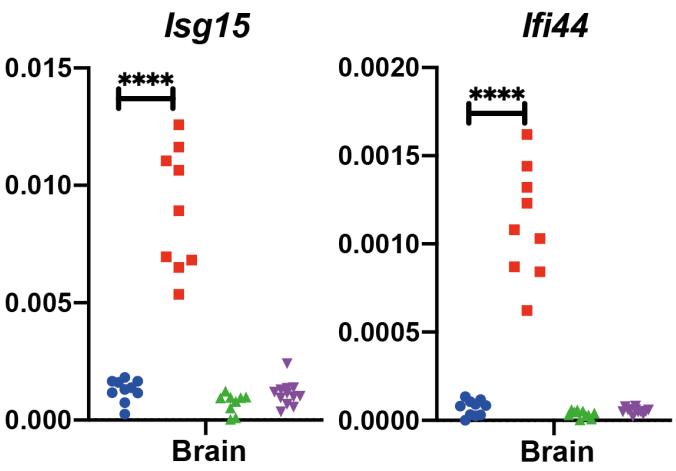

1155 Figure 6. ISG induction in Adar1 ${ }^{m Z \alpha / m Z \alpha}$ mice is MAVS-dependent.

1156 Levels of the indicated mRNAs were analysed by RT-qPCR in RNA samples

1157 extracted from tissues of WT and Adar1 ${ }^{m Z \alpha / m Z \alpha}$ animals that were either MAVS-

1158 sufficient or -deficient. Data are shown relative to Gapdh.

1159 Each dot represents an individual mouse. Pooled data from biological replicates

1160 are shown $\left({ }^{* * *} p<0.0001,{ }^{* * *} p<0.001,{ }^{* *} p<0.01,{ }^{*} p<0.05\right.$, unpaired t test). 


\section{Figure 7.}

A

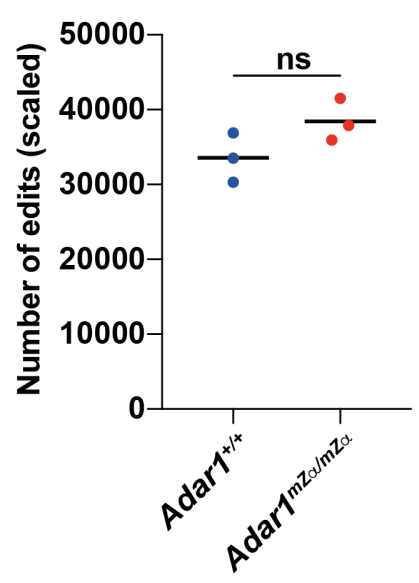

D

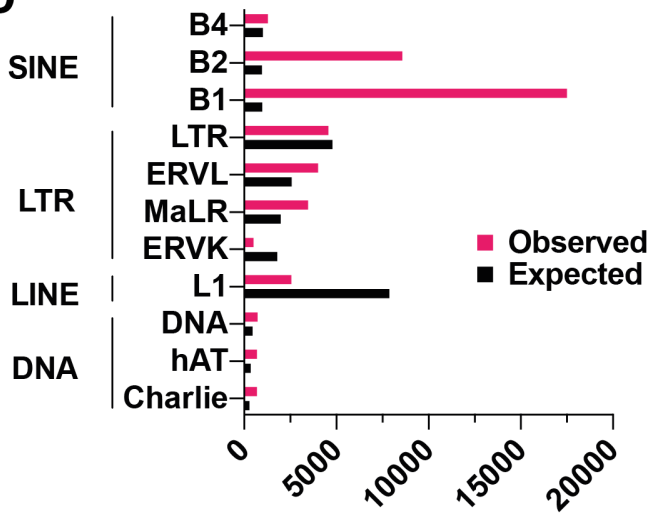

Number of Edits
B

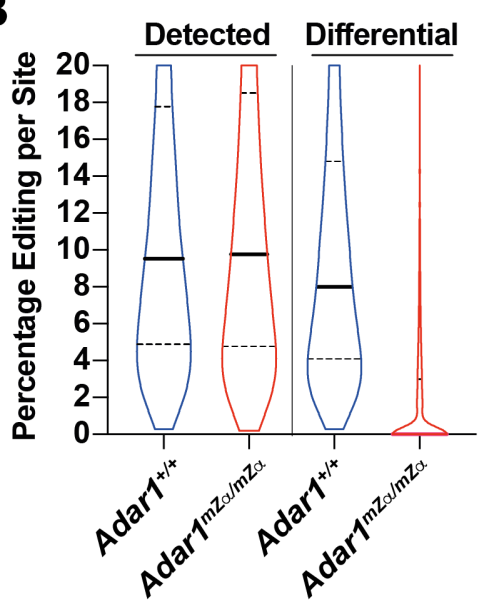

C

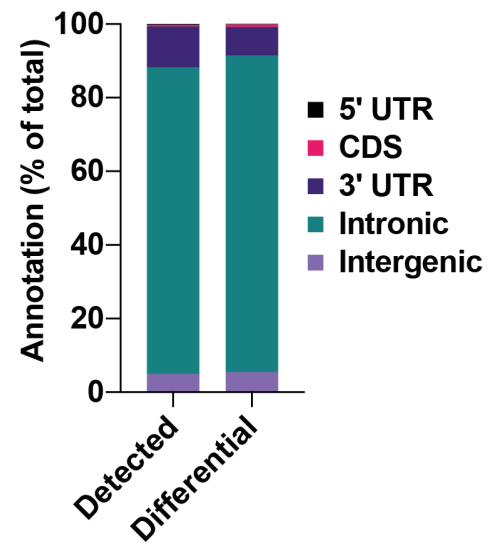

E

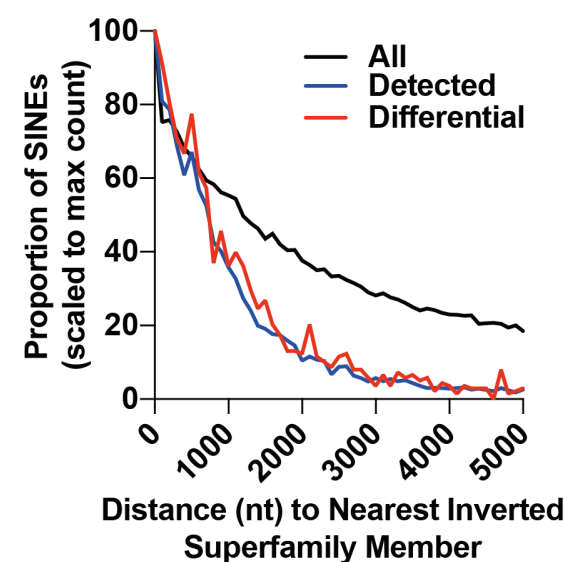

1163 Figure 7. ADAR1-p150's Za domain is required for editing of a subset of RNAs.

1164 A. Editing sites were mapped in RNA sequencing reads from three WT and 1165 three $A d a r 1^{m Z \alpha / m Z \alpha}$ lung samples $(Z>2.58)$. The numbers of edited sites were 1166 scaled to the total number of reads per sample. Each data point corresponds 1167 to an animal and the mean is shown (ns, not significant; unpaired $\mathrm{t}$ test).

1168 B. Editing frequencies for sites detectable in all three WT or Adar1 ${ }^{m Z \alpha / m Z \alpha}$ 1169 samples (left; $Z>2.58$ ) and for differentially edited sites (right; $Z>2.58,>2$-fold) 1170 are shown as violin plots. Solid horizontal lines show the median and dotted 1171 lines indicate quartiles. 
1172 C. Editing sites detected in WT samples and differentially edited sites were

1173 matched to annotated genomic features. The percentage of sites is shown for 1174 each category.

1175 D. The number of expected and observed editing sites in WT samples are 1176 shown for families of REs for which either value exceeded 500 . Please see text 1177 for details.

1178 E. The distances of SINEs to their nearest inverted super-family member were 1179 determined for all SINEs and for SINEs harbouring an editing site in WT 1180 samples (Detected) or containing a differentially edited site. Results are shown 1181 as proportions of SINEs with the maximum count set to 100.

1182 See also Figure S6. 


\section{Figure S6.}

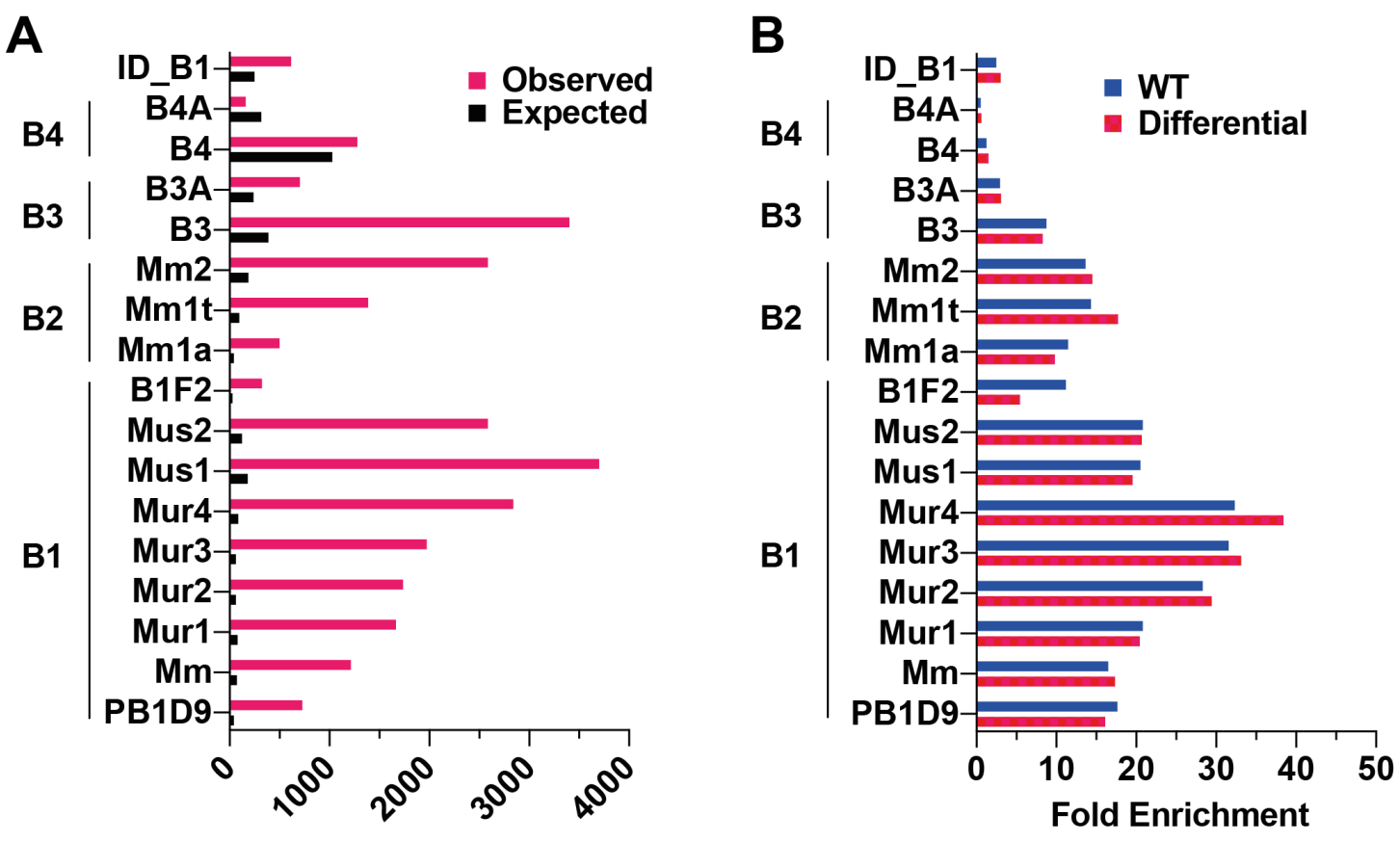

1185 Figure S6. Analysis of RNA editing in SINEs. Related to Figure 7.

1186 A. Sub-families of SINEs were analysed as in Figure 6D, but are plotted to

1187 include those where observed or expected values exceeded 250.

1188 B. Fold enrichments of editing events were calculated relative to expected

1189 numbers of edits for SINE sub-families using editing events detected in WT

1190 samples and differentially edited sites. 
bioRxiv preprint doi: https://doi.org/10.1101/2020.12.04.411793; this version posted December 4,2020 . The copyright holder for this

preprint (which was not certified by peer review) is the author/funder, who has granted bioRxiv a license to display the preprint in perpetuity. It is made available under aCC-BY 4.0 International license.

\section{Table S1. Differentially expressed REs.}

REs differentially expressed in Adar1 ${ }^{m Z} \alpha / m Z \alpha$ lungs are shown with their log2 fold change and adjusted $p$-value. The RE class, family and chromosomal location are indicated. REs were sorted by adjusted $p$-value. The cut-offs used were: $\log 2$ fold-change $>1$ or $<-1$, and adjusted $p$-value $<0.01$.

\begin{tabular}{|c|c|c|}
\hline Class|Family|Chr|Start|Stop & log2 fold change & padj \\
\hline Satellite|GSAT_MM|JH584304.1|60177|60876 & 3.3 & 0 \\
\hline LTR/ERVL-MaLR|MTD|JH584304.1|61136|61478 & 3.3 & $6.80 \mathrm{E}-259$ \\
\hline LTR/ERVL-MaLR|MTD|JH584304.1|25102|25465 & 3.0 & $4.93 \mathrm{E}-157$ \\
\hline LTR/ERVL-MaLR|MTD-int|5|120880478|120881813 & 3.3 & $1.00 \mathrm{E}-100$ \\
\hline LTR/ERVK|ETnERV2-int|18|60283765|60287191 & 2.1 & $4.51 \mathrm{E}-93$ \\
\hline LINE/L1|L1MdA_VII|18|60302236|60308420 & 1.9 & $4.12 \mathrm{E}-82$ \\
\hline LTR/ERVL-MaLR|MTD-int|5|120900459|120901797 & 2.3 & 9.73E-59 \\
\hline LINE/L1|L1M5|5|120744115|120744500 & 2.8 & $5.45 \mathrm{E}-56$ \\
\hline LINE/L1|Lx8b|18|60290416|60292037 & 1.9 & $1.30 \mathrm{E}-51$ \\
\hline LTR/ERVK|ERVB4_1-I_MM RLTR50B|18|60288796|60289913 & 2.1 & 1.67E-46 \\
\hline LTR/ERVK|IAPEY3_LTR IAPEy-int|1|173572498|173580638 & 1.1 & $6.52 \mathrm{E}-44$ \\
\hline LINE/L1|Lx7|3|151733082|151735087 & 2.7 & $1.69 \mathrm{E}-42$ \\
\hline SINE/B4|B4A|5|120879672|120879973 & 3.9 & $2.34 \mathrm{E}-38$ \\
\hline SINE/B4|B4A|5|120743868|120744091 & 2.5 & $6.13 \mathrm{E}-38$ \\
\hline LINE/L1|L1MdTf_III|7|104475378|104477900 & 1.6 & $1.40 \mathrm{E}-37$ \\
\hline SINE/B2|B3|JH584304.1|61870|61954 & 2.8 & $7.81 \mathrm{E}-37$ \\
\hline SINE/B2|B2 Mm2|5|120744880|120745045 & 2.8 & $5.86 \mathrm{E}-36$ \\
\hline LTR/ERVK|ERVB2_1-I_MM RLTR13D2|1|173566173|173572495 & 1.0 & $3.47 \mathrm{E}-35$ \\
\hline LTR/ERVK|RLTR33|12|103438085|103438897 & 1.7 & 9.56E-35 \\
\hline LINE/L1|L1MdN_I|18|60219113|60220489 & 1.7 & $1.00 \mathrm{E}-33$ \\
\hline LTR/ERV1|RLTR6-int|12|103440882|103441504 & 1.9 & $2.23 E-32$ \\
\hline SINE/B4|RSINE1|5|120744507|120744635 & 3.5 & $7.38 \mathrm{E}-32$ \\
\hline LINE/L1|Lx8|5|114904191|114904607 & 1.9 & $1.11 \mathrm{E}-26$ \\
\hline SINE/B2|B3|5|120744692|120744879 & 2.9 & $3.76 \mathrm{E}-26$ \\
\hline LINE/L1|L1MdA_I|7|104502396|104504479 & 1.5 & $4.46 \mathrm{E}-25$ \\
\hline LTR/ERVK|RMER12B|18|60308716|60309841 & 1.7 & $4.59 \mathrm{E}-25$ \\
\hline LTR/ERVK|ETnERV2-int|18|60287718|60288163 & 2.1 & $5.34 \mathrm{E}-25$ \\
\hline SINE/B4|B4A|5|120899645|120899943 & 2.3 & $9.68 \mathrm{E}-25$ \\
\hline LTR/ERV1|RLTR1A2_MM|18|60287192|60287717 & 2.2 & $3.30 \mathrm{E}-24$ \\
\hline LINE/L1|L1MdF_I|7|104489329|104493378 & 1.6 & $5.47 \mathrm{E}-24$ \\
\hline LTR/ERVL-MaLR|MTD MTD-int|5|120867256|120868952 & 2.7 & $2.72 \mathrm{E}-23$ \\
\hline LINE/L1|Lx8b|18|60292356|60292908 & 2.1 & $7.39 \mathrm{E}-23$ \\
\hline LINE/L1|Lx3_Mus|1|173476327|173479976 & 1.8 & $3.80 \mathrm{E}-22$ \\
\hline LINE/L1|L1MdF_III|7|104412877|104415655 & 1.0 & $8.14 \mathrm{E}-22$ \\
\hline LINE/L1|Lx7|3|151735621|151736718 & 2.5 & $1.26 \mathrm{E}-21$ \\
\hline LINE/L1|L1MdF_IV|18|60258255|60262863 & 1.8 & $4.41 \mathrm{E}-21$ \\
\hline LTR/ERVK|RLTR10-int|7|104417226|104418855 & 1.0 & $5.22 \mathrm{E}-21$ \\
\hline LTR/ERVL-MaLR|MTA_Mm|5|114907656|114908049 & 2.1 & $5.94 \mathrm{E}-21$ \\
\hline LTR/ERVK|RMER19B|11|119395887|119396564 & 1.3 & $7.35 \mathrm{E}-21$ \\
\hline LTR/ERVK|MurERV4-int|11|119398983|119400690 & 1.1 & $4.62 \mathrm{E}-20$ \\
\hline LTR/ERVK|RLTR13B1|5|120894364|120895346 & 2.3 & $1.73 \mathrm{E}-19$ \\
\hline SINE/B4|B4A|5|120732706|120732910 & 2.6 & $2.17 \mathrm{E}-19$ \\
\hline SINE/ID|ID2|5|114901484|114901562 & 1.8 & $7.16 \mathrm{E}-19$ \\
\hline SINE/B2|B2_Mm2|5|114910369|114910572 & 2.2 & $1.60 \mathrm{E}-18$ \\
\hline LINE/L1|L1MdF_III|7|104456010|104461764 & 1.4 & $6.23 \mathrm{E}-18$ \\
\hline LINE/L1|L1MdF_IV|8|62028789|62032657 & 1.4 & $6.98 \mathrm{E}-18$ \\
\hline LTR/ERVK|RLTR11A2|15|77730371|77730874 & 2.9 & $8.25 \mathrm{E}-18$ \\
\hline LTR/ERVK|RLTR10 RLTR10-int|7|104415825|104417145 & 1.1 & $1.24 \mathrm{E}-17$ \\
\hline LINE/L1|L1MdA_III|18|60218363|60219112 & 1.5 & $3.04 \mathrm{E}-17$ \\
\hline LINE/L1|Lx8|11|48893355|48894122 & 2.5 & $4.36 \mathrm{E}-17$ \\
\hline LINE/L1|Lx5|18|60255846|60257256 & 1.8 & $5.14 \mathrm{E}-17$ \\
\hline LINE/L1|Lx9|11|48988698|48990056 & 1.6 & $8.90 \mathrm{E}-17$ \\
\hline LTR/ERV1|LTR72_RN|18|60217070|60217447 & 1.6 & $1.33 \mathrm{E}-16$ \\
\hline
\end{tabular}


bioRxiv preprint doi: https://doi.org/10.1101/2020.12.04.411793; this version posted December 4,2020 . The copyright holder for this

preprint (which was not certified by peer review) is the author/funder, who has granted bioRxiv a license to display the preprint in perpetuity. It is made available under aCC-BY 4.0 International license.

\begin{tabular}{|c|c|c|}
\hline LINE/L1|L1MC5|3|151741122|151741823 & 2.9 & 1.94E-16 \\
\hline LTR/ERVK|ERVB2_1A-I_MM RLTR13D5|18|60282851|60283792 & 1.9 & $3.57 \mathrm{E}-16$ \\
\hline LTR/ERVK|RLTR17D Mm|18|60255056|60255845 & 2.1 & $4.71 \mathrm{E}-16$ \\
\hline LINE/L1|L1MdF_I|1|85299575|85304519 & 2.8 & $5.46 \mathrm{E}-16$ \\
\hline SINE/B2|B3|18|60247949|60248146 & 1.9 & $1.13 \mathrm{E}-15$ \\
\hline LINE/L1|L1MEc|16|97458642|97459049 & 3.0 & $2.18 \mathrm{E}-15$ \\
\hline LTR/ERVL-MaLR|ORR1C2|5|120748110|120748423 & 2.8 & $5.32 \mathrm{E}-15$ \\
\hline LINE/L1|L1MdTf_III|6|57628358|57634538 & 1.1 & $6.33 \mathrm{E}-15$ \\
\hline LINE/L1|Lx6|2|173195005|173200024 & 1.8 & $7.37 \mathrm{E}-15$ \\
\hline LTR/ERVL-MaLR|ORR1A2|18|60292038|60292355 & 2.4 & $7.76 \mathrm{E}-15$ \\
\hline LINE/L1|L1MdV_III|5|120882900|120884828 & 4.1 & $9.71 \mathrm{E}-15$ \\
\hline SINE/B4|B4A|5|120737450|120737698 & 2.8 & $1.24 \mathrm{E}-14$ \\
\hline LTR/ERVL-MaLR|MTD|X|112371164|112371262 & 2.3 & $1.28 \mathrm{E}-14$ \\
\hline LTR/ERVL-MaLR|MTD|11|72304177|72304543 & 1.2 & 1.44E-14 \\
\hline SINE/Alu|B1_Mur2|5|120731990|120732119 & 3.1 & $2.38 \mathrm{E}-14$ \\
\hline LTR/ERVL-MaLR|MTD MTD-int|5|120817871|120818905 & 1.4 & $2.75 \mathrm{E}-14$ \\
\hline LINE/L1|L1M5|6|3341749|3341957 & 1.1 & $3.15 \mathrm{E}-14$ \\
\hline LTR/ERVL-MaLR|MTEb|19|34585573|34585953 & 2.0 & $4.45 \mathrm{E}-14$ \\
\hline LINE/L1|L1MdV_III|7|104493403|104495643 & 1.5 & $4.59 \mathrm{E}-14$ \\
\hline SINE/B2|B3|5|120745046|120745085 & 2.7 & 1.17E-13 \\
\hline LINE/L1|L1MdN_I|7|104477902|104478732 & 1.3 & $1.60 \mathrm{E}-13$ \\
\hline LINE/L1|Lx8|18|60212692|60213382 & 1.6 & $1.71 \mathrm{E}-13$ \\
\hline LINE/L1|L1MdTf_III|18|60236091|60238578 & 1.6 & $2.06 \mathrm{E}-13$ \\
\hline LTR/ERVK|ERVB5_1-I_MM|11|83007973|83009733 & 1.7 & $3.34 \mathrm{E}-13$ \\
\hline LINE/L1|L1_Mur3|8|61931617|61933065 & 1.3 & $4.13 \mathrm{E}-13$ \\
\hline LINE/L1|L1MdF_IV|18|60231803|60232768 & 1.7 & $5.15 \mathrm{E}-13$ \\
\hline LTR/ERV1|MLTR14|7|104421879|104422356 & 1.2 & $5.39 \mathrm{E}-13$ \\
\hline LTR/ERVL-MaLR|MTC|16|97454326|97454700 & 2.7 & $6.93 \mathrm{E}-13$ \\
\hline LTR/ERVL-MaLR|MTB_Mm-int|17|78862042|78863246 & 1.0 & $7.35 \mathrm{E}-13$ \\
\hline DNA/hAT-Charlie|MER58A|5|120899366|120899528 & 2.4 & $1.55 \mathrm{E}-12$ \\
\hline LTR/ERVL|RMER15-int|18|60388388|60389084 & 1.4 & $2.49 \mathrm{E}-12$ \\
\hline LINE/L1|L1MdF_III|1|52127797|52128672 & 1.2 & $3.84 \mathrm{E}-12$ \\
\hline LTR/ERVL-MaLR|ORR1E|11|72305310|72305625 & 1.2 & $3.84 \mathrm{E}-12$ \\
\hline LTR/ERVK|RMER19C|5|120739285|120739711 & 3.8 & $3.85 \mathrm{E}-12$ \\
\hline LINE/L1|L1MdV_III|7|104450903|104454061 & 1.4 & $4.92 \mathrm{E}-12$ \\
\hline SINE/Alu|PB1D9|19|34586260|34586378 & 2.0 & $5.01 \mathrm{E}-12$ \\
\hline LINE/L1|Lx5|8|61953216|61953896 & 1.6 & $5.84 \mathrm{E}-12$ \\
\hline LINE/L1|L1MdA_III|7|104497785|104499051 & 1.6 & $6.75 \mathrm{E}-12$ \\
\hline LTR/ERVK|RLTR10F|5|120745593|120745641 & 2.3 & $9.12 \mathrm{E}-12$ \\
\hline LTR/ERVL|MT2C_Mm|12|103431337|103431828 & 3.1 & $1.01 \mathrm{E}-11$ \\
\hline LINE/L1|L1MdF IV|18|60263356|60264933 & 2.1 & $1.21 \mathrm{E}-11$ \\
\hline SINE/Alu|B1_Mus1|5|114898644|114898789 & 2.0 & $1.28 \mathrm{E}-11$ \\
\hline LINE/L1|Lx8|5|114904021|114904128 & 2.4 & 1.34E-11 \\
\hline LTR/ERVL-MaLR|ORR1C1 ORR1C1-int|8|62019273|62020492 & 1.8 & $1.82 \mathrm{E}-11$ \\
\hline LTR/ERVL-MaLR|MTD|16|97459784|97460166 & 2.5 & $2.57 \mathrm{E}-11$ \\
\hline LTR/ERV1|MER65-int|18|60215493|60215799 & 1.7 & $2.61 \mathrm{E}-11$ \\
\hline LINE/L1|Lx7|8|61930625|61931615 & 1.5 & 2.77E-11 \\
\hline LINE/L1|L1MdV_I|7|104473898|104475381 & 1.4 & $3.00 \mathrm{E}-11$ \\
\hline LTR/ERVL-MaLR|ORR1A4 ORR1A4-int|8|61959410|61960410 & 1.7 & $3.12 \mathrm{E}-11$ \\
\hline LTR/ERVL-MaLR|ORR1E|16|97455751|97456075 & 3.0 & $3.63 \mathrm{E}-11$ \\
\hline LTR/ERVL-MaLR|MTC|3|151744695|151745110 & 2.6 & $4.72 \mathrm{E}-11$ \\
\hline DNA/TcMar-Tigger|Tigger13a|19|28642966|28643654 & 9.3 & $5.06 \mathrm{E}-11$ \\
\hline LINE/L1|L1MEc|16|97460167|97460362 & 3.3 & $7.07 \mathrm{E}-11$ \\
\hline LTR/ERVK|RMER19B|17|78878705|78879529 & 1.2 & $8.11 \mathrm{E}-11$ \\
\hline SINE/Alu|B1F2|5|114899111|114899246 & 2.1 & $8.42 \mathrm{E}-11$ \\
\hline LINE/L1|Lx8|8|61978737|61979085 & 1.7 & $8.42 \mathrm{E}-11$ \\
\hline LTR/ERVK|RLTR17D_Mm|18|60228369|60229159 & 1.5 & $1.01 \mathrm{E}-10$ \\
\hline LINE/CR1|X6A_LINE|6|127449631|127450147 & 1.7 & 1.08E-10 \\
\hline SINE/B4|B4|11|119418705|119418955 & 1.3 & $1.62 \mathrm{E}-10$ \\
\hline LTR/ERVL|RMER10B|12|103434622|103435041 & 1.8 & $2.64 \mathrm{E}-10$ \\
\hline LINE/L1|Lx4A|7|104462257|104463184 & 1.7 & $2.88 \mathrm{E}-10$ \\
\hline SINE/Alu|B1_Mur1|11|119424502|119424651 & 1.2 & $2.88 \mathrm{E}-10$ \\
\hline LTR/ERVL-MaLR|ORR1A4-int|8|61961707|61963155 & 1.3 & $3.22 \mathrm{E}-10$ \\
\hline
\end{tabular}


bioRxiv preprint doi: https://doi.org/10.1101/2020.12.04.411793; this version posted December 4,2020 . The copyright holder for this

preprint (which was not certified by peer review) is the author/funder, who has granted bioRxiv a license to display the preprint in perpetuity. It is made available under aCC-BY 4.0 International license.

\begin{tabular}{|c|c|c|}
\hline \begin{tabular}{|l} 
LTR/ERV1|RLTR1B|16|97457671|97458166 \\
\end{tabular} & 2.2 & $3.52 \mathrm{E}-10$ \\
\hline SINE/B2|B3A|11|119404723|119404878 & 1.3 & $3.77 \mathrm{E}-10$ \\
\hline LTR/ERVL-MaLR|MTC|18|60381338|60381622 & 1.7 & $3.77 \mathrm{E}-10$ \\
\hline LINE/L1|L1MdV_I|5|105283637|105285975 & 1.6 & $3.97 \mathrm{E}-10$ \\
\hline LTR/ERVK|RLTR25B|19|34650691|34651330 & 1.4 & $4.78 \mathrm{E}-10$ \\
\hline SINE/B2|B3|5|114899419|114899545 & 2.0 & $6.53 \mathrm{E}-10$ \\
\hline LTR/ERVL|RMER15|19|28639198|28639693 & 8.9 & $6.63 \mathrm{E}-10$ \\
\hline LINE/L1|L1_Mur3|16|97548067|97549012 & 1.7 & $7.03 \mathrm{E}-10$ \\
\hline LINE/L1|L1MEi|19|28631069|28632121 & 8.8 & $8.12 \mathrm{E}-10$ \\
\hline LTR/ERVK|RLTR25A|8|61972997|61973607 & 1.4 & $8.16 \mathrm{E}-10$ \\
\hline LINE/L1|L1MdA_VII|18|60288431|60288795 & 1.8 & 1.45E-09 \\
\hline LINE/L1|L1Lx_III|3|151742481|151742961 & 2.4 & 1.67E-09 \\
\hline LTR/ERVK|MurERV4-int|11|119401805|119402501 & 1.3 & 1.86E-09 \\
\hline SINE/B2|B3|X|112370657|112370771 & 2.0 & $2.38 \mathrm{E}-09$ \\
\hline LTR/ERVK|MurERV4-int|11|119400881|119401263 & 1.3 & $2.38 \mathrm{E}-09$ \\
\hline LINE/L1|Lx9|JH584304.1|46386|46861 & 1.1 & 2.46E-09 \\
\hline LTR/ERVK|RMER17B|5|120869622|120870528 & 2.9 & $2.74 \mathrm{E}-09$ \\
\hline LTR/ERVL-MaLR|MTB_Mm|15|77733815|77734092 & 3.4 & 3.12E-09 \\
\hline LTR/ERVK|ERVB2_1-I_MM|1|173580639|173582295 & 1.1 & $3.35 \mathrm{E}-09$ \\
\hline LTR/ERVL-MaLR|ORR1B2|5|114908516|114908882 & 1.5 & 4.45E-09 \\
\hline LTR/ERVK|MYSERV-int|6|57638599|57641256 & 1.0 & $6.35 \mathrm{E}-09$ \\
\hline SINE/B4|B4|11|119446380|119446625 & 1.0 & $7.11 \mathrm{E}-09$ \\
\hline LTR/ERVK|ERVB4_1-I_MM|18|60288165|60288430 & 1.8 & 9.39E-09 \\
\hline LTR/ERVL-MaLR|MLT1A|18|60223904|60224219 & 1.5 & 1.15E-08 \\
\hline SINE/B2|B2_Mm2|19|34584659|34584843 & 2.2 & 1.27E-08 \\
\hline LTR/ERVL-MaLR|MTE2b|8|61970047|61970414 & 1.6 & $1.28 \mathrm{E}-08$ \\
\hline LTR/ERVK|ERVB5_1-I_MM|11|83010068|83011537 & 1.5 & $1.51 \mathrm{E}-08$ \\
\hline LTR/ERV1|MLTR14|7|104480250|104480718 & 1.3 & 1.59E-08 \\
\hline LTR/ERVL-MaLR|MTE2b|1|52136423|52136770 & 1.1 & 1.59E-08 \\
\hline SINE/B4|B4A|5|120741648|120741943 & 2.5 & 1.60E-08 \\
\hline LINE/L1|Lx8|19|28632845|28633192 & 8.4 & 1.81E-08 \\
\hline LINE/L1|Lx2A1|18|60277986|60280175 & 2.3 & 1.82E-08 \\
\hline LINE/L1|Lx3_Mus|18|60295395|60298143 & 1.8 & 1.91E-08 \\
\hline LINE/L1|L1MEc|16|97459476|97459783 & 2.7 & $2.30 \mathrm{E}-08$ \\
\hline LTR/ERVL-MaLR|MTD|5|120900388|120900472 & 3.2 & $2.76 \mathrm{E}-08$ \\
\hline LINE/L1|L1M4|16|97553934|97554356 & 2.3 & 2.81E-08 \\
\hline LTR/ERVK|IAPLTR2_Mm|3|151740656|151741121 & 2.1 & $3.42 \mathrm{E}-08$ \\
\hline LINE/L1|L1MdV_III|7|104488452|104489331 & 1.6 & $3.71 \mathrm{E}-08$ \\
\hline LTR/ERVK|MERVK26-int RLTR26_Mus|7|104448877|104450693 & 1.2 & 4.13E-08 \\
\hline SINE/Alu|B1_Mus2|18|60251725|60251812 & 2.6 & 4.69E-08 \\
\hline LTR/ERVL-MaLR|ORR1B1|11|119404156|119404499 & 1.0 & 6.92E-08 \\
\hline SINE/B2|B2_Mm1t|5|114909495|114909661 & 2.2 & $7.44 \mathrm{E}-08$ \\
\hline SINE/B4|RSINE1|11|119425189|119425383 & 1.2 & 7.93E-08 \\
\hline SINE/B2|B3A|18|60380840|60381056 & 1.7 & $8.13 \mathrm{E}-08$ \\
\hline SINE/B4|B4|19|28629227|28629484 & 8.2 & 9.75E-08 \\
\hline LTR/ERVK|RLTR42-int|17|36238528|36239128 & 4.8 & 1.06E-07 \\
\hline LTR/ERVL-MaLR|MTC|18|60382046|60382401 & 1.4 & $1.18 \mathrm{E}-07$ \\
\hline SINE/B4|ID_B1|11|119407311|119407556 & 1.0 & 1.18E-07 \\
\hline DNA/hAT-Charlie|Charlie16a|1|52132936|52133086 & 1.3 & 1.23E-07 \\
\hline LTR/ERVL-MaLR|MTB|16|97458167|97458530 & 2.0 & 1.37E-07 \\
\hline LINE/L1|L1MC5|18|60271813|60272228 & 2.2 & $1.40 \mathrm{E}-07$ \\
\hline SINE/B4|RSINE1|5|120877997|120878148 & 3.8 & 1.42E-07 \\
\hline LINE/L1|Lx3_Mus|1|173583337|173589127 & 1.4 & 1.42E-07 \\
\hline LINE/L1|L1M2|18|60252957|60253392 & 2.0 & 1.47E-07 \\
\hline LTR/ERV1|LTRIS4A|5|114905222|114905693 & 2.1 & 1.84E-07 \\
\hline LINE/L1|Lx8|8|61926037|61926661 & 2.5 & 1.95E-07 \\
\hline SINE/B2|B3|11|119408463|119408535 & 1.4 & 2.06E-07 \\
\hline SINE/Alu|PB1D11|5|114900810|114900897 & 2.0 & 2.39E-07 \\
\hline LINE/L1|Lx5|1|85293799|85295584 & 3.7 & $2.48 \mathrm{E}-07$ \\
\hline LTR/ERVK|RLTR13D3|18|60232779|60233438 & 1.8 & $2.54 \mathrm{E}-07$ \\
\hline LTR/ERVL-MaLR|MTD|5|120737214|120737449 & 3.1 & 2.65E-07 \\
\hline LTR/ERVL-MaLR|MTEb|16|97450859|97451049 & 3.4 & $2.73 \mathrm{E}-07$ \\
\hline SINE/B4|B4A|18|60257733|60257992 & 1.7 & 2.89E-07 \\
\hline
\end{tabular}


bioRxiv preprint doi: https://doi.org/10.1101/2020.12.04.411793; this version posted December 4,2020 . The copyright holder for this

preprint (which was not certified by peer review) is the author/funder, who has granted bioRxiv a license to display the preprint in perpetuity. It is made available under aCC-BY 4.0 International license.

\begin{tabular}{|c|c|c|}
\hline LTR/ERVK|MLTR25A|8|61960825|61961601 & 1.7 & 2.89E-07 \\
\hline LTR/ERVK|RLTR20A2B_MM|1|52124850|52125329 & 1.2 & $3.05 \mathrm{E}-07$ \\
\hline SINE/Alu|B1_Mus1|17|35395764|35395900 & 1.1 & $3.22 \mathrm{E}-07$ \\
\hline LINE/L1|L1LX_III|7|104442758|104443886 & 1.4 & 3.32E-07 \\
\hline LTR/ERVL|RMER15-int|18|60217650|60217971 & 1.2 & $3.36 \mathrm{E}-07$ \\
\hline DNA/hAT-Charlie|MER20|1|52158511|52158655 & 1.3 & $3.50 \mathrm{E}-07$ \\
\hline LINE/L1|L1_Mur3|18|60226049|60226282 & 2.1 & 3.64E-07 \\
\hline LTR/ERVK|RLTR20C1_MM|5|120734599|120734859 & 4.1 & 4.08E-07 \\
\hline LTR/ERVL-MaLR|MTEb|11|119419503|119419749 & 1.3 & 4.17E-07 \\
\hline DNA/hAT-Charlie|MER33|19|28641324|28641627 & 7.9 & 4.22E-07 \\
\hline LTR/ERVL-MaLR|MLT1A|18|60250995|60251268 & 1.7 & 4.23E-07 \\
\hline LINE/L1|L1MdF I|11|119397535|119397973 & 1.3 & 4.23E-07 \\
\hline SINE/Alu|B1_Mur4|5|114900337|114900479 & 1.6 & 4.29E-07 \\
\hline LINE/L1|L1_Mur2|5|105281882|105283598 & 1.7 & 4.42E-07 \\
\hline Other|RMER1A|8|61979640|61980291 & 1.5 & $4.58 \mathrm{E}-07$ \\
\hline LTR/ERVK|ETnERV2-int|8|62007507|62009017 & 1.6 & 4.83E-07 \\
\hline LINE/L1|L1MC5|3|151743348|151743525 & 2.7 & $5.34 \mathrm{E}-07$ \\
\hline LTR/ERVL-MaLR|MTD|12|26472066|26472478 & 2.0 & 5.39E-07 \\
\hline LINE/L1|L1MB1|18|60220588|60220785 & 1.4 & 5.59E-07 \\
\hline SINE/B4|ID_B1|2|173207281|173207474 & 1.9 & 5.93E-07 \\
\hline SINE/B4|ID_B1|11|119425805|119425924 & 1.3 & $6.35 \mathrm{E}-07$ \\
\hline LTR/ERVL-MaLR|ORR1A2|5|120740579|120740914 & 3.0 & $6.88 \mathrm{E}-07$ \\
\hline LINE/L1|Lx4A|7|104437169|104438548 & 1.4 & $7.31 \mathrm{E}-07$ \\
\hline LTR/ERVK|ERVB5_1-I_MM|11|83006799|83007974 & 1.4 & 9.02E-07 \\
\hline LINE/L1|L1M5|1|78402205|78403427 & 1.1 & $1.01 \mathrm{E}-06$ \\
\hline SINE/B2|B2_Mm2|5|114910612|114910685 & 2.4 & 1.06E-06 \\
\hline SINE/B4|B4A|1|52129374|52129536 & 1.4 & 1.22E-06 \\
\hline SINE/B2|B2_Mm2|19|28642281|28642465 & 7.7 & 1.38E-06 \\
\hline SINE/B2|B3|19|28633498|28633654 & 7.7 & $1.38 \mathrm{E}-06$ \\
\hline LINE/L1|Lx2B2|11|49062198|49062461 & 1.2 & 1.47E-06 \\
\hline LTR/ERV1|MER34A|6|57582287|57582506 & 1.1 & 1.49E-06 \\
\hline LINE/L1|L1MdF_I|GL456221.1|2915|7856 & 2.8 & 1.54E-06 \\
\hline LTR/ERVL|MLT2D|11|48885340|48885618 & 2.4 & 1.54E-06 \\
\hline LTR/ERVK|MMERVK9E_I-int|8|62004675|62005632 & 1.5 & 1.72E-06 \\
\hline LINE/L1|Lx8|18|60239540|60240228 & 1.8 & 1.84E-06 \\
\hline LTR/ERVK|BGLII|7|104482055|104482477 & 1.4 & 2.15E-06 \\
\hline LTR/ERVK|RMER6C|2|173214417|173215067 & 2.6 & 2.19E-06 \\
\hline LTR/ERVL-MaLR|MTEa-int|1|85289885|85291027 & 7.6 & $2.30 \mathrm{E}-06$ \\
\hline LTR/ERVL-MaLR|ORR1C2|2|131068596|131068990 & 1.1 & $2.40 \mathrm{E}-06$ \\
\hline LTR/ERVL-MaLR|ORR1F|18|60253720|60254029 & 2.1 & 2.42E-06 \\
\hline LTR/ERVK|RMER12|5|120762281|120763522 & 3.3 & 2.49E-06 \\
\hline SINE/B4|RSINE1|4|99841078|99841236 & 7.6 & 2.59E-06 \\
\hline LINE/L1|Lx4A|7|104504433|104505979 & 1.4 & $2.59 \mathrm{E}-06$ \\
\hline LTR/ERVL-MaLR|MTD-int|5|120819453|120820125 & 1.2 & $2.78 \mathrm{E}-06$ \\
\hline LINE/L1|L1MC|11|58190640|58190990 & 1.4 & $3.05 \mathrm{E}-06$ \\
\hline LINE/L1|L1MdFanc_I|8|62027358|62028774 & 1.4 & $3.18 \mathrm{E}-06$ \\
\hline LINE/L1|L1MdF_V|6|57656263|57657234 & 1.6 & 3.19E-06 \\
\hline SINE/B4|B4A|11|119428315|119428565 & 1.8 & $3.55 \mathrm{E}-06$ \\
\hline LTR/ERVK|RLTR31B2|11|48886943|48887241 & 2.0 & $3.61 \mathrm{E}-06$ \\
\hline LINE/L1|L1MEg|14|22926181|22927055 & 1.2 & $3.61 \mathrm{E}-06$ \\
\hline LTR/ERVL-MaLR|MLT1A|18|60248622|60248960 & 1.5 & $3.84 \mathrm{E}-06$ \\
\hline LTR/ERVL-MaLR|MLT1E1A|8|61928913|61929235 & 1.9 & 4.17E-06 \\
\hline LINE/L1|Lx8|18|60383318|60384031 & 1.1 & 4.25E-06 \\
\hline LTR/ERVL-MaLR|MTA_Mm MTA_Mm-int|19|56257034|56258929 & 1.3 & 4.57E-06 \\
\hline LINE/L1|L1MCc|1|173466324|173466705 & 2.3 & 4.62E-06 \\
\hline LINE/L1|L1Lx_IV|11|82998919|83000309 & 1.6 & 4.81E-06 \\
\hline SINE/B4|B4A|5|120741975|120742193 & 2.7 & 4.96E-06 \\
\hline SINE/B4|B4A|19|28635419|28635576 & 7.6 & 4.96E-06 \\
\hline SINE/B4|ID_B1|11|119403020|119403132 & 1.2 & $5.58 \mathrm{E}-06$ \\
\hline LINE/L1|L1M5|18|60226313|60226492 & 2.0 & 5.89E-06 \\
\hline LTR/ERVL-MaLR|ORR1A3|11|119407950|119408239 & 1.1 & $6.40 \mathrm{E}-06$ \\
\hline LINE/L1|L1MC|11|58189736|58190050 & 1.3 & 7.01E-06 \\
\hline SINE/B2|B3A|8|61987073|61987211 & 1.7 & $7.39 \mathrm{E}-06$ \\
\hline
\end{tabular}


bioRxiv preprint doi: https://doi.org/10.1101/2020.12.04.411793; this version posted December 4,2020 . The copyright holder for this

preprint (which was not certified by peer review) is the author/funder, who has granted bioRxiv a license to display the preprint in perpetuity. It is made available under aCC-BY 4.0 International license.

LTR/ERVK|RMER20B|3|151742296|151742480

SINE/B4|RSINE1|16|97453740|97453952

LTR/ERVL-MaLR|ORR1G|18|60226675|60226792

LTR/ERV1|LTR72_RN|18|60387696|60387959

SINE/B4|ID_B1|12|26447776|26447975

LTR/ERVL-MaLR|ORR1B1-int|7|104412596|104412775

SINE/Alu|PB1D10|5|114903889|114904001

DNA/hAT-Charlie|MER20|5|120732243|120732442

LTR/ERVK|MLTR18D_MM|19|34642526|34643041

LTR/ERVL-MaLR|ORR1F|16|97539474|97539795

LTR/ERVL-MaLR|MTE2a|18|60222383|60222695

LTR/ERVK|MLTR25A|8|61972378|61972814

LTR/ERVL-MaLR|MTD MTD-int|11|119438208|119439017

LINE/L1|LX8b|7|104422425|104422813

SINE/Alu|B1 Mur2|11|58189251|58189397

SINE/B2|B2_Mm2|5|114900909|114901081

LTR/ERVK|RMER6D|8|61937912|61938757

LINE/L1|L1MdF IV|14|59239026|59244038

LTR/ERVL-MaLR|MTB_Mm|15|77406091|77406368

SINE/Alu|B1_Mus 1|18|60224405|60224548

SINE/Alu|B1_Mur3|11|119403373|119403524

LTR/ERVK|RMER17D|18|60376370|60377162

LINE/L1|L1MdGf_II|8|61952074|61952803

SINE/B2|B3A|5|120736482|120736718

LTR/ERVK|RMER20B|3|151742962|151743316

SINE/B4|RSINE1|4|99840780|99840864

LTR/ERVK|RLTR10|7|104415656|104415786

LTR/ERVL-MaLR|MTD|6|121255828|121256203

LTR/ERVK|RMER6C|8|62032655|62033307

LINE/L1|L1MdFanc_II|11|48895925|48896912

LTR/ERVL-MaLR|MTD|1|52138546|52138957

LINE/L1|LX2B2|11|48990324|48990587

SINE/B4|B4A|11|72310037|72310328

LINE/L1|Lx8b|18|60275235|60275895

LTR/ERVK|MMERVK9E_I-int|8|62005696|62006980

LINE/L1|Lx8b|6|57648031|57648834

SINE/B2|B3A|5|120906530|120906727

LINE/L1|L1M2|6|121257693|121258500

LINE/L1|L1MdF V|7|105888905|105891419

SINE/B4|B4A|18|60222757|60223022

LINE/L1|L1MdMus_I|7|105905000|105906394

SINE/B2|B3|18|60223226|60223431

LINE/L1|L1MEc|16|97540878|97541130

LTR/ERVL-MaLR|ORR1B1|10|128274867|128275232

SINE/B2|B2_Mm2|5|120736758|120736943

LTR/ERVK|RMER6A|8|61944108|61944875

SINE/B2|B2 Mm2|17|78880852|78881043

LINE/L1|L1M5|8|61946379|61947158

SINE/Alu|B1_Mus1|5|114909326|114909471

LINE/L1|Lx5|11|48881306|48882584

LINE/L1|Lx8|11|78973853|78974577

SINE/B2|B2_Mm2|19|28632419|28632602

LTR/ERVK|ERVB4_1C-LTR_Mm|1|52125995|52126510

LTR/ERVL-MaLR|MTC|14|59357742|59357949

LTR/ERVK|ERVB5 1-I MM ERVB5 2-LTR MM|11|83005040|83006189

SINE/B4|RSINE1|18|60213658|60213808

LINE/L1|L1MdF_II|6|57667427|57673682

LTR/ERVK|RLTR20A3_MM|7|104463189|104463682

SINE/Alu|PB1D7|5|120876099|120876194

LTR/ERVL-MaLR|MTD|19|34649682|34650059

SINE/Alu|B1_Mus2|11|119397366|119397508

LTR/ERVL|MT2B1|18|60266284|60266703

LTR/ERVL|MT2B2|16|23610543|23610701

\begin{tabular}{|c|c|}
\hline 2.7 & 8.09E-06 \\
\hline 2.7 & $8.54 \mathrm{E}-06$ \\
\hline 2.8 & 8.94E-06 \\
\hline 1.2 & $9.12 \mathrm{E}-06$ \\
\hline 4.2 & 1.01E-05 \\
\hline 1.4 & 1.03E-05 \\
\hline 2.0 & 1.07E-05 \\
\hline 2.4 & 1.21E-05 \\
\hline 1.5 & 1.27E-05 \\
\hline 2.5 & 1.37E-05 \\
\hline 1.5 & 1.38E-05 \\
\hline 1.4 & 1.49E-05 \\
\hline 1.3 & 1.60E-05 \\
\hline 1.0 & 1.60E-05 \\
\hline 1.2 & 1.60E-05 \\
\hline 1.9 & 1.64E-05 \\
\hline 1.4 & 1.74E-05 \\
\hline 1.0 & 1.75E-05 \\
\hline 4.2 & 1.89E-05 \\
\hline 2.0 & 1.89E-05 \\
\hline 1.5 & 1.89E-05 \\
\hline 1.3 & $2.06 \mathrm{E}-05$ \\
\hline 1.6 & 2.07E-05 \\
\hline 2.9 & 2.09E-05 \\
\hline 1.9 & $2.12 \mathrm{E}-05$ \\
\hline 7.3 & 2.22E-05 \\
\hline 1.3 & $2.23 \mathrm{E}-05$ \\
\hline 1.2 & 2.24E-05 \\
\hline 2.1 & 2.33E-05 \\
\hline 2.5 & 2.39E-05 \\
\hline 1.1 & $2.40 \mathrm{E}-05$ \\
\hline 1.8 & $2.56 \mathrm{E}-05$ \\
\hline 1.2 & $2.56 \mathrm{E}-05$ \\
\hline 3.0 & $2.59 \mathrm{E}-05$ \\
\hline 1.4 & 2.65E-05 \\
\hline 1.0 & 2.83E-05 \\
\hline 2.1 & 2.97E-05 \\
\hline 1.2 & 3.22E-05 \\
\hline 1.0 & $3.33 \mathrm{E}-05$ \\
\hline 1.4 & 3.54E-05 \\
\hline 1.1 & 3.88E-05 \\
\hline 1.4 & 3.95E-05 \\
\hline 2.8 & 3.98E-05 \\
\hline 1.1 & 3.98E-05 \\
\hline 3.2 & $4.16 \mathrm{E}-05$ \\
\hline 2.1 & 4.30E-05 \\
\hline 1.4 & $4.30 \mathrm{E}-05$ \\
\hline 1.8 & 4.69E-05 \\
\hline 1.9 & 4.70E-05 \\
\hline 2.4 & 4.97E-05 \\
\hline 1.0 & 5.04E-05 \\
\hline 7.2 & $5.25 \mathrm{E}-05$ \\
\hline 1.1 & 5.62E-05 \\
\hline 1.4 & $5.66 \mathrm{E}-05$ \\
\hline 1.7 & 6.18E-05 \\
\hline 1.6 & 6.18E-05 \\
\hline 1.1 & 6.18E-05 \\
\hline 1.4 & 6.53E-05 \\
\hline 4.1 & $6.65 \mathrm{E}-05$ \\
\hline 1.8 & 6.96E-05 \\
\hline 1.5 & 7.02E-05 \\
\hline 2.0 & 7.08E-05 \\
\hline 1.8 & $7.08 \mathrm{E}-05$ \\
\hline
\end{tabular}


bioRxiv preprint doi: https://doi.org/10.1101/2020.12.04.411793; this version posted December 4,2020 . The copyright holder for this

preprint (which was not certified by peer review) is the author/funder, who has granted bioRxiv a license to display the preprint in perpetuity. It is made available under aCC-BY 4.0 International license.

\begin{tabular}{|c|c|c|}
\hline $\mid$ LINE/L1|L1M5|8|62026273|62026678 & 1.9 & $7.22 \mathrm{E}-05$ \\
\hline SINE/B2|B3|11|119431991|119432188 & 1.5 & $8.27 \mathrm{E}-05$ \\
\hline LINE/L1|L1MA9|18|60389514|60389752 & 1.2 & $8.52 \mathrm{E}-05$ \\
\hline LTR/ERVK|RMER16B2|19|34643495|34643896 & 1.6 & $9.10 \mathrm{E}-05$ \\
\hline SINE/B2|B3|11|48885122|48885339 & 2.9 & 9.26E-05 \\
\hline LTR/ERVK|RLTR31D_MM|8|61934369|61934756 & 1.5 & 9.26E-05 \\
\hline SINE/B4|B4A|1|52121302|52121516 & 1.5 & 9.44E-05 \\
\hline 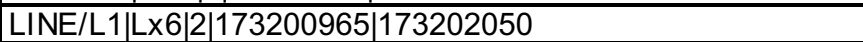 & 2.1 & 9.82E-05 \\
\hline LINE/L1|L1MC3|5|100554042|100554239 & 1.8 & 0.000109224 \\
\hline LTR/ERVK|ERVB4_1-I_MM RLTR43C|8|62002691|62003827 & 1.4 & 0.000109224 \\
\hline LINE/L1|L1_Rod|6|57584670|57585726 & 1.1 & 0.000110408 \\
\hline $\begin{array}{l}\text { LTR/ERVK|RLTR33|7|104482478|104483095 } \\
\end{array}$ & 1.1 & 0.000112452 \\
\hline LINE/L1|Lx2A1|18|60275890|60277983 & 1.7 & 0.000114821 \\
\hline LTR/ERVL-MaLR|MTC|18|60235502|60235795 & 1.8 & 0.000116123 \\
\hline LINE/L1|Lx8|18|60380013|60380364 & 1.5 & 0.000116123 \\
\hline LTR/ERVL-MaLR|ORR1F|5|120760326|120760690 & 2.6 & 0.00012678 \\
\hline LTR/ERV1|MER65-int|18|60386130|60386423 & 1.1 & 0.000133868 \\
\hline LTR/ERVL-MaLR|ORR1A2|1|173467096|173467424 & 1.9 & 0.00013703 \\
\hline LINE/L1|Lx8|8|94438097|94440818 & 1.0 & 0.000152871 \\
\hline SINE/B2|B3|11|119448108|119448296 & 1.1 & 0.000154092 \\
\hline SINE/Alu|PB1|11|119422838|119422954 & 1.2 & 0.000158146 \\
\hline LINE/L1|L1ME3A|1|85672489|85672941 & 1.0 & 0.000158146 \\
\hline SINE/B2|B2_Mm1t|11|78980069|78980247 & 1.7 & 0.000159374 \\
\hline LINE/L1|L1MdFanc_I|8|62026867|62027358 & 1.8 & 0.000168661 \\
\hline LTR/ERVL-MaLR|ORR1D1|8|61993767|61994083 & 1.9 & 0.000168999 \\
\hline LINE/L1|L1MdF_III|5|109141850|109144085 & 1.7 & 0.00017257 \\
\hline $\begin{array}{l}\text { LTR/ERVK|RLTR50B|18|60281383|60281838 } \\
\end{array}$ & 1.7 & 0.000172929 \\
\hline LINE/L1|L1MB3|16|97449241|97449562 & 2.5 & 0.000177 \\
\hline SINE/Alu|B1_Mur3|16|35844933|35845040 & 1.2 & 0.000177668 \\
\hline LTR/ERVK|RLTR17|1|173482685|173483219 & 2.2 & 0.000179126 \\
\hline SINE/B2|B3|GL456211.1|227084|227304 & 3.2 & 0.000182121 \\
\hline LINE/L1|Lx8|8|61988622|61989015 & 1.6 & 0.000186362 \\
\hline LTR/ERVK|RMER17A2|11|48885977|48886924 & 1.6 & 0.000186858 \\
\hline LTR/ERVL-MaLR|ORR1D1|8|62016352|62016678 & 1.9 & 0.000207871 \\
\hline DNA/TcMar-Tigger|Tigger17a|1|52148302|52148747 & 1.1 & 0.000209188 \\
\hline SINE/B4|RSINE1|11|119421171|119421274 & 1.8 & 0.000217129 \\
\hline SINE/B4|B4A|5|120866302|120866579 & 3.2 & 0.000219053 \\
\hline SINE/B2|B2_Mm1t|11|58190313|58190486 & 1.4 & 0.000220304 \\
\hline SINE/B2|B3|14|59352375|59352576 & 1.4 & 0.000223123 \\
\hline SINE/Alu|B1_Mus1|18|60249131|60249275 & 1.6 & 0.00023365 \\
\hline SINE/B4|ID_B1|1|78411074|78411271 & 1.5 & 0.00023459 \\
\hline LTR/ERVK|ERVB4_1-I_MM|18|60282151|60282841 & 1.8 & 0.000240016 \\
\hline LINE/L1|Lx7|11|49092819|49093419 & 1.2 & 0.000244381 \\
\hline LINE/L1|L1MA9|6|57597772|57598304 & 1.1 & 0.000249114 \\
\hline SINE/Alu|B1_Mus1|12|103436139|103436281 & 1.9 & 0.00027349 \\
\hline LINE/L1|L1MdA_III|16|36223021|36229214 & 1.2 & 0.000274576 \\
\hline SINE/B4|RSINE1|5|120872117|120872273 & 3.3 & 0.000287785 \\
\hline LTR/ERVL-MaLR|MTD|11|72309643|72309975 & 1.1 & 0.000289508 \\
\hline SINE/B4|B4A|1|173484993|173485286 & 2.2 & 0.000290371 \\
\hline SINE/B4|B4A|18|60231038|60231308 & 1.5 & 0.000327918 \\
\hline LTR/ERVL-MaLR|MTA_Mm|16|97552450|97552832 & 1.9 & 0.000331455 \\
\hline LINE/L1|L1MdV_I|11|119469230|119469675 & 1.0 & 0.000339371 \\
\hline SINE/B2|B3A|8|61937106|61937279 & 1.7 & 0.000348467 \\
\hline SINE/B2|B3A|17|6453751|6453921 & 2.1 & 0.000353282 \\
\hline LTR/ERVL-MaLR|ORR1A2|7|104497343|104497650 & 1.6 & 0.00035773 \\
\hline LTR/ERVL-MaLR|ORR1D2-int|7|105893142|105893563 & 1.0 & 0.00035773 \\
\hline LINE/L1|Lx8|8|61959169|61959373 & 1.9 & 0.000360775 \\
\hline LINE/L1|Lx8|19|12528103|12528695 & 1.8 & 0.000365486 \\
\hline LINE/L1|L1MdF_III|7|104454974|104455697 & 1.4 & 0.000367396 \\
\hline LINE/L1|L1MdA_IV|11|118381899|118388191 & 1.3 & 0.000368207 \\
\hline SINE/Alu|PB1|16|35845564|35845645 & 1.0 & 0.000374836 \\
\hline LINE/L1|L1MdA_III|18|60406432|60412549 & 1.2 & 0.00038205 \\
\hline LTR/ERVL|RMER10B|16|23611518|23611704 & 1.8 & 0.00040784 \\
\hline
\end{tabular}


bioRxiv preprint doi: https://doi.org/10.1101/2020.12.04.411793; this version posted December 4,2020 . The copyright holder for this

preprint (which was not certified by peer review) is the author/funder, who has granted bioRxiv a license to display the preprint in perpetuity. It is made available under aCC-BY 4.0 International license.

\begin{tabular}{|c|c|c|}
\hline LINE/L1|Lx7|1|173470250|173470764 & 1.9 & 0.000408506 \\
\hline LTR/ERVK|RLTR25A|8|61960411|61960742 & 2.2 & 0.000410879 \\
\hline LINE/L1|Lx6|7|104440983|104441613 & 1.3 & 0.000418042 \\
\hline SINE/Alu|PB1D10|11|119403173|119403281 & 1.2 & 0.000428833 \\
\hline LTR/ERVL-MaLR|ORR1A2|5|120893806|120893895 & 3.5 & 0.000439001 \\
\hline 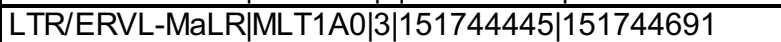 & 2.5 & 0.000451551 \\
\hline LTR/ERV1|RLTR23|5|120818906|120819376 & 1.1 & 0.000453883 \\
\hline LINE/L1|L1MC5|3|151740389|151740655 & 2.6 & 0.000462351 \\
\hline LINE/L1|Lx2B|8|61987536|61987650 & 2.2 & 0.000462351 \\
\hline SINE/Alu|B1_Mur3|11|72309443|72309576 & 1.8 & 0.000466519 \\
\hline SINE/B2|B3A|5|120886654|120886852 & 2.8 & 0.000474244 \\
\hline LTR/ERVL-MaLR|ORR1B2-int|18|60308447|60308715 & 1.8 & 0.000476449 \\
\hline $\begin{array}{l}\text { LINE/L1|L1Lx_IV|11|83024253|83025643 } \\
\end{array}$ & 1.3 & 0.000478685 \\
\hline SINE/Alu|B1_Mur4|18|60388241|60388387 & 1.5 & 0.000504818 \\
\hline LINE/L1|L1MEg|14|22924975|22925754 & 1.1 & 0.000521911 \\
\hline LINE/L1|L1MC3|19|12525661|12526010 & 2.0 & 0.000523155 \\
\hline SINE/B2|B3|11|119396967|119397132 & 1.2 & 0.000532394 \\
\hline LINE/L1|L1MdV_I|6|57655972|57656262 & 1.8 & 0.00058615 \\
\hline LTR/ERV1|MER65-int|18|60242375|60242677 & 2.0 & 0.000593172 \\
\hline LINE/L1|L1Lx_IV|7|104447255|104447947 & 1.2 & 0.000595394 \\
\hline LTR/ERVL|RMER15-int|18|60388050|60388240 & 1.2 & 0.000595471 \\
\hline SINE/Alu|B1_Mus1|11|119422309|119422456 & 1.3 & 0.000597017 \\
\hline LINE/L1|Lx8|14|59362138|59362787 & 1.3 & 0.000608974 \\
\hline LINE/L1|L1MEc|16|97542889|97543268 & 2.3 & 0.000613872 \\
\hline LINE/L1|L1Lx_I|8|61950817|61951123 & 1.7 & 0.000627706 \\
\hline LINE/L1|Lx3B|18|60271246|60271457 & 2.0 & 0.000635352 \\
\hline $\begin{array}{l}\text { LTR/ERVK|RLTR33|7|104481788|104482054 } \\
\end{array}$ & 1.2 & 0.000639421 \\
\hline LINE/L1|L1MdA_IV|15|75013194|75019358 & 1.0 & 0.000654485 \\
\hline LTR/ERVK|MMERVK10D3_I-int|19|12537134|12538136 & 1.6 & 0.00066349 \\
\hline SINE/B4|RSINE1|18|60384304|60384453 & 1.2 & 0.000669838 \\
\hline LINE/L1|L1MdA II|Y|90726495|90727209 & 6.2 & 0.000676413 \\
\hline LTR/ERVK|RMER17C2|11|119394660|119395025 & 1.1 & 0.000679554 \\
\hline LINE/L1|L1ME2|19|34584395|34584639 & 1.8 & 0.000701496 \\
\hline LTR/ERVL|MT2B2|5|114912527|114913101 & 1.5 & 0.000762304 \\
\hline LTR/ERVL-MaLR|ORR1C2|11|118395751|118396103 & 1.6 & 0.000762944 \\
\hline LTR/ERV1|MMVL30-int|18|60249553|60250002 & 1.4 & 0.000823898 \\
\hline SINE/B4|B4|1|173475932|173476222 & 1.8 & 0.000849572 \\
\hline SINE/B4|B4A|1|52133585|52133834 & 1.1 & 0.000870689 \\
\hline LINE/L1|L1_Mur2|7|104496617|104497342 & 1.3 & 0.00094743 \\
\hline SINE/B2|B3A|1|85660064|85660261 & 1.1 & 0.000971813 \\
\hline LTR/ERVK|RMER19B|1|85214688|85215577 & 3.1 & 0.000987718 \\
\hline SINE/B2|B3A|11|58190051|58190291 & 1.6 & 0.001005606 \\
\hline LINE/L2|L2|4|128922527|128922668 & 2.6 & 0.001051836 \\
\hline LINE/L1|Lx8b|18|60375408|60375552 & 2.8 & 0.001063904 \\
\hline SINE/Alu|B1_Mur1|11|72310329|72310474 & 1.5 & 0.00107883 \\
\hline LTR/ERV1|MER34|8|61991169|61991412 & 1.3 & 0.001089669 \\
\hline SINE/Alu|B1_Mus1|18|60251484|60251628 & 2.4 & 0.00110542 \\
\hline LINE/L1|L1_Rod|16|97549085|97549369 & 1.8 & 0.001150467 \\
\hline SINE/B4|B4A|5|120742594|120742675 & 2.3 & 0.001173077 \\
\hline SINE/B4|ID_B1|5|120736246|120736457 & 2.4 & 0.001203452 \\
\hline LINE/L1|L1MdGf_I|4|96209256|96210247 & 5.5 & 0.001205117 \\
\hline LINE/L1|Lx7|11|48898552|48898950 & 3.0 & 0.001264124 \\
\hline SINE/B4|B4A|8|61938958|61939194 & 1.9 & 0.001273237 \\
\hline SINE/B4|B4A|12|26455259|26455616 & 3.1 & 0.001297065 \\
\hline SINE/B4|RSINE1|3|151741825|151741992 & 2.3 & 0.001354579 \\
\hline LINE/L2|L2c|17|78881711|78882045 & 1.3 & 0.001408036 \\
\hline SINE/Alu|B1_Mur3|11|119427174|119427277 & 1.3 & 0.001415298 \\
\hline LINE/L1|L1M5|6|57664127|57664870 & 1.4 & 0.001441351 \\
\hline LTR/ERVL|RMER10A|11|58191702|58192067 & 1.4 & 0.001493181 \\
\hline SINE/B2|B3|1|78405712|78405917 & 1.4 & 0.001633648 \\
\hline LINE/L1|L1M2|18|60245064|60245319 & 1.7 & 0.001694221 \\
\hline SINE/Alu|PB1D10|11|119474405|119474499 & 1.6 & 0.001812519 \\
\hline LINE/L1|L1M1|1|78410131|78410363 & 1.3 & 0.001823318 \\
\hline
\end{tabular}


bioRxiv preprint doi: https://doi.org/10.1101/2020.12.04.411793; this version posted December 4,2020 . The copyright holder for this

preprint (which was not certified by peer review) is the author/funder, who has granted bioRxiv a license to display the preprint in perpetuity. It is made available under aCC-BY 4.0 International license.

\begin{tabular}{|c|c|c|}
\hline LTR/ERVL|LTR53-int|8|61923911|61924391 & 2.0 & 0.001837723 \\
\hline DNA/TcMar-Tc1|EutTc1-N2|7|104499725|104499945 & 1.4 & 0.001884216 \\
\hline SINE/B2|B3A|8|61970949|61971157 & 1.6 & 0.001896582 \\
\hline LINE/L1|L1MC4|6|121243607|121243843 & 2.9 & 0.001905609 \\
\hline LTR/ERVL|RMER15-int|18|60243994|60244664 & 1.5 & 0.001914539 \\
\hline LINE/L1|L1MdF_I|GL456221.1|185129|190073 & 2.1 & 0.00193405 \\
\hline LINE/L1|L1MdGf_II|7|104461765|104462256 & 1.8 & 0.001965446 \\
\hline SINE/B2|B2_Mm1t|5|120742377|120742561 & 2.4 & 0.001970116 \\
\hline SINE/B2|B3A|18|60234288|60234503 & 1.9 & 0.001990529 \\
\hline Unknown|YREP_Mm|18|60224643|60224761 & 1.7 & 0.002034878 \\
\hline LTR/ERV1|RodERV21-int|5|38628522|38629464 & 2.3 & 0.002074407 \\
\hline LTR/ERVL-MaLR|ORR1G|18|60227122|60227332 & 1.4 & 0.002074407 \\
\hline LTR/ERVK|ERVB5_2-LTR_MM|11|83011538|83011994 & 1.7 & 0.002105801 \\
\hline LINE/L1|L1MC5a|5|120729622|120729973 & 3.3 & 0.002120947 \\
\hline LINE/L1|L1MdA_VII|14|22550685|22551432 & 1.3 & 0.002120947 \\
\hline SINE/B2|B3A|8|61929572|61929765 & 1.8 & 0.002135782 \\
\hline SINE/B4|RSINE1|1|52121688|52121837 & 1.5 & 0.002244338 \\
\hline SINE/B2|B3|18|60250421|60250516 & 1.8 & 0.00227286 \\
\hline SINE/Alu|B1_Mus1|5|120737774|120737916 & 2.2 & 0.002313263 \\
\hline LINE/L1|L1MdV_III|1|173472409|173472805 & 2.1 & 0.002313263 \\
\hline LINE/L1|L1MdTf_I|11|11287224|11294492 & 1.4 & 0.002358409 \\
\hline SINE/B4|B4A|5|120869392|120869621 & 3.0 & 0.002427648 \\
\hline LINE/L1|L1MD2|1|78415831|78416284 & 1.1 & 0.002580399 \\
\hline DNA/hAT-Charlie|URR1A|8|61989152|61989341 & 1.8 & 0.002588266 \\
\hline SINE/B4|B4A|10|128280206|128280475 & 1.1 & 0.002608665 \\
\hline SINE/B4|ID_B1|6|121257175|121257271 & 2.3 & 0.0026213 \\
\hline SINE/B2|B2_Mm2|11|58205520|58205716 & 1.8 & 0.002654082 \\
\hline LINE/L1|L1M3|7|104480884|104481245 & 1.2 & 0.002675589 \\
\hline SINE/B2|B2 Mm2|4|128922392|128922528 & 2.7 & 0.002693458 \\
\hline LTR/ERVL-MaLR|MLT1A0|16|97552073|97552408 & 1.8 & 0.002912433 \\
\hline LINE/L1|L1M3|18|60225894|60226042 & 2.4 & 0.002922993 \\
\hline SINE/Alu|B1_Mur4|11|119432213|119432355 & 1.4 & 0.002957208 \\
\hline SINE/B4|B4A|11|119454023|119454233 & 1.1 & 0.003132828 \\
\hline LTR/ERVK|RLTR25A|1|85292929|85293798 & 2.8 & 0.003188085 \\
\hline SINE/B4|RSINE1|5|120734442|120734572 & 3.4 & 0.003210838 \\
\hline SINE/B2|B3A|8|62017361|62017545 & 2.3 & 0.003228318 \\
\hline SINE/B4|B4|5|120814775|120815080 & 1.3 & 0.003330175 \\
\hline SINE/B2|B3|2|122154363|122154562 & 1.0 & 0.003385239 \\
\hline SINE/B4|B4A|12|103430589|103430874 & 2.6 & 0.003428791 \\
\hline DNA/hAT-Charlie|URR1B|6|57634600|57634757 & 1.5 & 0.003486983 \\
\hline LINE/L1|Lx5c|3|151730142|151730853 & 2.7 & 0.003555802 \\
\hline LTR/ERVK|MMERVK10D3_I-int RLTR10D2|4|156157848|156161930 & 1.2 & 0.003555802 \\
\hline SINE/B2|B3|11|119403552|119403719 & 1.1 & 0.003661118 \\
\hline SINE/B2|B2_Mm2|11|119474900|119475066 & 1.4 & 0.003666262 \\
\hline SINE/Alu|B1_Mur1|11|119426938|119427074 & 1.2 & 0.003667705 \\
\hline LTR/ERVK|RMER17C2|11|48891203|48891735 & 2.0 & 0.003754317 \\
\hline LINE/L1|L1MdA_VI|18|60412548|60416252 & 1.5 & 0.003804298 \\
\hline SINE/Alu|PB1|11|119415833|119415919 & 1.3 & 0.00384182 \\
\hline LTR/ERVK|RMER4A|1|52145655|52146094 & 1.1 & 0.003931657 \\
\hline SINE/B4|ID_B1|1|78408347|78408481 & 1.3 & 0.004223362 \\
\hline LTR/ERVK|RLTR53_Mm|3|7605461|7605702 & 1.2 & 0.004487373 \\
\hline SINE/B2|B3A|14|59352033|59352172 & 1.1 & 0.004525402 \\
\hline LTR/ERVL|LTR33|8|61980345|61980747 & 1.4 & 0.004585898 \\
\hline LINE/L1|Lx8|11|48897140|48897506 & 2.9 & 0.00469754 \\
\hline SINE/MIR|MIR|11|78984217|78984391 & 1.2 & 0.004703329 \\
\hline SINE/Alu|B1_Mur4|1|85678728|85678875 & 1.1 & 0.004703329 \\
\hline SINE/B2|B3|1|85699200|85699407 & 1.1 & 0.004748338 \\
\hline SINE/B2|B3A|11|119453072|119453230 & 1.1 & 0.004748338 \\
\hline LTR/ERV1|LTR72_RN|18|60243439|60243666 & 1.9 & 0.004758321 \\
\hline SINE/Alu|B1_Mm|JH584304.1|45633|45776 & 1.0 & 0.004811999 \\
\hline SINE/Alu|B1F|19|34589599|34589737 & 1.8 & 0.004941696 \\
\hline LTR/ERVK|MurERV4-int RMER4B|5|38640610|38642621 & 1.8 & 0.005052178 \\
\hline SINE/Alu|B1F|17|36016700|36016833 & 1.0 & 0.005108486 \\
\hline
\end{tabular}


bioRxiv preprint doi: https://doi.org/10.1101/2020.12.04.411793; this version posted December 4,2020 . The copyright holder for this

preprint (which was not certified by peer review) is the author/funder, who has granted bioRxiv a license to display the preprint in perpetuity. It is made available under aCC-BY 4.0 International license.

\begin{tabular}{|c|c|c|}
\hline 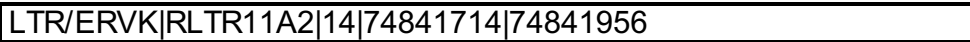 & 1.5 & 0.005149262 \\
\hline LINE/L1|L1M3|5|105287249|105287488 & 2.1 & 0.005207743 \\
\hline LINE/L1|L1ME2|19|34608766|34609012 & 1.6 & 0.005229814 \\
\hline LTR/ERVL-MaLR|ORR1B1|1|85206513|85206871 & 2.0 & 0.00524806 \\
\hline SINE/B2|B3|12|103430943|103431152 & 2.7 & 0.005295518 \\
\hline SINE/B2|B3|5|120742194|120742376 & 2.2 & 0.005295518 \\
\hline LTR/ERVK|MLTR11B|8|61922797|61923291 & 2.5 & 0.005350656 \\
\hline SINE/B4|B4A|3|151732580|151732796 & 2.2 & 0.005350656 \\
\hline LTR/ERVK|RMER17A2|11|83025644|83026552 & 1.4 & 0.005414877 \\
\hline SINE/Alu|B1_Mur1|5|120741326|120741462 & 2.2 & 0.005446161 \\
\hline LINE/L1|Lx9|8|61996144|61997073 & 1.4 & 0.005583858 \\
\hline LTR/ERVK|RLTR12BD_Mm|11|119413650|119414012 & 1.4 & 0.005603168 \\
\hline LINE/L1|Lx7|5|81690438|81691087 & 1.2 & 0.00570399 \\
\hline LINE/L1|Lx5b|16|97541515|97541575 & 3.7 & 0.00581336 \\
\hline LTR/ERVL-MaLR|MTC|18|60234785|60235077 & 1.8 & 0.005929058 \\
\hline LINE/L1|L1MC4|1|105984514|105984997 & 1.5 & 0.006181554 \\
\hline LINE/L1|Lx6|3|151725975|151728003 & 2.7 & 0.006490343 \\
\hline LTR/ERV1|MLTR14|11|119393861|119393938 & 1.2 & 0.006490343 \\
\hline LINE/L1|L1MdFanc_I|8|61966298|61966923 & 1.6 & 0.006798172 \\
\hline Unknown|MurSatRep1|8|61986589|61986618 & 2.1 & 0.006944851 \\
\hline LTR/ERVK|RMER6C|1|173466744|173467049 & 1.9 & 0.007173117 \\
\hline LTR/ERVL|RMER15|16|97552833|97553254 & 1.7 & 0.007459961 \\
\hline SINE/Alu|B1F1|10|128273839|128273957 & 1.2 & 0.007468964 \\
\hline LINE/L1|L1MdA_V|1|147487927|147488645 & 1.1 & 0.007581135 \\
\hline SINE/Alu|B1_Mur2|11|119422475|119422589 & 1.1 & 0.007632876 \\
\hline SINE/B2|B3|1|52161968|52162165 & 1.3 & 0.007756351 \\
\hline SINE/B2|B3|14|59244430|59244631 & 2.6 & 0.00778006 \\
\hline SINE/B4|RSINE1|16|35862636|35862773 & 1.1 & 0.007852115 \\
\hline LTR/ERVL-MaLR|ORR1D1|11|78966330|78966666 & 1.1 & 0.007852374 \\
\hline SINE/Alu|PB1D10|1|52157797|52157904 & 1.1 & 0.00786182 \\
\hline LTR/ERVL-MaLR|ORR1E|16|97545892|97546219 & 1.6 & 0.007932381 \\
\hline LTR/ERVK|RLTR10D2|11|83014754|83015108 & 1.8 & 0.00795139 \\
\hline LINE/L1|Lx4B|18|60254283|60254608 & 1.4 & 0.008019575 \\
\hline SINE/Alu|PB1|JH584304.1|46147|46243 & 1.3 & 0.008096681 \\
\hline SINE/B4|RSINE1|11|119454707|119454839 & 1.2 & 0.008275749 \\
\hline SINE/B2|B2_Mm2|11|48892662|48892842 & 2.2 & 0.008551993 \\
\hline SINE/B4|ID_B1|10|128280630|128280828 & 1.1 & 0.008555514 \\
\hline LTR/ERVL-MaLR|MTC|5|114931510|114931937 & 4.4 & 0.008616601 \\
\hline LTR/ERVL|RMER15-int|5|38610880|38612957 & 1.6 & 0.008698384 \\
\hline LINE/L1|Lx3_Mus|5|109113342|109113831 & 2.3 & 0.008784429 \\
\hline LINE/L1|L1_Mus3|16|35876707|35879416 & 2.1 & 0.008815001 \\
\hline LINE/L1|L1MdMus_II|5|109131054|109134304 & 1.3 & 0.009424916 \\
\hline SINE/B2|B3A|11|119419727|119419826 & 1.1 & 0.009454442 \\
\hline SINE/B2|B3A|16|35855574|35855739 & 1.0 & 0.009590665 \\
\hline LTR/ERVL-MaLR|ORR1B1|11|119397240|119397294 & 1.5 & 0.009627717 \\
\hline LINE/L1|Lx4B|18|60227587|60227901 & 1.5 & 0.009650305 \\
\hline SINE/Alu|B1 Mur2|4|42698174|42698309 & -1.2 & 0.006343316 \\
\hline SINE/Alu|B1_Mus2|14|52188546|52188712 & -1.3 & 0.006282691 \\
\hline SINE/Alu|B1_Mur4|4|42702271|42702324 & -1.0 & 0.00577895 \\
\hline LTR/ERVK|ERVB7 _1-LTR_MM ETnERV-int|7|133528843|133536216 & -4.1 & 0.005738875 \\
\hline LINE/L1|Lx6|5|109930987|109932960 & -1.1 & 0.004709914 \\
\hline LTR/ERVL-MaLR|ORR1A2|4|42198416|42198743 & -1.8 & 0.003795357 \\
\hline LTR/ERVL-MaLR|MTC|4|41860499|41860704 & -1.2 & 0.002380466 \\
\hline LTR/ERVL-MaLR|ORR1D1|5|81438765|81439074 & -1.3 & 0.001738738 \\
\hline LINE/L1|Lx8|5|81442017|81442485 & -1.1 & 0.001387036 \\
\hline SINE/Alu|B1_Mus1|4|42701837|42701939 & -1.3 & 0.001332738 \\
\hline LINE/L1|L1MB4|GL456350.1|213136|214351 & -1.3 & 0.001244243 \\
\hline LINE/L1|Lx3B|1|38194814|38195586 & -1.1 & 0.001203452 \\
\hline SINE/Alu|B1_Mus1|4|42211905|42212047 & -3.1 & 0.000987718 \\
\hline LINE/L1|L1LX_III|14|22888262|22889657 & -1.3 & 0.00085488 \\
\hline LTR/ERVL-MaLR|MTD|4|42470347|42470605 & -1.4 & 0.000541809 \\
\hline LTR/ERVL-MaLR|MTD|4|42206462|42206627 & -1.2 & 0.000526551 \\
\hline
\end{tabular}


bioRxiv preprint doi: https://doi.org/10.1101/2020.12.04.411793; this version posted December 4,2020 . The copyright holder for this

preprint (which was not certified by peer review) is the author/funder, who has granted bioRxiv a license to display the preprint in perpetuity. It is made available under aCC-BY 4.0 International license.

\begin{tabular}{|c|c|c|}
\hline LTR/ERV1|LTRIS2|4|41882251|41882738 & -1.9 & 0.000395352 \\
\hline SINE/B2|B3|4|42006940|42007096 & -1.6 & 0.000368207 \\
\hline LTR/ERVL-MaLR|MTC|4|41859834|41859870 & -5.7 & 0.000364103 \\
\hline LTR/ERVK|RMER17B2|4|42199930|42200852 & -1.6 & 0.000331455 \\
\hline LINE/L1|Lx9|2|106407857|106408375 & -1.2 & 0.000292512 \\
\hline LINE/L1|L1M4b|4|42207136|42207346 & -5.0 & 0.00029125 \\
\hline SINE/Alu|B1_Mus1|14|52189113|52189250 & -1.3 & 0.000225471 \\
\hline LINE/L1|L1MB4|GL456350.1|215333|215759 & -1.7 & 0.000179446 \\
\hline LTR/ERVK|ERVB7_1-LTR_MM ETnERV-int|3|78552311|78559462 & -2.2 & 0.000126775 \\
\hline LTR/ERVL-MaLR|MTC|4|42209075|42209111 & -7.0 & 8.34E-05 \\
\hline SINE/B4|B4A|4|42205385|42205658 & -1.3 & 7.74E-05 \\
\hline SINE/Alu|B1_Mur4|4|42005473|42005619 & -1.2 & $7.08 \mathrm{E}-05$ \\
\hline SINE/Alu|B1_Mus2|4|42202263|42202409 & -1.5 & $6.34 \mathrm{E}-05$ \\
\hline LTR/ERVL-MaLR|ORR1A3|4|42201549|42201891 & -1.4 & $5.86 \mathrm{E}-05$ \\
\hline DNA/hAT-Tip100|Arthur2|4|41855107|41855330 & -1.1 & 4.99E-05 \\
\hline LTR/ERVK|MMERVK10C-int RLTR10B2|8|3945964|3951863 & -1.1 & $4.34 \mathrm{E}-05$ \\
\hline LTR/ERVK|RMER17B2|4|41944961|41945909 & -1.2 & $3.08 \mathrm{E}-05$ \\
\hline SINE/B2|B3|4|41846277|41846489 & -1.1 & $2.22 \mathrm{E}-05$ \\
\hline LTR/ERVK|ERVB7_1-LTR_MM ETnERV-int|3|8383520|8390993 & -3.2 & $1.63 \mathrm{E}-05$ \\
\hline SINE/Alu|B1_Mus2|4|42699410|42699556 & -1.1 & $5.87 E-06$ \\
\hline SINE/Alu|B1_Mur1|4|42699613|42699730 & -1.1 & 4.11E-06 \\
\hline scRNA|BC1_Mm|JH584293.1|158471|158531 & -7.4 & $2.78 \mathrm{E}-06$ \\
\hline LINE/L2|L2|18|78192885|78194073 & -3.5 & 1.06E-06 \\
\hline LTR/ERVL-MaLR|ORR1B2|4|42210920|42211264 & -3.1 & 9.23E-07 \\
\hline SINE/Alu|B1_Mur3|4|41845780|41845916 & -1.2 & $2.66 \mathrm{E}-07$ \\
\hline LTR/ERVL-MaLR|ORR1E|4|42488823|42489144 & -1.6 & 2.57E-07 \\
\hline SINE/ID|ID4|4|42689431|42689510 & -1.2 & 2.13E-07 \\
\hline SINE/Alu|B1_Mur2|4|42006829|42006920 & -1.4 & $2.08 \mathrm{E}-07$ \\
\hline SINE/Alu|B1_Mur4|4|42693249|42693395 & -1.3 & $1.76 \mathrm{E}-07$ \\
\hline SINE/B4|RSINE1|4|42698000|42698095 & -1.3 & $8.46 \mathrm{E}-08$ \\
\hline LTR/ERVL-MaLR|ORR1A3|4|42698696|42699038 & -1.6 & $4.88 \mathrm{E}-08$ \\
\hline LINE/L1|Lx5|4|42692601|42692763 & -1.2 & $2.87 E-08$ \\
\hline SINE/B2|B3|4|42677410|42677598 & -1.3 & $1.91 \mathrm{E}-08$ \\
\hline LINE/L1|L1MdTf_I|10|106206469|106213575 & -2.0 & 1.75E-08 \\
\hline LINE/L1|L1MdF_I|4|42699736|42700028 & -1.3 & $1.60 \mathrm{E}-08$ \\
\hline LTR/ERVL-MaLR|ORR1A3|4|42010910|42011252 & -1.1 & $1.44 \mathrm{E}-08$ \\
\hline SINE/B2|B3|4|42694716|42694872 & -1.1 & 1.35E-08 \\
\hline SINE/Alu|B1_Mur2|4|42690321|42690460 & -1.1 & $8.84 \mathrm{E}-09$ \\
\hline LTR/ERVL-MaLR|MTC|4|42208669|42208881 & -3.3 & 5.97E-09 \\
\hline LTR/ERV1|MERV1_I-int RLTR41|4|41997400|42000692 & -1.1 & 5.26E-09 \\
\hline Unknown|YREP Mm|4|42698157|42698308 & -1.5 & 3.92E-09 \\
\hline LTR/ERVL-MaLR|MTD|4|42212252|42212563 & -3.6 & $2.84 \mathrm{E}-09$ \\
\hline LTR/ERVL-MaLR|MTD|4|42211419|42211544 & -3.1 & 1.45E-09 \\
\hline LTR/ERVL-MaLR|ORR1E|4|42693396|42693452 & -1.4 & 1.39E-09 \\
\hline LTR/ERVL-MaLR|MTD|4|42703609|42703774 & -1.2 & 1.26E-09 \\
\hline LINE/L1|L1M4b|JH584293.1|158632|158842 & -6.4 & $1.20 \mathrm{E}-09$ \\
\hline SINE/B2|B2_Mm2|4|21873292|21873426 & -1.4 & $9.41 \mathrm{E}-10$ \\
\hline SINE/B2|B2_Mm1t|4|42487831|42488007 & -1.5 & $7.00 \mathrm{E}-11$ \\
\hline SINE/B2|B3|4|42206861|42207067 & -2.8 & 7.19E-12 \\
\hline LTR/ERVL-MaLR|ORR1E|4|42005151|42005472 & -1.3 & $3.84 \mathrm{E}-12$ \\
\hline SINE/B2|B3|4|42692346|42692558 & -1.2 & $1.67 \mathrm{E}-12$ \\
\hline SINE/B2|B2_Mm1t|4|41859871|41860047 & -5.8 & $8.98 \mathrm{E}-13$ \\
\hline LTR/ERV1|LTR72_RN|4|41863323|41863472 & -2.5 & $8.63 \mathrm{E}-13$ \\
\hline SINE/B4|B4A|4|42696105|42696301 & -1.5 & 1.93E-13 \\
\hline LTR/ERVL-MaLR|ORR1D2|4|41866797|41866870 & -6.0 & $3.33 \mathrm{E}-14$ \\
\hline LTR/ERV1|MERV1_I-int RLTR41|4|42493603|42496895 & -1.4 & $2.28 \mathrm{E}-14$ \\
\hline LTR/ERVL-MaLR|ORR1E|4|42692927|42693248 & -1.3 & $1.71 \mathrm{E}-14$ \\
\hline LTR/ERV1|RLTR1B-int|4|41881485|41882110 & -1.4 & $4.25 \mathrm{E}-15$ \\
\hline LTR/ERVK|IAPEz-int $\sim$ IAPLTR1_Mm|2|154354263|154359592 & -1.0 & $3.35 \mathrm{E}-15$ \\
\hline LTR/ERVK|ETnERV-int|4|41882740|41882895 & -2.4 & $2.39 \mathrm{E}-15$ \\
\hline LTR/ERVL-MaLR|MTD|4|42703056|42703249 & -1.3 & $1.37 \mathrm{E}-15$ \\
\hline LINE/L1|L1M5|4|42688781|42688992 & -1.3 & $6.88 \mathrm{E}-16$ \\
\hline SINE/Alu|B1_Mur2|4|21872875|21873007 & -1.9 & 9.59E-17 \\
\hline
\end{tabular}


bioRxiv preprint doi: https://doi.org/10.1101/2020.12.04.411793; this version posted December 4,2020 . The copyright holder for this preprint (which was not certified by peer review) is the author/funder, who has granted bioRxiv a license to display the preprint in perpetuity. It is made available under aCC-BY 4.0 International license.

\begin{tabular}{|c|c|c|}
\hline SINE/B2|B3A|4|42688563|42688744 & -1.2 & $6.68 \mathrm{E}-17$ \\
\hline DNA/hAT-Tip100|Arthur2|4|42701104|42701325 & -1.3 & $2.80 \mathrm{E}-17$ \\
\hline SINE/B2|B2_Mm1t|4|42006288|42006464 & -1.5 & $1.95 \mathrm{E}-17$ \\
\hline LINE/L1|Lx9|4|42696517|42697053 & -1.3 & $3.62 \mathrm{E}-19$ \\
\hline SINE/B4|B4A|4|42702532|42702805 & -1.3 & $2.99 \mathrm{E}-20$ \\
\hline SINE/B4|B4|4|41861171|41861469 & -1.5 & $2.73 \mathrm{E}-20$ \\
\hline LTR/ERVL-MaLR|MTD|4|41862178|41862303 & -6.4 & $6.78 \mathrm{E}-21$ \\
\hline SINE/B2|B2_Mm2|4|42006123|42006221 & -1.5 & $1.95 \mathrm{E}-21$ \\
\hline LINE/L1|L1MD2|4|42689041|42689329 & -1.3 & $8.59 \mathrm{E}-22$ \\
\hline LTR/ERV1|LTRIS2|4|41877124|41877612 & -1.8 & $7.03 \mathrm{E}-22$ \\
\hline LTR/ERVL-MaLR|MTEa|4|42689524|42689847 & -1.1 & $4.80 \mathrm{E}-22$ \\
\hline LTR/ERVL-MaLR|MTC|4|41859428|41859640 & -7.2 & 2.79E-22 \\
\hline LINE/L1|L1MD2|4|42689848|42690320 & -1.2 & $6.12 \mathrm{E}-23$ \\
\hline LTR/ERVL-MaLR|ORR1A2|4|42695575|42695902 & -1.4 & $3.42 \mathrm{E}-23$ \\
\hline LTR/ERVL-MaLR|ORR1B2|4|41861679|41862023 & -4.9 & $5.00 \mathrm{E}-24$ \\
\hline LINE/L1|L1MdV_III|4|42682716|42684974 & -1.2 & $4.51 \mathrm{E}-25$ \\
\hline LTR/ERVL-MaLR|ORR1D2|4|41869118|41869231 & -5.5 & $2.52 \mathrm{E}-27$ \\
\hline LINE/L1|Lx5|4|41869274|41869392 & -4.0 & $5.24 \mathrm{E}-28$ \\
\hline LINE/L1|Lx9|4|41864119|41864457 & -3.1 & $1.55 \mathrm{E}-28$ \\
\hline LTR/ERVK|RMER17B2|4|42697077|42697999 & -1.5 & $1.29 \mathrm{E}-28$ \\
\hline SINE/Alu|B1_Mus1|4|41862664|41862806 & -6.0 & $6.72 \mathrm{E}-32$ \\
\hline LINE/L1|Lx5|4|41860065|41860499 & -6.5 & $2.14 \mathrm{E}-32$ \\
\hline LINE/L1|L1MD2|4|42690461|42691435 & -1.2 & $6.41 \mathrm{E}-34$ \\
\hline LTR/ERVK|RMER16-int|4|41880620|41881663 & -2.0 & $1.18 \mathrm{E}-38$ \\
\hline LTR/ERVL-MaLR|MTD|4|41863011|41863322 & -6.8 & $1.33 \mathrm{E}-40$ \\
\hline LTR/ERV1|MERV1_I-int RLTR41|4|42685154|42688451 & -1.2 & $8.05 \mathrm{E}-43$ \\
\hline LTR/ERVK|RLTR40|4|21871708|21872365 & -1.8 & $2.50 \mathrm{E}-45$ \\
\hline LTR/ERVK|ERVB7 1-LTR_MM ETnERV-int|4|41870907|41877123 & -3.1 & $2.95 \mathrm{E}-48$ \\
\hline LINE/L1|L1MEg|4|41866400|41866748 & -5.6 & $2.14 \mathrm{E}-50$ \\
\hline LTR/ERVL-MaLR|MTD|4|41864735|41864993 & -4.3 & $1.66 \mathrm{E}-52$ \\
\hline SINE/B2|B3|4|41865957|41866165 & -5.1 & 8.07E-64 \\
\hline LTR/ERVL-MaLR|ORR1E|4|41868720|41868968 & -4.6 & $1.22 \mathrm{E}-74$ \\
\hline LTR/ERV1|RLTR1B-int|4|41877612|41880640 & -2.1 & 4.96E-98 \\
\hline
\end{tabular}


Table S2. qPCR probes and primers.

\begin{tabular}{|c|c|}
\hline Taqman Probes & Assay Probe ID \\
\hline Ifnb1 & Mm00439552_s1 \\
\hline Ifng & Mm01168134_m1 \\
\hline Tnfa & Mm00443258_m1 \\
\hline$/ 11 b$ & Mm00434228_m1 \\
\hline $1 / 6$ & Mm00446191_m1 \\
\hline Ifit1 & Mm00515153_m1 \\
\hline Ifit2 & Mm00492606_m1 \\
\hline Ifi44 & Mm00505670_m1 \\
\hline $\operatorname{lsg} 15$ & Mm01705338_s1 \\
\hline $\operatorname{lsg} 20$ & Mm00469585_m1 \\
\hline Zbp1 & Mm01247052_m1 \\
\hline Oas1a & Mm00836412_m1 \\
\hline$N P$ & $\begin{array}{c}\text { Custom probe based on NC_002019.1 } \\
\text { Assay ID:AIX02UC }\end{array}$ \\
\hline Actin & Mm02619580_g1 \\
\hline Gapdh & Mm99999915_g1 (4352932E) \\
\hline SYBR Green oligos & Sequence \\
\hline$M$ & $\begin{array}{l}\text { F: 5'-CTTCTAACCGAGGTCGAAACGTA } \\
\text { R: 5'-GGTGACAGGATTGGTCTTGTCTTTA } \\
\text { from: Shin et al. 2013, Virology Journal 10:303 }\end{array}$ \\
\hline Gapdh & $\begin{array}{l}\text { F: 5'-CATGGCCTTCCGTGTTCCTA } \\
\text { R: 5'-CCTGCTTCACCACCTTCTTGAT } \\
\text { from: Tsujita et al. 2006, PNAS 103:11946 }\end{array}$ \\
\hline
\end{tabular}

